BROWN

J JUDAIC

4 STUDIES

\title{
Scholastic Rabbinism
}

\author{
A Literary Study of the Fathers \\ according to Rabbi Nathan
}

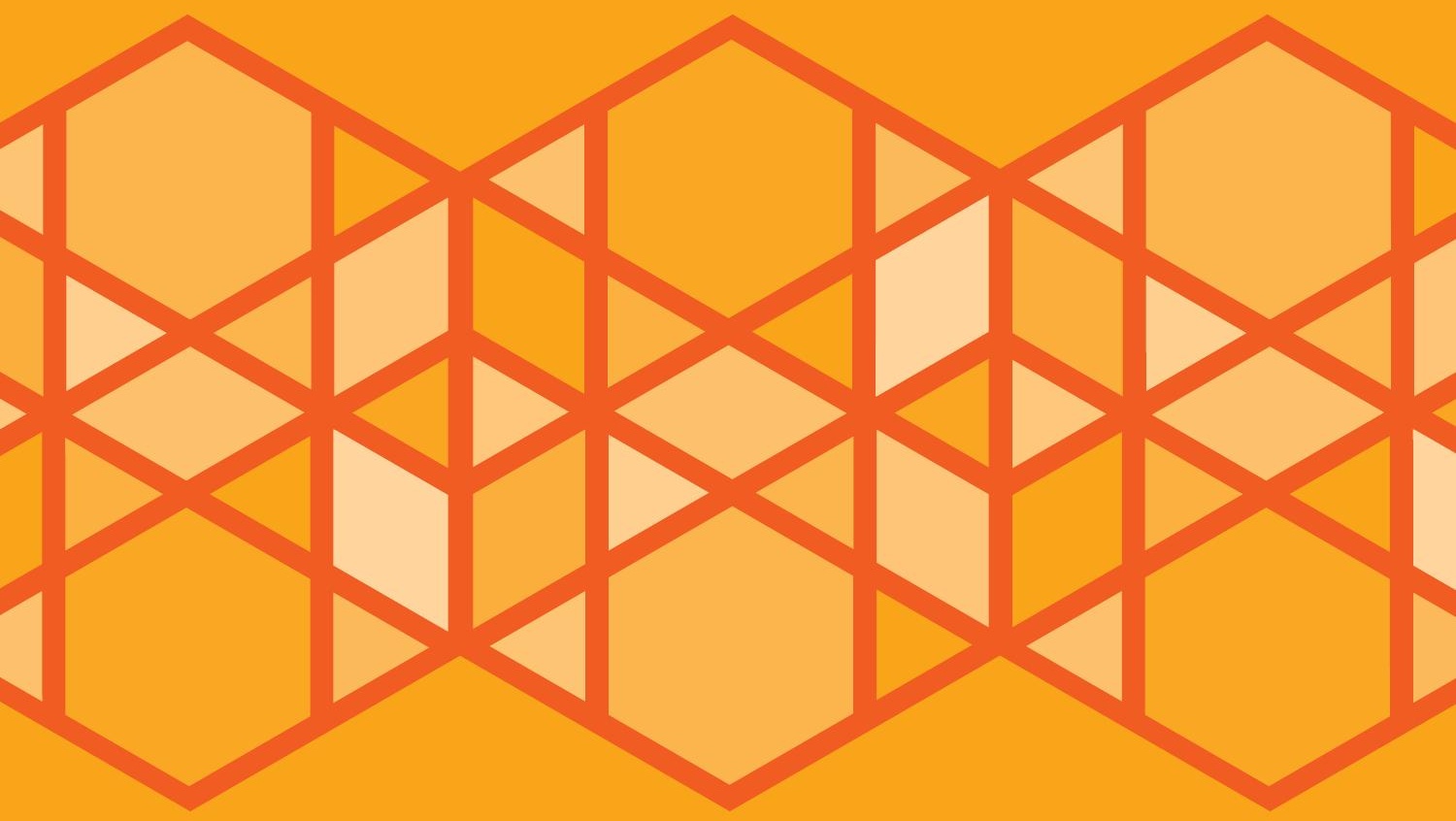


Scholastic Rabbinism 


\author{
BROWN UNIVERSITY \\ BROWN JUDAIC STUDIES \\ Edited by \\ Jacob Neusner \\ Wendell S. Dietrich, Ernest S. Frerichs, \\ Alan Zuckerman \\ Board of Editors \\ David Altshuler, George Washington University \\ David R. Blumenthal, Emory University \\ Baruch M. Bokser, University of California, Berkeley \\ Joel Gereboff, Arizona State University \\ David Goldenberg, Dropsie University \\ Robert Goldenberg, State University of New York, Stony Brook \\ David Goodblatt, Haifa University \\ William Scott Green, University of Rochester \\ Peter Haas, Vanderbilt University \\ Martin Jaffee, University of Virginia \\ Shamai Kanter, Temple Beth El, Rochester, New York \\ Jack L. Lightstone, Concordia University \\ Irving Mandelbaum, University of Texas \\ Alan Mintz, University of Maryland \\ Alan J. Peck, Tulane University \\ Gary G. Porton, University of Illinois \\ Marc L. Raphael, Ohio State University \\ Richard S. Sarason, Hebrew Union College-Jewish Institute of Religion \\ Tzvee Zahavy, University of Minnesota \\ Editorial Committee: \\ Roger Brooks \\ Louis Newman
}

Number 14

SCHOLASTIC RABBINISM

A Literary Study of

the Fathers According to Rabbi Nathan

by Anthony J. Saldarini 


\title{
SCHOLASTIC RABBINISM A Literary Study of the Fathers According to Rabbi Nathan
}

\author{
by \\ Anthony J. Saldarini
}

Scholars Press 


\section{SCHOLASTIC RABBINISM \\ A Literary Study of \\ the Fathers According to Rabbi Nathan}

by Anthony J. Saldarini

Copyright (C 2020 by Brown University

Library of Congress Control Number: 2019953407

Open access edition funded by the National Endowment for the Humanities / Andrew W. Mellon Foundation Humanities Open Book Program.

The text of this book is licensed under a Creative Commons Attribution-NonCommercial-NoDerivatives 4.0 International License: https: / / creativecommons.org/licenses / by-nc-nd /4.0/. To use this book, or parts of this book, in any way not covered by the license, please contact Brown Judaic Studies, Brown University, Box 1826, Providence, RI 02912. 
In Memory of my Father

Roger Louis Saldarini

1902-1980 
Publication of this book is made possible with the support of The Max Richter Foundation, in honor of Professor David R. Blumenthal. 
TABLE OF CONTENTS

Page

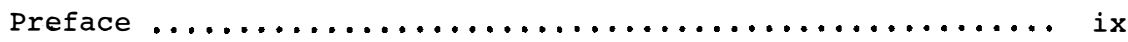

Chapter One. INTRODUCTION...................... 1

Chapter Two. THE CHAPTERS OF THE FATHERS.............. 9

Chapter Three. THE LITERARY STRUCTURE OF THE FATHERS

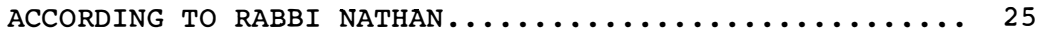

Chapter Four. THE THEMATIC DEVELOPMENT OF THE CHAIN

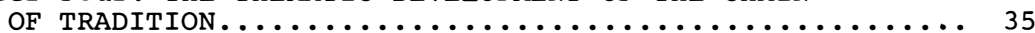

Chapter Five. THE NATURE OF THE CHAIN OF TRADITION....... 67

Chapter Six. THE SCHOOL OF RABBAN JOHANAN ben ZAKKAI

AND HIS DISCIPLES : A NEW WAY OF LIFE............. 79

Chapter Seven. THE SAYINGS OF THE EARLY SAGES .......... 93

Chapter Eight. THE ENUMERATION SAYINGS............... 109

Chapter Nine. LITERARY CONCLUSIONS................. 121

Chapter Ten. HISTORICAL CONCLUSIONS............... 135

Footnotes................................. 143

Bibliography................................ 155 

Brown Judaic Studies has been publishing scholarly books in all areas of Judaic studies for forty years. Our books, many of which contain groundbreaking scholarship, were typically printed in small runs and are not easily accessible outside of major research libraries. We are delighted that with the support of a grant from the National Endowment for the Humanities/Andrew W. Mellon Foundation Humanities Open Book Program, we are now able to make available, in digital, open-access, format, fifty titles from our backlist.

In Scholastic Rabbinism: A Literary Study of the Fathers According to Rabbi Nathan (1982), the late Anthony J. Saldarini compares the two rabbinic texts, Ethics of the Fathers (Pirke Avot) and the two textual versions of The Fathers According to Rabbi Nathan (Avot d'Rabbi Nathan), arguing that both had a common origin in oral stories that were selected and shaped by later scholastic editors. Saldarini suggests that The Fathers According to Rabbi Nathan took shape in the second to third centuries, CE, a relatively early date for many scholars who have worked on this text.

This edition incorporates typographical and some factual corrections of the original text.

Michael L. Satlow Managing Editor October, 2019 

The aim, scope and method used in this study will be explained in the first, introductory chapter. Before beginning that discussion we shall clarify some abbreviations, peculiarities of the texts being studied and methods of reference. The following abbreviations will be used for the texts which are the main object of study:

PA - Pirke Abot, The Chapters of the Fathers. ARN - Abot de Rabbi Nathan, The Fathers According to Rabbi Nathan. ARNA - Abot de Rabbi Nathan, Version A. ARNB - Abot de Rabbi Nathan, Version B. PA will ordinarily refer to the Tractate Abot as found in the Mishna. Since ARNA and ARNB, which comment on PA, have each a different version of the text, $P A$ will sometime refer to the version of the text found in one or another version of ARN. This usage will be explicitly noted. When all versions agree, PA refers to the whole tradition. Since Abot de Rabbi Nathan comes in two versions, the abbreviation ARN will refer to both versions together when they have common characteristics. It will be a shorthand for refering to two documents which should most properly be referred to separately.

PA will be referred to in the text by chapter and mishna number. Each version of ARN will be referred to within the text by chapter number, thus eliminating numerous footnotes and page references to both text and translation. References to the rest of Rabbinic literature will be according to standard practice. The following abbreviations will be used: m. - Mishna followed by the name of the tractate. t. - Tosefta followed by the name of the tractate. b. - Babylonian Talmud followed by the name of the tractate. p. - Palestinian Talmud followed by the name of the tractate. The text generally used for the Mishna is that by $H$. Albeck and H. Yalon. The text of both versions of ARN is by S. Schechter and referred to as Schechter, ARN. The standard texts of the Talmuds and Midrashim have been consulted. The translations of PA and ARNA are by J. Goldin. The former is found in Goldin's book The Living Talmud; the latter is referred to in the notes as Goldin, ARNA. Both translations have been modified occasionally to eliminate the older English second person (thee, etc.) and to 
reflect differences of interpretation. The translation of ARNB is by the author and referred to as Saldarini, ARNB. Danby's translation of the Mishna and the Soncino translation of the Talmud have been consulted.

The transliteration of names into English varies greatly in the secondary literature. What seems to be the most common form of familiar names has been retained. Hebrew and Aramaic words have been precisely transliterated either with or without vowels as required by context. Inconsistencies in transliteration found in the bibliography reflect the different transliteration systems found on the English title pages of Hebrew books. The notes refer to secondary literature by author and abbreviated title. Full references are found in the bibliography. Standard abbreviations for periodicals, Biblical books, etc. have been used.

This study often speaks of the author(s) and editor(s) of PA and ARN. In the following chapters we argue that $P A$ and the versions of ARN resulted from a long process of transmission whose exact stages and forms cannot be recovered with precision. The organization of each document and their coherent themes show that at crucial stages each of the three documents was formed by people who may properly be called authors. Numerous other smaller changes and revisions argue that the long process of transmission was aided by the work of less influential figures who may be called editors. Except for Judah the Prince's work on the Mishna we know nothing about who might have produced these traditions and texts except what we can infer from the content of the works themselves. The vagueness of the texts produces the vagueness of the references to author(s) and editor(s) in this study.

I thank Boston College which granted me a Sabbatical semester in Fall, 1980 during which I completed the research on $P A$ and ARN which has occupied me the last few years. I also thank Professor Jacob Neusner of Brown University for accepting this study into the Brown Judaic Series.

Anthony J. Saldarini.

Boston College

Easter/Passover, 1981/5741 
Pirke Abot, the Chapters of the Fathers, has been read for edification and education by pious Jews in synagogue, school and home since antiquity. It has also introduced many Christians to Judaism, especially since its sayings have been presented as a compendium of Jewish ethics, ideals and wisdom. But Pirke Abot (henceforth PA) is primarily a tractate of the Mishna, even though it is unique among Mishna tractates in that it does not speak of law (halaka) governing some specific sphere of life. PA with its chain of authorities stretching from Moses to Judah the Prince's son, Gamaliel III, along with its stories about Johanan ben Zakkai and his disciples and its sayings by sages who lived in the time of the destruction of the Temple, anchors the whole Rabbinic tradition in antiquity and legitimizes its substance by reference to the early sages. The concrete function of PA within the Mishna and the exact message communicated by its structure, themes and genre will be the first object of this study.

Though PA lacks an Aramaic commentary in both the Palestinian and Babylonian Talmuds, it does have a Hebrew commentary which sometimes elucidates individual sayings and at other times elaborates or adds to the material in PA. As we shall see in succeeding chapters, the commentary, Abot de Rabbi Nathan (The Fathers According to Rabbi Nathan) is not subsequent to and built around the Mishna Tractate Abot; rather Abot de Rabbi Nathan (henceforth ARN) includes much but not all of PA within it, sometimes in a variant form or in a different order. Consequently, PA and ARN developed within a common tradition to reach different and parallel forms. ARN exists in two versions, ARNA and ARNB. ARNA is customarily printed in the Talmud in the volume with PA and has been known and read for centuries. ARNB was discovered in manuscripts by Solomon Schechter in the last century and first published along with ARNA in $1887 . .^{1}$ In ch. 2 of his introduction he cites numerous Medieval authors who used Version $B$ when quoting ARN. Consequently, the two versions of ARN were both known in the tradition, but ARNA became more closely associated with the Babylonian Talmud and so better known. ARN follows the order of PA: the chain of tradition, Johanan ben Zakkai, the early sages 
and the enumeration sayings. Within this framework ARN contains an enormous fund of stories, sayings, exegeses and comments, some directly pertinent to $\mathrm{PA}$ and some relevant to the goals and themes of ARN. Though the two versions of ARN are not treatises or books in the modern sense, they each possess a sophisticated structural and thematic unity which derives from their setting and purpose. The two versions of ARN have enough in common that both may be referred to together as ARN. But despite their common form and content, each stands alone as an independent literary entity. The analyses which follow will take each version separately to show its individuality within the common tradition. PA, which is much briefer and has a fixed place within the Mishna, will be treated first and in its entirety. It will then be available for comparison with ARN in the subsequent chapters. These three documents must be seen as part of a religious and cultural tradition which was both oral and written and which remained fluid over centuries. The authors and editors of these materials preserved, rearranged, rephrased, and reinterpreted with a freedom unknown to readers of the printed book, but with a reverence and respect for the past often lacking in those familiar with print. Detailed analyses will show the development of this tradition, insofar as it can be ascertained, and elucidate the meaning of the documents which have survived.

This volume intends primarily to understand what the documents which have survived actually say, individually and collectively. Theories about their origins and sources remain a secondary goal. Consequently, greatest attention will be given to the contents, order, structure, themes and emphases of the three surviving texts. A full understanding of their meaning requires an effort at locating them within Rabbinic literature and society. Theories about their provenence and orientation will arise from their contents, form and relationships to other documents. Finally, our research will peer into the past to discern how the whole tradition probably developed and how these three final works came to stand in their present relationship to one another.

The proximate scope of this investigation will be PA and the two versions of ARN. Since a complete commentary on all this material would fill at least three volumes, comments will be restricted to the literary structures and themes which carry the most weight within each work. Philological, textual and grammatical problems as well as exegetical details will be treated when 
necessary to clarify or support a larger argument. ${ }^{2}$ Many passages in ARN have parallels in Rabbinic literature, especially in the Midrashim. ${ }^{3}$ Detailed comparisons to establish forms and priority among the versions is a specialized task beyond the scope of this study. Some parallels have been briefly analyzed to advance the argument in crucial passages. Similar materials in Greco-Roman literature have been cited in relation to certain themes and sections, though much more material is available for comparision.

The method used may be loosely classified as literary analysis. The texts have been primarily analysed in final form with hypotheses concerning origins and redaction following only when possible or appropriate. Since we are treating whole documents, larger structural features and major themes will dominate our investigation. Structure shows the parts in relation to the whole and identifies some parts as more important than others. Themes show the continuing interests of the authors, both conscious and unconscious, and they exercise a constant effect on the reader whose attention is controlled by those topics and exhortations most frequently and emphatically repeated. Themes function in a collection such as ARN in the same way that arguments function within a logical treatise. Both structure and theme give objective evidence for what is central and important. Comparative material will establish genres and the cultural setting of texts and themes.

Though Rabbinic literature resists historical analysis, some hypotheses concerning sources, development, additions, dates and social setting will be proposed in the course of the analysis and in the concluding chapters. The weight of the evidence in PA and ARN suggests that ARN originated in a school setting and that it functioned as an explanation and justification for a life based on study of Torah. A majority of the passages and themes, especially in the chain of tradition and the section on Johanan ben Zakkai and his disciples concern sages, study, Torah, disciples and other matters related to a school. All point toward a way of life centered on the study of and explicit obedience to Torah. Biblical authorities, verses and events are integrated into the Rabbis' self understanding in such a way as to provide continuity and authority for their way of life. In addition, Greco-Roman models and modes of expression can be discerned embedded in the Rabbinic material; they were probably absorbed from the culture of the Hellenistic and Roman Empires which fostered schools, religious societies and related literature. The internal relationships among blocks of teachings and comparisons of the two versions 
of ARN with each other and with PA suggest that certain parts of $P A$ and ARN came into existence during the second century and others during the third. The development of the texts can be established with probability for some passages while it remains obscure in many others. In all these historical inquiries the focus will remain on the final forms of the documents and their unique syntheses of Biblical, Rabbinic and Greco-Roman traditions.

\section{contents}

The succeeding chapters carry out steps in the analysis of PA and the two versions of ARN and gradually amass data and conclusions which are summarized in the final chapters. Ch. 2 examines $P A$ as a whole, since it is included in both versions of ARN. Examination of the literary structure and composition, sources and redaction, genre and purpose, Greco-Roman influences, themes and historical setting prepare us for treatment of these same topics at greater length in the chapters on ARN. Since PA has a firm context in the Mishna and is more tightly organized than some parts of ARN, it provides a good test for method and an example of one direction in which the tradition moved.

Chs. 3 to 8 study the literary structure and themes of the four major sections of ARN. The sections are: 1. The chain of tradition (ARNA, chs. 1-13; ARNB chs. 1-27); 2. Johanan ben Zakkai and his disciples (ARNA, chs. 14-18, ARNB, chs. 28-31); 3. The early sages (ARNA, chs. 31-41; ARNB, chs. 32-35); 4. Enumeration sayings (ARNA, chs. 31-4l; ARNB, chs. 36-48). Each chapter first analyzes ARNA and then ARNB. In the analysis of ARNB significant similarities and differences between the two versions are pointed out. In both parts the distinctive natures of the two versions are preserved.

Ch. 3 gives a broad overview of the literary structure of each version and summarizes the contents of each section. Ch. 4 is the longest and most laborious as it traces the extensive complex of stories, sayings and exegeses united under the chain of tradition. This part of ARN received the greatest elaboration and it is for the chain of tradition that both PA and ARN are best known. Ch. 5 takes the results of ch. 4 and sketches the structure of the chain, shows how it developed and establishes the nature and purpose of this genre within a Greco-Roman and Jewish context. Ch. 6 argues that the section on Johanan ben Zakkai and his disciples is most influenced by Greco-Roman models and that virtually all the materials are oriented toward establishing and defining a 
Rabbinic school similar in significant ways to the Greco-Roman schools of philosophy. Ch. 7 shows that the sayings of the early sages (late first and early second centuries) generally support the themes and purposes enunciated in and implied by the first two sections even though this part of ARN is less tightly organized than the previous two. Finally, ch. 8 examines the sequence and content of the enumeration sayings as well as their function in other cultures. Though the enumerations stand apart from the rest of ARN in their form, they set forth the fundamental institutions and ideas of Judaism and in their way serve the same purpose as the chain of tradition.

Ch. 9 gathers together the Iiterary data and observations from the previous chapters and enlarges on the conclusions drawn there. Similarities, differences, relationship to the Talmuds and the literary origins of ARN are all treated. Ch. 10 gathers together the evidence for the hypothesis that ARN is closely related to a Rabbinic school, further defines the meaning of that concept and suggests dates for the development of the major part of the texts as we have them.

\section{secondary Literature}

Little has been written directly on ARN, though many studies treat individual aspects of it. The one major book, often cited in the notes, is by Louis Finkelstein, entitled Mabo le-Massektot Abot we-Abot d'Rabbi Nathan (Introduction to the Treatises Abot and Abot of Rabbi Nathan.) Finkelstein utilizes all the manuscripts and a comparative analysis of content to propose several sources lying behind the texts as we have them. These sources are assigned partly to the schools of Hillel and Shammi. Though we do not accept his entire theory, many of his observations are useful and his major conclusions are summarized in ch. 3. Judah Goldin, who translated ARNA, wrote an article which compared in detail the tendencies in ARNA with those in ARNB. ${ }^{4}$ In a number of parallel passages ARNA stresses study of Torah and ARNB stresses good deeds. Goldin acknowledges that both themes occur in both versions, but he highlights the peculiar emphases of each version. In ch. 9 his results are compared with those arrived at here. In general, our investigation looks at the larger literary units and structures which are common to both versions of ARN while Goldin's article picks up the subtle differences which give each a special character. 
Goldin has written several other articles on individual pericopae in ARN which will be cited along with other literature in the appropriate places.

\section{Torah}

Since Torah is mentioned so often in PA and ARN and has such a wide range of meanings, a preliminary description of Torah will be given. The word Torah means direction or instruction, and hence guidance and oracle. ${ }^{5}$ In the Hebrew Bible Torah can be something as simple as parents' instruction to their children. It also denotes an oracular response by a priest and the word of God communicated through a prophet. In Isaiah 8:16 it seems to mean the prophet's own system of teaching and his instruction in the principles of religion. ${ }^{6}$ In the septaugint Torah is translated most often by the Greek word nomos. Nomos can denote several things, including generally recognized custom, natural principles and laws derived from a legal system. C.H. Dodd held that Hellenistic Judaism turned the Biblical Torah into law narrowly understood. 7 (Cf. the narrow meanings of English "law" and Latin "lex".) J.A. Sanders correctly criticized Dodd's position for making too sharp a distinction between Palestinian and Hellenistic Judaism. ${ }^{8}$ Both Palestinian and Hellenistic Judaism retained a broad understanding of Torah and nomos.

The precise meanings of Torah in PA and ARN will emerge in the course of this study. To initiate the discussion, a few generalities will suffice. In the words of George Foot Moore, "Torah in one aspect is the vehicle, in another and deeper view it is the whole content of revelation". 9 Torah can refer to the Bible which is written revelation; most properly Torah is the Pentateuch, but it can mean the whole Bible as well. Torah also includes customs and traditions closely or loosely related to the Bible and any other teachings integrated into the whole complex of Judaism. Josephus says, "The Pharisees have passed on to the people certain regulations handed down by former generations and not recorded in the Laws of Moses." ${ }^{10}$ Rabbinic literature calls these customs and later teachings as well as the whole Rabbinic corpus of midrash, mishna, etc. oral Torah, that is Torah delivered to Moses on Sinai orally rather than in writing. ${ }^{11}$ while ARN makes no mention of oral Torah explicitly, it is clear from context that Torah includes both the Bible and all the traditions, laws and interpretations which constitute the Rabbinic tradition. This whole body of learning is the object of study so strongly urged in ARN. Torah is 
seen ultimately as the self revelation of God, God's will and the only mode of human access to God. Torah is for the authors of PA and $A R N$ and much of the Rabbinic tradition the supreme symbol for God and a godly life. It includes not only laws, but stories, myths, images, and ethical statements, that is, both halaka and haggada. 

CHAPTER TWO

\section{THE CHAPTERS OF THE FATHERS}

A brief consideration of the whole of the Chapters of the Fathers will furnish an overview of the traditions to be studied here and of the problems which confront us. The literary structure, composition, possible sources and their redaction, the genre and purpose, cultural influences, themes and historical setting of PA will all help to open the text to twentieth century understanding. Ostensibly, PA is a tractate of the Mishna and the document upon which both versions of the Fathers According to Rabbi Nathan comment. In fact, $\mathrm{PA}$ is unique within the Mishna and must be studied separately. As we shall see below, its presence in the Mishna is troubled. In addition, Tractate Abot of the Mishna is not the precise document being commented on in ARN. Each version of ARN cites lemmas from $P A$ which differ in wording, order and content from PA and from each other. The parts of ARN corresponding to $\mathrm{PA}$, chs. 3 and 4 are a collection of sayings in which the materials found in $P A$ are indistinguishable from other sayings; that is, for the most part the format is not citation of a passage followed by commentary. Nevertheless, the materials in the three versions of $\mathrm{PA}$ form an identifiable tradition which has a common core and has undergone a complex and varied development. The examination of the Mishna Tractate Abot in this chapter will initiate the study of the nature, development and purposes of the whole tradition.

Mishna Tractate Abot contains six chapters, of which the sixth is generally recognized as a later addition; it is not commented on in ARN and will be omitted here. Ch. 5 consists of enumeration sayings with groups numbering ten down to three, followed by a few disparate sayings. Because these sayings constitute a special problem they will receive a less full treatment in this chapter and be fully explained along with ARN in ch. 8 below. 1

\section{Literary structure and Composition}

The first four chapters of PA manifest several literary structures which hold diverse materials together; in addition, the formal characteristics of many of the sayings give shape to the finished product. Ch. 1 presents the chain of tradition, a series of figures who passed on the Torah, beginning with Moses 
who "received Torah from Sinai," that is, from God. The series moves from Biblical to Rabbinic authorities culminating with Hillel and Shammai. The chain of tradition continues implicitly with the mention of Rabban Gamaliel and Simeon his son at the end of ch. 1.2 The chain continues in the same fashion at the beginning of ch. 2 with Rabbi Judah the Prince and his son Gamaliel. None of these final leaders are said to have "received Torah," the technical phrase used in the chain of tradition proper, but their place in chs. 1 and 2 clearly implies that they are the heirs of Moses and his successors down to Hillel and Shammai.

The Biblical figures at the beginning of the chain, Moses, Joshua, the elders and the prophets are not assigned sayings, presumably because their teachings are already in scripture. From the Men of the Great Assembly on individual teachings are assigned to named teachers. This practice is in contrast to the pseudonymous attribution of many Biblical and non-Biblical books to earlier authorities, for example, Enoch or Solomon. The placing of these named teachers in sequence with Biblical authorities implies the unity and equal authority of teachings in the Biblical and postBiblical periods.

The nature of the sayings attributed to the members of the chain of tradition give us further information about the development and purpose of the chain. A majority of the sayings are tripartite wisdom instructions, characterized by verbs in the imperative tense. ${ }^{3}$ The first saying, that of the Men of the Great Assembly, is an example of tripartite instruction, with three imperatives: "Be deliberate in judgment, raise up many disciples and make a hedge about the Torah." It is introduced by a formula containing an explicit number, "they said three things," and so is set within the enumeration form. The second saying in the chain, by Simeon the Just, is also a complex form. It is a wisdom sentence, characterized by a verb in the indicative tense, and an enumeration with an introductory rubric and three items: "On three things the age stands--on the Torah, on the Temple service, and on acts of piety." 4 of the sayings in ch. 1 , numbers 1, 3-8, 10, 15-16 are tripartite wisdom instructions; this form dominates ch. 1 .

of the sayings in $\mathrm{ch}$. 1 which are not tripartite wisdom instructions, 12-14 which are the sayings of Hillel stand out. Along with Hillel's sayings in $2: 4 \mathrm{~b}-7$ they have their own peculiarities and are marked off from the other sayings in PA.4a Hillel is the only sage in the chain of tradition up to this point 
who has more than one saying attributed to him. The sayings do not follow the dominant form and one saying in each of the groups $(1: 13 ; 2: 6)$ is in Aramaic. In addition, $1: 9$ and 11 are wisdom instructions, but they are not tripartite. Rather, each gives motives for obeying the instruction.

The saying of Rabban Gamaliel (1:16), the first of the princes implicitly joined to the chain of tradition, is a tripartite wisdom instruction. Those of Simeon his son (1:17-18) and later figures (2:1-4a) are not. $1: 17$ is an autobiographical wisdom sentence, rather than an instruction, and $1: 18$ is a wisdom sentence, parallel to Simeon the Just's at the beginning of the chapter and forming a neat inclusion to close ch. 1: "Rabban Simeon ben Gamaliel says: By three things is the world sustained: By justice, by truth and by peace, as Scripture says: 'Truth and justice (and) peace judge in your gates. (Zech. 8:16)'" Note that a Scriptural proof verse is offered, a sign of a later stage in the enumeration form. 5

In PA 2:1-4a two further princes, Judah the Prince and Gamaliel his son are named. Their sayings are long, complex and differ greatly from the earlier sayings in ch. 1 . This change of form indicates that these figures have been added to the chain of tradition and that the controling inspiration which guided the formation of the chain has altered with the passing of time. Whoever first conceived and organized the chain of tradition used the sequence of teachers and a group of tripartite wisdom instructions to give his work shape. Hillel, the most famous and popular founder of the Rabbinic school and way of life, attracted further sayings at the end of the tradition and the princes added on, Gamaliel, Simeon, Judah the Prince and Gamaliel all vary from the original pattern.

Between the chain of tradition and the statement that Johanan ben Zakkai took over from Hillel and Shammai (2:8) lies a second collection of Hillel sayings $(4 b-7)$. This collection differs in form from the sayings in the chain of tradition, but it has some formal similarities with and strong Hellenistic tendencies like the Johanan materials following. Hillel and Johanan were put side by side by the organizer of ch. 2 as the "founding fathers" of Rabbinic Judaism. In both versions of ARN Johanan ben Zakkai comes after Hillel and Shammai, in chronological order. Since the Tractate Abot is part of the Mishna, it is very probable that Rabbi Judah the Prince moved Johanan so that Hillel would be succeeded by Gamaliel, Simeon and himself and thus the authority of the patriarchal house would be established. 6 
The precise nature of these collections can be seen from a closer examination. $2: 4 \mathrm{~b}$ is a series of five negative imperatives concerning community, self and learning. 2:5 has characterizations of five different types of human being: the boor, the Am Ha-Aretz, etc., followed by an exhortation. Similarly 2:8 has five disciples of Johanan ben Zakkai, each characterized by a nickname. The categorizing of types of humans is a common rhetorical procedure. $2: 6$ is an Aramaic saying (cf. also $1: 13$ ) introduced by an autobiographical setting $(1: 17)$. The autobiographical story plus saying is also a well attested Hellenistic form. 7 2:7 is a series of nine pairs organized by the formula "the more...the more...," e.g., "the more flesh, the more worms," and it is closed by a pair of parallel sentences urging study of Torah. This return to parallel pairs shows the influence of Biblical wisdom and also Hellenistic types, as opposed to the tripartite form in ch. 1.8 Thus, the collection of Hillel sayings in ch. 2 stands apart from the materials preceding.

The sayings and stories associated with Johanan ben zakkai and his five disciples are influenced by both Jewish and Hellenistic models. Johanan's statement is not tripartite, but like preceding sayings, it encourages Torah study $(2: 8)$. Johanan then introduces and characterizes five disciples, each with his own epithet. The listing and characterization of disciples is common in the lives of Hellenistic philosophers.9 The controversy at the end of 2:8 about the greatest of the disciples, Eleazer ben Arak or Eliezer ben Hyrcanus, is a typically Rabbinic form, but the dialogue about the right way to which a man should cleave (2:9) has been shown to be a Hellenistic disputation.10

2:10-14 are introduced by the rubric "They (Johanan's five disciples) each said three things." This introduction resembles that given the saying of the Men of the Great Assembly in ch. 1 and it suggests that Johanan's disciples are part of the chain of tradition, even though the claim is never explicitly articulated. Like the sayings in $\mathrm{ch}$. 1 , these sayings are wisdom instructions. The one exception, $2: 11$, is a wisdom sentence and an enumeration of three things, like $1: 3.11$

The final two sayings of ch. 2 are by Rabbi Tarfon. They do not continue the forms dominant in ch. 2, nor does Rabbi Tarfon fit among the disciples of Johanan. Tarfon's sayings do continue the themes of the preceding saying, 2:14, namely work and reward. 2:15 contains five brief statements; five is a favorite number of this section. $2: 16$ has a collection of statements completed by a 
summary instruction which also concludes the chapter and section with a characteristic reference to the future age: "And know: the reward of the righteous is in the future to come."

Ch. 3 is composed overwhelmingly of wisdom sentences (characterized by the indicative tense), in contrast to chs. 1 and 2 which are dominated by wisdom instructions (imperative tense). Ch. 3 falls into three parts: 1-12, five early sages, Akabya ben Mahalaleel, Hananiah Prefect of the Priests, Nehunya ben Ha-Kana, Hanina ben Dosa and Dosa ben Harkinas; 13-16, Rabbi Akiba; 17-18, concluding sayings on Torah. In the first part the five early sages match the five disciples of Johanan ben Zakkai found in ch. 2. The opening and concluding sayings of the section are wisdom instructions (3:1, 2a and 12). All the sayings between (except 7a) are wisdom sentences. $3: 1$ by Akabya ben Mahalaleel is introduced by two imperatives followed by the citation of three things to which one must attend. The three things, which are questions here, link ch. 3 with identical phrases in chs. 1 and 2.12 The questions in Akabya's saying, where are you from, where are you going and before whom will you give an account, are general enough to arise in any culture. But especially as answered here, they may have an anti-Gnostic quality to them.13 This Greco-Roman influence further connects this saying with ch. 2 .

Akabya's saying is linked to the one following (3:2 attributed to Hananiah Prefect of the Priests) by form and theme: both are wisdom sentences and both take a negative view of humanity: "Pray for the welfare of the Empire, because were it not for the fear it inspires, every man would swallow his neighbor alive." Half of the sayings in ch. 3 are about Torah and most others have mention of Torah or something associated with Torah. $3: 2 \mathrm{~b}$ is by Hananiah ben Teradyon, linked to $2 \mathrm{a}$ by the common name Hananiah. $3: 2 \mathrm{~b}$ is about Torah study between two or alone; $3: 3$ is about talk of Torah among three while eating. $3: 4$ is by another Hananiah, namely Hananiah be Hakinai. $3: 5$ is by Nehunya ben Ha-Kana, a sage with a patronymic similar to Hakinai. $3: 6$ is by Halafta of Kefar Hananiah and concerns study of Torah in groups of 10, 5 , 3,2 , and 1. Thus, 3:2-6 are tightly woven together by names, themes and form.

$3: 7 \mathrm{a}$ is an instruction, rather than a sentence, and it is attributed to Eleazar of Bartota, a sage not otherwise known. This saying is not found in either version of ARN and its theme, giving to God, interrupts the stress on constant study of Torah found in this section. It is most probably an addition, perhaps 
meant to urge sages to generous effort. Subsequent sayings are again linked by name, theme and form. $3: 7 \mathrm{~b}$ and $3: 8$ both interpret Dt. 4:9, "Only take heed, and keep your soul diligently, lest you forget the things which your eyes have seen, and lest they depart from your heart all the days of your life," to mean that distraction from study and forgetting Torah are to be avoided. 3:8-10 are linked by names: Dostai, Hanina ben Dosa and Dosa ben Harkinos. 3:8 contains a mishnaic question and answer, unusual in PA. 3:9-10a are pairs of contrasting sentences. 3:10b lists four things that bring death and 3:1l lists five things which take away one's share in the world to come. $3: 12$, like 1-2a, is a wisdom instruction and closes the opening section of ch. 3 by inclusion.

3:13-16 are all attributed to Akiba and all are wisdom sentences. 12 and 13 are linked by expressions which sound similar ( $q$ l $\mathrm{r}^{\prime} \mathrm{s}$, submissive and $q$ lwt $\mathrm{r}^{\prime} s$, frivolity). The sayings do not have the same form. 13 has five clauses, 14 has three, 15 has four in two parallel sentences and 16 is longer and more complex. 16 continues the theme of 15 , judgment. 14

Ch. 3 concludes with two sayings (16-17) composed of balanced, contrasting sentences, mostly concerned with Torah. They form a fitting conclusion to the chapter. Ch. 3 is unified by a series of verbal, thematic and formal links. It is an edited collection of disparate materials, a conclusion supported by the two versions of ARN where the materials in ch. 3 have been redacted quite differently. It differs from chs. 1 and 2 of PA in that wisdom sentences dominate and in the varied, rather than tripartite, construction of the sentences.

Ch. 4 is a more diverse collection of sayings than any of the previous three chapters. Torah is the most frequent theme, but sin, judgment and social relations are also frequent. Less use is made here of similar names. Neither wisdom sentences or instructions dominate. Sayings 1-9 have pairs of clauses or parallism; in the rest of ch. 4 parallel and tripartite sayings are mixed. The names of the four who entered the garden, Akiba, Ben Zoma, Ben Azzai and Elisha ben Abuyah, may have been the original core of this collection, as Finkelstein suggests, but now Akiba is in the previous chapter, Elisha is isolated at the end and only Ben Zoma and Ben Azzai are at the beginning. 15 In general, ch. 4 has been less thoroughly edited and is less unified than the previous three chapters of PA. Some of the sayings and links between them resemble materials seen earlier, but the collection lacks 
consistent and thorough organization. The enumeration sayings of ch. 5 are organized by number: nine groups of ten, two groups of seven and seven groups of four. Several disparate sayings with one group of three conclude the chapter. The groups of ten are concerned with creation, the early generations, the patriarchs, Exodus and the Temple. These enumerations familiarize the audience with the events, people and institutions which form the foundation of Israel. The first group of seven gives the seven characteristics of the wise man, the ideal type which PA wishes to develop. The same saying states laconically that the clod is the opposite. The second group of seven enumerates seven types of calamity which follow upon seven varieties of sin. Presumably, sin is the activity of the fool, the opposite of the wise man. These two themes continue into the seven groups of four which follow. The first group of four names the four times when sin and therefore punishment is most likely. The other six groups of four catalogue types of humans, temperment, disciples, givers of charity, people attending the study house and people sitting in the presence of the sages. The world, humans, sin and study are comprehended and ordered by a series of enumerations.

Sources and Redaction

The structure, literary forms and techniques of composition, as well as the distinctive contents of certain chapters in PA have encouraged many to speak of sources which have been combined to form PA. J.N. Epstein discerned three early collections: the chain of tradition down to Hillel and Shammai (1:1-15), the stories about Johanan ben Zakkai and his disciples (2:8-14) and the enumeration sayings (5:1-19).15 L. Finkelstein distinguished five collections: the chain of tradition, Johanan and his disciples, five early sages (Akabya et al. in ch. 3), the four who entered the garden (ch. 4) and the enumeration sayings.17 D. Georgi in a paper on the Gospels identifies the second collection of Hillel sayings $(2: 4 \mathrm{~b}-7)$ as an early source. ${ }^{18}$ We have seen in the previous section that various data support the division of PA into parts. The question demanding attention concerns the origin of those distinctions which divide the parts.

Scholars have spoken of literary or fixed oral sources which are taken over with little or no change, of traditions which developed and were used and of redaction which can produce a markedly different final product. For the most part it is impossible to discern what has happened in the background to PA. Comparison with the two versions of ARN, to be carried on in ch. 5-7 below 
will furnish some clues. For the present, a study of PA suggests that the chain of tradition extended as far as Hillel and Shammi and that about the time of the formation of the Mishna Gamaliel and simeon his son were added at the end of $\mathrm{ch}$. 1 to form a literary unit bounded by inclusion (1:2 and 18). Subsequently the line of the princes was added to at the beginning of ch. 2 with Rabbi Judah the Prince and Gamaliel his son.

The materials concerning Johanan ben Zakkai and his disciples have a distinctive and strongly Hellenistic flavor and are probably associated with the founding and guiding of a school. (This will be developed at greater length in ch. 6 below.) However, even if a group of sayings arose independently, or the sayings were independently passed on in the tradition, they are tied to $\mathrm{PA}$ and have been carefully redacted in place. The sayings of the five disciples are similar to the sayings found in $\mathrm{ch}$. I and may be an attempt to parallel the Johanan collection to the chain of tradition without explicitly saying that the disciples received the Torah. The claim that Johanan received the Torah $(2: 8)$ anchors that implicit claim for the disciples. The Hillel sayings (2:4b-7) which precede the Johanan collection associate Hillel with Johanan's school and give it legitimacy. Since these sayings occur in a different context in ARN, their position and use in PA are the work of the redactor. Further, the form of the Hillel collection, especially its use of groups of five $(4 b, 5)$ links it with Johanan and his five disciples.

Ch. 3 is not built around as obvious a structure as the chain of tradition. Finkelstein has suggested that a source containing an early group of five sages was used as the core of this section, an idea which must be explored in ch. 7 when ARN is used as comparative material. If such a source was used, its outline is not very visible or important in PA. However, ch. 3 is a collection of sayings by early sages in the Rabbinic tradition. The form of the sayings is the wisdom sentence, similar to the older folk proverb found in various books of the Bible and in Near Eastern culture in general. Consequently, the collection in ch. 3 makes an implicit claim to authority based on the ancient tradition of wisdom and as such, it parallels and extends the chain of tradition in ch. 1. Akiba, the most famous and respected sage of the early second century, gives further weight to the claims of ch. 3. Clearly, the chapter as we have it has been unified by similar names, literary forms and themes. Possibly 1-12 predated the final composition of $P A$, but this is not certain. 
Ch. 4 does not manifest any dominant source or structure. As was mentioned above, it may have had the four who entered the garden as its core, but they do not function that way now. Ch. 4 reinforces the themes found in the first three chapters, especially Torah and study. The sages cited in ch. 4 come mostly from the second century and because they follow the chain of tradition in ch. 1, the founders of the school in ch. 2 and the early sages in $\mathrm{ch} .3$ they too extend the chain into the late second century. The order of the first four chapters of PA follows a rough chronological order with precedence given to those in authority. Most important are those directly in the chain of tradition. The founder of the school after 70 and his special disciples come second. The early sages from the transition period next. Finally, a selection of teachers from the next most formative period, the second century after the Bar Kosiba War, complete the group. The chapters fall into a logical order and are completed by ch. 5 which is a popular collection of enumerations. Ch. 5 manifests no sources and is drawn from a vast pool of material which could have come into existence at any time. It moves the focus from the tradents and their specific activity, study, to history and the world in all its complexity, a world which has been comprehended and ordered in a series of lists.

The literary structure and possible sources of PA give some indications of the nature of the document, but a full consideration of its genre and purpose are necessary for an adequate understanding of its message.

\section{The Genre and Purpose of PA}

Though PA is one of the 63 tractates of the Mishna, it has long been recognized as unique and it should not be called Mishna for the purpose of genre identification. Mishna tractates have one common subject of discussion, with an orderly development of relevant topics. 19 PA has a collection of sayings by various sages with no tight thematic or logical unity and progression. The only comparable tractate is Eduyyot which collects the testimony of various sages about diverse questions. But Eduyyot's testimonies concern halaka like the rest of Mishna, and the literary unity of the tractate is assured by its concern to preserve what are supposed to be early, formative legal teachings.

$P A$ lacks the halakic interchange between diverse points of view and the progression toward a resolution of problems which is characteristic of the rest of the Mishna. Most sayings stand in isolation and when some do directly conflict, they are not 
together in conscious dialogue (e.g., $3: 2$ and $3: 5$, pro and antigovernment). Only a very few alternate opinions and discussions are reported, e.g., Abba Saul in 2:8, the answers of the five disciples of Johanan ben Zakkai in $2: 9$ (a special case), 3:2, 3:8 and 4:5. Anonymous opinions, usually considered to be authoritative in the rest of the Mishna, are lacking. Consequently, the precise genre of PA cannot be simply Mishna, even though it is numbered as one of the tractates of Mishna. Wisdom

$\mathrm{PA}$ is similar to Biblical wisdom literature in that it is a collection of disparate sayings with some unity given by form and theme. Though a general relationship to the wisdom tradition can be seen, PA and Proverbs are separated by many particular features. Biblical wisdom sayings are characterized by balanced halves which are synonymous, contrasting, climatic, etc. The dominant form in PA is the tripartite saying, made up of three clauses or sometimes of three items and a verb. The three parts are sometimes equal in length and parallel in structure, but at other times the third clause is different in length or a negative in contrast to the preceding positives. There seem to be no clear Biblical antecedents for this form. The groups of "three and four" in Amos 1--2 and Proverbs 30 do not produce tripartite sayings, nor even enumerations of three or four things in all cases. The Hebrew idiom there, compared to $P A$, is other than what we seek. Ben Sira 26:5 speaks of "three and four" and then enumerates three things. Ben Sira is closer in form to some materials in PA than is Proverbs, but the dominant form in Ben Sira remains the traditional parallel saying.

PA like Proverbs has a mixture of wisdom sentences and instructions which cluster in different sections. Many of the sayings in each concern moral behavior and both stress knowledge and learning, called wisdom in Proverbs and Torah in PA. God (usually referred to as "Heaven" in PA) is mentioned in both, but not excessively. Proverbs is collected in the names of Solomon, Hezekiah, Agur and others, while individual sayings are attributed to various sages in PA. (We might also note that PA ch. 6, which was composed in later centuries to reinforce the themes of $P A$, quotes extensively from Proverbs.) Both Proverbs and PA must be included in a comprehensive survey of the genre wisdom literature, but many specific changes have made PA a very different collection from Proverbs. 20 
Greco-Roman Influences

Direct Greek influence on Palestine began with Alexander's conquest of Syria-Palestine in 332 B.C.E., became especially strong before and during the Maccabean crisis and continued in a Greco-Roman form after Pompey's conquest in 63 B.C.E. 21 Hellenistic ways of life, thought and expression were integral to Jewish Palestinian culture from at least the mid third century on, and these tendencies affected Pharisaism and later Rabbinic writings. Hellenistic schools were especially influential on Jewish modes of organization and expression. The emergence of definable sects, Pharisees, Sadducees, etc. and more importantly the attention given to them fits most comfortably into the Greco-Roman world with its recognized philosophical schools, religious societies and craft associations. 22 Even granted that Josephus slants his descriptions of Jewish groups to represent them as philosophical schools, similarities in organization, teachings, rules, leadership and writings place the sects and other Jewish groups within the larger context of Hellenistic religious and philosophical societies and schools. 23 Greco-Roman culture influenced the composition of PA. Parts of it have strong similarities to Greco-Roman writings, especially those associated with schools of thought. Bickerman long ago established the parallel between the chain of tradition in PA and the lists of founders and disciples and heads of schools in Greco-Roman literature. 24 Because the Rabbinic chain of tradition begins with Moses and includes several Biblical figures before it gets to the pairs and later Rabbis, the Rabbinic school is anchored in antiquity, its teaching is built on revelation and its subsequent authority is ensured by the continuity of teachers into the second century.

The materials associated with Johanan ben Zakkai and his five disciples are also heavily influenced by Greco-Roman school literature. Listing several disciples of one master and then giving their teachings is found in Diogenes Laertius for Plato and others. The questions and answers in PA 2:9 about the good and bad ways have parallels in Epicurean materials. Elsewhere in PA, both Antigonus of Soko's name and saying (1:3) are Greek in origin and meaning. 25 Ben Azzai's saying, as well as his whole corpus, is related to Greco-Roman materials. 26 Fischel has catalogued other topoi and forms shared by Greco-Roman and Rabbinic materials. All these parallels do not place PA itself neatly within a GrecoRoman genre, but they do indicate a literary product standing between two worlds and strongly connected to school literature. 
This is in contrast to the Mishna which is characteristically Jewish. 27

Three Greco-Roman sources have structural similarities to $\mathrm{PA}$ : the sayings of the seven sages, collections of sayings and stories of the philosophers and the Gnostic sayings collections. The seven sages (Thales of Miletus, Bias of Priene, Pittacus, Solon and three others whose names vary) were traditonal Greek wise men about whom a number of stories were told. 28 They are listed by Plato (Protagoras 343a) and in many other sources earlier and later. A collection of their sayings was made by Demetrius of Phaleron (350-280) and preserved in Stobaeus. 29 other versions of the sayings abound in literature up through the Middle Ages. The sayings are all common proverbs ("Nothing to excess," "Know yourself," etc.) and have been assigned to the sages within the tradition of folk wisdom. The sayings of the seven sages are similar to PA in that sayings are assigned to named sages. The sages themselves are revered as the great teachers of the past and especially of the formative period of society $(600$ B.C.E. in Greece; the early Rabbis in Judaism). The content of the sayings, proverbial folk wisdom, resembles only a small number of the sayings in PA. PA's dominant interest in Torah, obedience and study set it apart from the Greek sayings which, like Proverbs, lack a unifying theme.

A second comparative source for PA can be found in collections of the sayings and deeds of philosophers, of which Diogenes Laertius is the most prominent example. Both the teachings and the lives of many philosophers are recounted at length. In PA although some biographical interest is manifested $(1: 17 ; 2: 6 ; 8,9)$, the main focus of these passages and the rest of $P A$ is on the sayings. Diogenes Laertius' collection of sayings and stories is generally more close to the contents of the Gospels and ARN than to that of $\mathrm{PA}^{30}$.

PA as a whole is closest to the genre "sayings collection." In Gnostic and probably in Christian circles the sayings of a founding or prominent teacher were gathered together. J.M. Robinson has made a fundamental study of this genre in early Gnostic writings with an eye to " $Q$ " and other hypothetical early Christian collections of Jesus' sayings. ${ }^{31}$ PA is a collection of sayings, but instead of one dominant authority it contains reference to many authorities of the same group, that is, the Rabbinic sages and their predecessors in the chain of tradition. The overall effect is the same in that the teachings and authority of the religious school are established. 
We do not claim that PA is "copied" from or "based on" GrecoRoman models, but rather that the Rabbis felt the need to collect their teachings and show the continuity and nature of their school, a desire they shared with the world in which they lived. When they set out to do this, they were guided in a general way by the sayings and stories found in the Eastern Mediterranean. With similarities to Mishna and Proverbs, PA stands firmly within the Judaism of late antiquity which was in vital contact with GrecoRoman ways of thought.

The formal similarities between PA and Biblical, Mishnaic and Greco-Roman literary genres are of only limited assistance in understanding the nature of PA. They suggest some contexts and purposes for PA which will be pursued below. A collection of sayings by named sages can serve to establish the credentials of an intellectual, social or religious group. It meets the need for popular wisdom (Proverbs, the sayings of the seven sages) and this has been a use to which PA has commonly been put in succeeding centuries when it has been treated as a repository of "ethics" for teaching. The dominance of Torah as the major theme of PA (see the section below) suggests an amalgamation of all wisdom and truth under a category proper to Judaism a process similar to the grafting of Christian ideology to Greco-Roman and Biblical wisdom in the Sentences of sextus. ${ }^{32}$ In summary, we may say that $P A$ is a collection of wisdom sayings organized to establish the authority of a continuous and coherent group of teachers and teachings and centered around the major emphases of that group, Torah and Torah study.

The Themes of $P A$

Most of the sayings in PA will fit into two very general categories: Torah and good behavior. In the chain of tradition it is Torah which is passed on from generation to generation. The world is sustained by Torah ( $1: 2)$, mankind is to be brought to Torah (1:12). The heaviest emphasis is placed on study of Torah, on the master-disciple relationship, on obedience to Torah and its accurate interpretation $(1: 4,5,6,15,17 ; 2: 1,12,14,16$; $3: 7,8,17 ; 4: 6,9,14)$. Study must be constant and accurate; students should honor teachers and remember their words. Learning must be joined with good works and all commandments must be taken with extreme seriousness.

A second group of sayings, similar to the Biblical proverbs, exhorts to good behavior or offers observations on humanity, human 
behavior and the world itself. As in wisdom literature, the observations are not logically arranged, but read as a whole they convey a view of the world and encourage a way of life. In PA the moral life is specifically focused toward a life of reverence for, obedience to and knowledge of Torah, a life led by masters and disciples bound together by their adherence to Torah. Fraternal relations between master and student and fellow students are a special concern $(1: 11 ; 4: 12)$. PA envisions a whole life filled with study, good works and a rich community life. The most sharp focus for this way of life would be found in a school, similar to the schools of philosophy in the Greco-Roman Empire where masters and disciples associated very closely and gave themselves to an encompassing way of life.

\section{The Historical setting of PA}

The place of PA in the tradition has long been disputed. It is unlike other tractates in the Mishna and its location in the Talmud has varied. ${ }^{33}$ Furthermore, the Mishna itself underwent revision and development during several centuries after 200.34 Therefore, PA may have been revised and honed into its present shape over a period of time.

To anticipate a little our study of the two versions of ARN and their different texts of PA, it seems that a common core of sayings underlies $P A$ and the two versions of ARN. The themes and concerns of these traditions, especially Torah, study, disciples and Torah-centered behavior, form a foundation document for the way of life initiated by the sages after $70 \mathrm{C.E}$. and developed especially during the second century. Though our direct knowledge of what happened at Jamnia, Usha and elsewhere is limited, it is probable that the way of life envisioned in PA flourished in the second century and was formulated in the traditions found in PA. $P A$ and ARN as we have them certainly underwent development during Talmudic times, but the collections underlying them probably date from the second century and possibly the end of the first. The chain of tradition, the stories of Johanan's five disciples and the early sages in ch. 3 could well have been used by a second century group fighting for recognition and stability in a country totally dominated by Rome. The content of the sayings, stressing Torah and good conduct, bespeak the struggle to establish a new way of life without the Temple but within the ancient wisdom traditions, now reoriented to fit new needs. 
The way of life envisioned by the Rabbis most probably was institutionalized as a school. Schools, in the ancient sense, were groups of teachers and students who both studied a certain corpus of materials and lived a specific way of life. They often dressed distinctively, had a center for their activities and distinguished themselves from the rest of society. In their study schools fostered a tradition, reverenced their founder, emphasized teaching, learning, studying and writing and were careful to pass on authoritative traditions. ${ }^{35} \mathrm{All}$ of these characteristics may be predicated of the Rabbis, with proper adjustments, as will be seen in more detail in ch. 6 .

The third century is a likely time for further development and consolidation of the traditions in PA and the two versions of ARN. In Greco-Roman literature it was a period of compiling chriae and other stories of philosophers and leaders. ${ }^{36}$ Neusner places the development of the biographical materials of Eliezer ben Hyrcanus during the third century. ${ }^{37}$ This complex of needs and concerns could easily provide a context for the separate development and consolidation of the traditions in PA and ARN which must have undergone development in independent circles of places. We can only know for certain that the tradition contained in these three sources did have a common beginning and independent development. 



\section{CHAPTER THREE}

THE LITERARY STRUCTURE OF THE

FATHERS ACCORDING TO RABBI NATHAN

A review of the larger and more comprehensive literary structures in the two versions of ARN will give order and shape to subsequent detailed discussions of particular sections and problems. A close study of a few key passages and transitions will indicate how the traditions were organized and reworked by authors and editors during the literary development of these works. The sources, oral or written, cannot be established for many parts of the tradition; where they can be found with some probability, they will be noted. Our primary interest will remain the complete works which have been passed down to us. The order and organization of the whole will provide a framework for examination of themes and special concerns.

ARNA

ARNA contains forty-one chapters which can be roughly divided as follows:

1-14: The chain of tradition from Moses to Johanan ben Zakkai, characterized by the rubric "He received" or "He took over" $(q b l)$, meaning that the authority mentioned took over the Torah from his predecessors.

15-18: The sayings of Johanan ben Zakkai's five disciples, plus ch. 18 on the five sages whom Judah the Prince used to praise.

19-22: Four chapters, each beginning with a sage from the time of the destruction of the Temple: Akabya ben Mahalaleel, Hananiah, Prefect of the Priests, Dosa ben Harkinos and Hanina ben Dosa. At the end of ch. 22 Rabban Gamaliel and Simeon his son conclude the section.

23-26: The four who entered the garden to learn mystical lore: Ben Zoma, Elisha ben Abuya, Ben Azzai and Akiba.

27-30: Additional sages and sayings.

31-41: Enumeration sayings. Chs. 31-35 contain groups of ten; 36-38 groups of seven; 39 groups of five (and six); 40-41 groups of four and three (and others).

The chain of tradition is introduced by a discussion of the purification which Moses, the recipient of Torah, underwent and by a story about the importance of studying Torah. The treatment of Moses communicates both the dignity of receiving Torah and the awe which should greet it. The very structure of the chain 
establishes the divine origin of Torah and the reliability and authority of those who received Torah. The commentary on the chain treats a series of subjects relevant to the central concerns of the chain. The first six members of the chain, from Moses to Haggai, Zechariah and Malachi, are Biblical and briefly presented. The continuity of revelation is easily established from sinai to the last of the prophets by the written Torah. The seventh link in the chain is the Men of the Great Assembly, who are the transition group from the last of the prophets to the named sages. With them begins the practice of characterizing each figure with a saying. Their saying, "Be deliberate in judgment, and raise many disciples, and make a hedge about the Torah," allows ARNA to broach several topics crucial to the authority and stability of the chain of tradition and Torah. "Be deliberate in judgment" means that the men of Hezekiah were able to interpret Proverbs, Song of Songs and Qoheleth in such a way that they were acceptable for public reading. The expositions of the eight hedges made by God, Adam, Job, Moses, the Torah, Prophets, Writings and Sages explain and clear up misunderstandings about written and oral Torah. They function as a sub-chain of tradition which shows how Torah is to be understood, applied and safeguarded. The directive to "raise many disciples" assures the continuation of the chain in succeeding generations.

Simeon the Just was the last of the Men of the Great Assembly, but his saying is used to interpret a later event. "On three things the world stands--on the Torah, on the Temple service and on acts of loving kindness" comes to refer to study of Torah and good deeds as replacements for the sacrifices in the Temple after its destruction in $70 \mathrm{C.E}$. The destruction is recounted with lurid detail, but at the core of the account is the story of Johanan ben Zakkai's escape from Jerusalem to start his school at Jamnia which was to become the new center of Judaism. Antigonus of Soko's saying is the occasion for discussing the origin of the Sadducees, the opponents of the Pharisees. The sayings of the rest of the pairs and the commentary developed around them center heavily on Torah and on the good deeds that should accompany Torah; to a lesser extent, good legal judgment and practice is encouraged. The chain is rounded off by a discussion of Hillel and Shammi in which Hillel is connected with Moses and Aaron. Thus the first and last links in the chain are united to form a neat literary conclusion with the implication that both Moses and Hillel 
are authoritative bearers of the Torah which has been passed on through the generations which separate them.

In ARNA, ch. 14, the chain of tradition continues through Johanan ben zakkai who "took over from Hillel and Shammai." This link in the chain, which was added to the original chain of tradition, ${ }^{1}$ is supported by the statement that Hillel had eighty disciples of whom Johanan was the least (or youngest - $q t n$ ).

After Johanan no more sages are said to have "received" the Torah. But the chain of tradition is implicitly continued in the statement that Johanan had five disciples. Each is described and sayings by each are presented. Johanan is paralleled to Hillel who immediately precedes; both are leaders who produced disciples to transmit and teach the Torah. Thus, the chain of tradition implicitly continues through the sages of the early second century and beyond. The importance of Hillel and Johanan is reinforced by further stories told about both of them in chs. 15-17 which is a commentary on the sayings of Johanan's disciples. The sages of the first and early second century are laid out together in the text to form the foundation of rabbinic Judaism.

The very next chapter, ch. 18, begins: "In like manner Rabbi Judah the Prince used to list the excellences of the Sages: of Rabbi Tarfon, Rabbi Akiba, Rabbi Eleazar ben Azariah, Rabbi Johanan ben Nuri, and Rabbi Jose the Galilean." This chapter, added by the author of ARNA (since it is not found in ARNB), ranks Rabbi Judah the Prince with Johanan ben Zakkai. Judah the Prince does not have five disciples, but does name five sages; and for each he has a descriptive name, just as Johanan had for his disciples. The mention of sages from the early to mid-second century and of Judah the Prince implicitly extends the chain of tradition to the early third century.

The next section of ARNA is less clearly organized than the chain of tradition and the presentation of Johanan ben zakkai's five disciples. Chs. 19-22 are each begun by a sage whose 1 ife spanned the destruction of the Temple in $70 \mathrm{C.E}$.: Akabya ben Mahalaleel, Hananiah, Prefect of the Priests, Dosa ben Harkinas and Hanina ben Dosa. $2 \mathrm{Ch}$. 19 contains Akabya's famous saying on the low origins of human nature plus commentary, along with deathbed teachings of Eliezer concerning ritual purity. Eliezer's teachings on purity seem to counterbalance Akabya's on human nature. Ch. 20 has extensive anti-Gentile material. Ch. 21 details four obstacles to the study of Torah and ch. 22 contains seven sayings about Torah, its importance and its study. The last two of the 
seven sayings are by Rabban Gamaliel and Simeon his son, apparently not located here as part of the chain of tradition (cf. PA 1:16-17) but as part of a collection of seven sayings on Torah. The next four chapters of ARNA (chs. 23-26) are each opened by one of the four sages who entered the garden to study mystical lore. ${ }^{3}$ Though they are noted for this elsewhere and that association seems to have drawn them together here, no explicit mention is made of the story of their mystical experiences. Chs. 23 and 24, in the names of Ben Zoma and Elisha ben Abuyah, continue the theme of Torah found in chs. 21 and 22 which immediately precede. 4 This thematic unity makes it impossible to clearly separate these four sages from the previous four. Ch. 25, introduced by Ben Azzai, concerns death and different signs and teachings connected with it. Ben Azzai's saying from PA 4:2 on obedience along with associated materials comes only at the end of the chapter. Akiba begins ch. 26 with a series of five hedges (about honor, wisdom, etc.) which echo the earlier hedges about Torah in chs. 1 and 2 . Thus one of the most productive teachers of Torah is connected with building hedges, a central task of Torah study. The rest of the chapter is a series of folk sayings and exhortations to Torah, purity and living in the Holy Land. These four chapters, along with the previous four, are not as tightly structured as previous sections of ARNA. Further detailed comment on their origin and make-up must be reserved to ch. 7 .

Four chapters of loosely structured materials (chs. 27-30) precede the final eleven chapters of enumerations. Some few sayings from $P A$, especially ch. 4, are scattered through the chapters. Many sayings and blocks of material present here are found in ARNB, chs. 32-35, the section on the early sages. Chs. 27 and 29 combine the themes of Torah and honor, including the honor of God, masters, disciples and neighbors. In ch. 27, PA 4:6 (Rabbi Jose) at the beginning and 4:12 (Rabbi Eleazar ben Shammua) at the end are both concerned with honor and are both expounded by complete commentary. The middle of the chapter concerns Torah. ${ }^{5} \mathrm{Ch} .28$ is a loose collection of sayings about Torah, featuring at its center Simeon ben Gamaliel, Gamaliel, Judah the Prince and Hillel. Near the end of the chapter Eleazar Ben Shammua expounds three types of scholars, a parallel to Abba Saul ben Nammas in ch. 29 who expounds four types of scholars. Over half of ch. 29 is composed of Eleazar Hakkappar materials including a section on honor and another on atonement (cf. ARNB, ch. 34 below). Ch. 30 continues the same general topic with a discussion of sin, reward 
and punishment (though the chapter begins with a saying on fulfilling words of Torah attributed to Rabbi Nathan).

The final eleven chapters of ARNA (chs. 31-41), corresponding to $P A$, ch. 5, are composed of groups of numerical sayings from tens down to threes. The groups of ten things in chs. 31-35 concern central cosmic, historical or institutional structures and events: creation, the early generations, the Exodus and wandering in the desert, Torah, the Shekinah, Jerusalem and the Temple. Ch. 36 has various numbered groups associated with sin. Chs. 37 and 38 contain groups of seven pertaining to the structure of the universe and especially classes of human beings and of $\sin$. (A few groups with other numbers are also present.) Ch. 39, with various numbered groups, continues the same topic and allied matters such as reward and punishment, the wicked, righteous and repentance. In ch. 40 several enumerations of four types of people are presented and then fours and threes concerned with the meaning of figures seen in dreams. $\mathrm{Ch} .41$ has an assortment of materials with threes dominating. The traditional ending of PA $(6: 11)$ concludes ARNA.

\section{$A R N B$}

ARNB follows the same general structure as ARNA, but with many specific differences, especially in the later chapters. A rough division of the chapters can be made as follows:

1-27: The chain of tradition from Moses to Hillel. Hillel is probably the last figure in the chain of tradition as found in the original traditions of ARN.

28-31: The sayings of Johanan ben Zakkai and his five disciples, plus ch. 31 which begins with "Johanan ben Zakkai took over from Hillel and Shammai" and contains a series of sayings by him and others. Ch. 31 seems to be independent.

32: Three of the sages from about $70 \mathrm{C.E} .:$ Nehunya ben HaKana, Hanina ben Dosa and Akabya ben Mahalaleel. The last saying of $\mathrm{ch} .3 \mathrm{l}$ is by Hananiah, Prefect of the Priests. The end of $\mathrm{ch}$. 32 has the sayings of the princes.

33: Three of the four who entered the garden: Akiba, Ben Zoma and Ben Azzai followed by a block of materials found also in PA, ch. 4 .

34: Dosa ben Harkinos' saying followed by blocks of material found also in $\mathrm{PA}$, chs. 3 and 4 .

35: Elisha ben Abuyah, the last of the four who entered the garden, who was probably put last because he became an apostate. 
His saying begins a complex collection joined by verbal and thematic links.

36-48: Enumeration sayings. Chs. 36-40 contain groups of ten (with one five); 41 contains groups of seven; $42-43$ have threes, tens and sevens; 44 contains fives; 45 has sevens, threes and fours; 46-48 contain mostly threes ending with tens which form an inclusion with ch. 36. Various other items have been added to the enumeration forms in these later chapters.

The introductory paragraph in ch. 1 lays down a principle which establishes Moses' (and the Torah's) exalted status by unequivocally noting its origins: "No one who glorifies himself is (truly) great unless someone greater than he glorifies him" and in fact God glorified Moses. A dispute about whether Moses was specially purified leads to an enumeration of several types of purification practiced by all Isreal and this discussion of purification prepares the reader to receive Torah in a proper frame of mind. The first seven links in the chain, from Moses to the Men of the Great Assembly and their saying, are recited as a whole and then each link is given as a lemma and supported by Scriptural example. But two names are added in the elaboration, Eli and samuel. As in ARNA, the discussion of the saying of the Men of the Great Assembly and the sayings of subsequent members of the chain of tradition bring up a series of topics crucial to Torah: its authority, limits, stability, study, interpretation and the way of life associated with it. ARNB has several extended sections not found in ARNA on the creation of humans and on the relations of males and females (chs. 8-9), on work (ch. 21) and on reward and punishment (ch. 22). The straight sequence of the chain of tradition ends with Hillel in chs. 24-27.

In ch. 28 the story of Hillel's eighty (here: pairs) of disciples, among whom Johanan ben Zakkai was youngest or least, and the scene at Hillel's deathbed make the transition from the chain of tradition to the collection of materials about Johanan and his five disciples (chs. 29-30). Several stories about Hillel are integrated into these materials in order to closely connect Johanan and his disciples with Hillel, the last and most prominent of the post-Biblical members of the chain. In them the traditions are passed on. Ch. 31 begins with the standard link in the chain, "Rabban Johanan ben Zakkai took over from Hillel and Shammai." Because this statement is separated from Hillel by three chapters and because ch. 31 itself is not found in ARNA, it seems to have been added by a later editor of ARNB eager to explicitly state that 
Johanan was a member of the chain of tradition. He begins the chapter with Johanan's saying which was already cited in slightly different form at the end of $\mathrm{ch} .28$. The saying is followed by a paragraph of commentary and then a group of seven sayings attributed to Johanan. The Johanan materials are followed by a saying of Hillel (PA 2:4); Hillel is once again linked with Johanan and serves to integrate him into the transmission of tradition.

The structure of chapters $32-35$ is much less clear than the structure of the preceding chapters and the corresponding chapters in ARNA. The pro-government saying of Hananiah, Prefect of the Priests, is tacked onto the end of ch. 31, probably so that a progovernment saying would not be the opening saying of a chapter. Nehunya ben Ha-Kana begins ch. 32 with a saying on Torah. Six sayings follow to make a group of seven of which five concern Torah and four are found in PA, ch. 4. Hanina ben Dosa comes next, his saying interpreted by a parable; Akabya ben Mahalaleel is third with the explanatory saying of Simeon ben Eleazar. The chapter concludes with sayings attributed to Gamaliel, Simeon ben Gamaliel and Judah the Prince. These sayings are divided into ten groups, each introduced by a name or by the formula "He used to say." Ch. 32 has been carefully edited into four coherent sections. Except for the saying of Akabya ben Mahalaleel, the dominant theme is Torah, though works are strongly stressed in the commentary on the saying of Hanina ben Dosa.

Ch. 33, like ch. 32, consists of four sections. Akiba begins the chapter with five types of hedge, six admonitions and five characterizations of different types of men. (The saying on the five types of men is attributed to Hillel in PA 2:5). Ben zoma follows with characterizations of four types of men and one additional saying. Ben Azzai has an assortment of sayings attributed to him and the chapter finishes with a group of seven sayings, several of which are found in PA 3:14-18.

Ch. 34 opens with the saying of Dosa ben Harkinas and four others, to form a group of five loosely connected by the theme of avoiding idleness. The rest of $\mathrm{ch}$. 34 has affinities with $\mathrm{ch} .33$ preceding, ch. 29 of ARNA and PA, ch. 4; most probably a group of common traditions were used by $P A$ and both versions of ARN since the materials are present in all, but differently located and used.

Ch. 35 begins with Elisha ben Abuyah who was placed last because he apostasized. The chapter is framed by sayings on studying Torah in one's youth: Elisha at the beginning and Judah, Jose and Judah at the end. The sayings within the chapter are diverse, 
but various blocks of sayings can be discerned through verbal and thematic links and comparison with parallel passages.

Chs. 36-48 contain enumeration sayings, parallel to those which concluded ARNA and which are in PA, ch. 5. Chs. 36-40 contain groups of ten (with one five) and ch. 41 has sevens. The succeeding chapters usually have a dominant number, but with other numbers and other ungrouped materials mixed in. Chs. 41-43 have sevens, with threes and tens and other numbers. Ch. 44, fives; ch. 45, one seven, then threes and fours; chs. 46-48, mostly threes, with tens at the end of ch. 48 to form an inclusion with ch. 36. The popularity of these enumerations has led to many additions and expansions which obscured any order which may have been in this final section of ARNB.

A brief review of both versions of ARN shows that each has four similar groups of material: the chain of tradition, Johanan ben zakkai and his disciples, early sages from the late first and early second centuries and enumerations. Both speak extensively about Torah, study of Torah and good behavior. Small units of sayings (three, five, seven, etc.) occur frequently and a variety of Tannaitic sages are quoted. Biblical figures and exegeses along with simple citations of verses dot each version. Both versions, along with $\mathrm{PA}$, derive from one complex and developing tradition. The variations in that tradition and the purpose and message of the two versions of ARN will engage us in the next few chapters.

\section{Finkelstein's source Hypothesis}

Before moving to detailed analysis of ARN, the highpoints of Finkelstein's source hypothesis will be presented. Finkelstein's Mabo is the only major modern study of AFN. Since we use it frequently but do not accept Finkelstein's complete theory, a brief review is appropriate. In his "Introductory Study" Finkelstein identified four main sources for ARN; later in his Mabo he dealt with five major sources which will be used here. ${ }^{6}$ In characterizing the first three collections Finkelstein designates them shammaite or Hillelite based on the presence of attitudes, teachings and details which he assigns to these schools. Further study of parallels and manuscripts give Finkelstein hints as to what shape the traditions had originally and how they have been combined and changed.

The five major collections in $P A$ and $A R N$ are: collection I: Shammite. The chain of tradition from Moses to the 
last of the pairs, Hillel and Shammai. (PA 1:15; ARNA, chs. 1-13; ARNB, chs. 1-27).

Colzection II: Hillelite. Sayings concerning Johanan ben Zakkai and his five disciples along with materials concerning Hillel. (PA 2:8-14; ARNA, chs. 14-17; ARNB, chs. 28-31).

Collection III: Shammaite. Sayings of the sages who lived around the time of the destruction of the Temple: Akabya ben Mahalaleel; Hananiah, Prefect of the Priests; Nehunya ben Ha-Kana; Hanina ben Dosa; Dosa ben Harkinas (PA 3:1-14; ARNA, chs. 19-22; ARNB, chs. 31 end, 32,34$)$. Collection IV: The four who entered the orchard to learn mystical lore: Elisha ben Abuyah, Ben zoma, Ben Azzai, and Akiba. (PA 3: 17-20 and 4:1-2, 20; ARNA, chs. 23-26; ARNB, chs. 33,35). Colzection V: Enumeration sayings (PA 5; ARNA, chs. 31-41; ARNB, chs. 36-48).

The chain of tradition, the materials about Johanan ben zakkai and the enumeration sayings stand out as separate sections. Collections III and IV are not so clearly delineated in the sources, as can be seen in the varied order of these materials in the sources cited above. Consequently, we have treated collections III and IV as one section under the rubric Early Sages, that is, sages who were active between the War of Destruction and the Bar Kosiba war. It is very possible that the four who entered the orchard (Collection IV) came from an independent source, but the shape and purpose of that work has been lost and in PA and ARN these sages function with Akabya and his colleagues as early sages, contemporary with and immediately following Johanan ben zakkai.

Though Finkelstein's studies provide much data and many insights, his source hypothesis is open to the usual criticism leveled at such theories. Source criticism deals mainly with documents, but the documents in Rabbinic literature are the result of oral tradition and underwent many changes in transmission even after they were written. ${ }^{7}$ It is most probable that there never was an original text, version or source, but rather a fluid and variable tradition. 8 Many of the characteristics and details pointed out by Finkelstein more probably derive from later editors who gave PA and the two versions of ARN their final shape. Consequently, our study has focused on the final form of the texts and the message communicated by them. It is likely that earlier blocks of material contributed to the texts we have now, but their exact shape and purpose cannot be recovered. Some tentative suggestions 
will be made, but always subordinate to the primary task of elucidating the final text.

Finkelstein's assignment of the first three collections to Hillelite and Shammite circles is riven with difficulties. Finkelstein draws materials from many different sources to establish the views of the School of Hillel and Shammi and then correlates them with individual comments in $\mathrm{PA}$ and the versions of ARN. However, Rabbinic documents have been so continuously and thoroughly edited that individual passages have had ample opportunity to be added, omitted or modified. In addition, the reports we receive on the Schools of Hillel and Shammai have often been adapted to the needs and purposes of their contexts. Appeals to disparate sources open up significant problems of interpretation which are not cleared away by Finkelstein's study. The reconstruction of first and second century thought and so of the development of PA and ARN will be less detailed and more tentative in this study than in Finkelstein's. 
The first section of both versions of ARN is the chain of tradition from Moses to the last of the pairs, Hillel and Shammi. The chain itself is a special genre with an intercultural background and a complex purpose. This chapter will analyze how the chain is used and developed thematically in each of the versions of ARN. In the next chapter we shall look at the chain as a special structure and genre in order to understand its function and meaning in $P A$ and both versions of ARN. The special relationship of Johanan ben Zakkai to the chain and also of the princes, Gamaliel, Judah the Prince, etc., will be considered in chs. 5 and 6 .

As usual in Rabbinic commentaries, diverse materials have been gathered without strict logical and thematic unity. Many items have entered ARN through association with relevant materials or because a topic was popular in the tradition. Despite the variety of materials collected in both versions of ARN, certain major themes persist throughout the section on the chain of tradition. Torah, given by God and taught by the sages, stands at the center and dominates the appearance of all other themes. The study of Torah, the authority of Rabbinic teaching, master-disciple relationships and appropriate behavior for one who adheres to Torah capture much of the interest of the commentators in ARN. These themes and the very form of the chain suggest that both versions of ARN are addressed to the members of the Rabbinic school, both masters and disciples. Schools in antiquity promoted ways of life with study of their central teachings at their core. Philosophical schools and similar religious organizations proliferated in the Greco-Roman world, especially in the Eastern Mediterranean. The Rabbinic way of life, a Torah centered life, is presented as a school in the structure and themes of ARN. This hypothesis will be tested in this and subsequent chapters and will be developed at length in $\mathrm{ch} .6$.

Each version of ARN will be treated in turn so that each may be seen individually. Major themes will be pointed out and unities which hold the works together will be noted. ARNA will be presented at greater length; ARNB will be treated with reference to ARNA both to avoid lengthy repetition when they are substantially the same and to highlight the characteristics of each when they differ. 


\section{$A R N A$}

"Moses was sanctified by the cloud and received Torah at. Sinai." ARNA comments on its initial statement by recording a traditional dispute concerning Moses" preparation to receive the Torah on Mt. Sinai. R. Jose the Galilean says that Hoses was covered by a cloud for six days to be purified (Ex. 24:16), but R. Akiba says that the cloud covered "it", i.e., the mountain, for six days and that Moses was called up only on the seventh day, as an honor. This dispute is a fitting introduction to the chain of tradition and to Torah, the main theme of ARNA, because it makes the reader look closely at Moses, the man who received Torah, and consider carefully the attitudes and preparation proper to receiving and learning Torah.

Moses" status is made clear by the conflicting comments of R. Nathan and R. Mattiah ben Heresh. Nathan says that Moses was "purged of all food and drink in his bowels before he was sanctified and became like the ministering angels." Moses unique role has led to a claim for him of suprahuman status, a claim already feared and refuted by Akiba's previous denial of a special period of sanctification for Moses. Mattiah responds to this danger by reaffirming Moses' humanity: the seven day waiting period was only to fill him with awe before receiving Torah. Moses' purification and preparation are implicitly paralleled with the priority and attention to be given to the study of Torah by the ideal scholar, an ideal expounded in the story immediately following in which Mattiah rebukes his teacher, Josiah, for leaving study of Torah to attend to worldly business. Both Moses and scholars must show great respect for Torah.

One final polemical assertion establishes Torah as a firm foundation for the chain of tradition and the way of life drawn from it: "By the hand of Moses was the Torah given at sinai." Paul attacked the law by saying it was only temporary and was given by angels, not God himself (Galatians 3:19), but the verses quoted here say that God himself gave Torah to Moses and that Moses was only the middleman between God and Israel. 'Torah's origin and authority are clear and unquestionable; the first link in the chain, God to Moses, was not broken by the intervention of others, even angels.

After presenting the Torah and the recipient of Torah, ARNA expounds on the notion of sanctification. Moses consecrated Aaron and his sons as priests. Their being set apart is subsequent to and subordinate to the setting apart of Moses, the lawgiver and 
teacher of Torah. By implication the later Rabbis, the guardians of Torah, are superior to the priests.

Subsequent links in the chain of tradition are presented, each with a supportive verse from Scripture: Joshua, the elders, the judges and the prophets. The final Biblical link in the chain is Haggai, Zechariah and Malachi, traditionally identified as the last of the prophets. The Men of the Great Assembly follow; they and all the subsequent non-Biblical members of the chain identify themselves through a saying. The saying of the Men of the Great Assembly, a group seen in the tradition as the link between Biblical and Maccabean times, becomes a charter for the study of Torah as practiced by the author of ARNA. "Be deliberate in judgment" now refers to interpreting difficult and shocking passages in Proverbs, the Song of Songs and Qoheleth. A second, natural interpretation, that one should be patient, is also applied to Torah: Moses forgot what God had told him because he became angry. Anger leads to forgetting the words of Torah and forgetfulness is the bane of scholars who memorize the tradition. Though the instruction to "Be deliberate in judgment" may have been originally addressed to judges, ${ }^{2}$ here it is turned toward the scholars and students who study, interpret and teach Torah. Scripture, Moses and passing on Torah occupy the center of this way of life and fill the early part of ARNA.

The chain of tradition up to the Men of the Great Assembly continually discusses topics crucial to the nature, preservation and interpretation of Torah. Moses and Mt. Sinai, preparation for and proper attitudes toward the word of God, the origin and authority of Torah and the study of Torah all contribute to the discussion. Events at Sinai, texts from the Bible and the current concerns of the author and audience are interwoven into one whole under the aegis of Torah. The emphasis on study and on the authority of the teaching suggest that ARNA is directed toward scholars, students and teachers in a scholastic setting.

The Hedges

ARNA next interprets the third clause of Simeon's saying, "Make a hedge about the Torah." J. Goldin suggests that the change in order is a deliberate midrashic decision. Since the first clause has been referred to Torah (the sages are to be deliberate in their teachings), it is natural that the hedge should follow, since it too is applied to the way they teach Torah. ${ }^{3}$

Comments on the hedge continue the themes already begun in the previous sections, especially the interpretation and explanation 
of Scripture and ideas central to scripture. Eight figures are said to have made a hedge about Torah: God, Adam, Torah itself, Moses, Job, the Prophets, the Writings and the Sages. This series forms a sub-chain of tradition and functions in an analogous way. For the author, making a hedge, which is a process of explaining, arguing, reasoning, defending and interpreting, is not a late human creation or an arbitrary exercise of human reason perpetrated on the written word of God. Even God knew that his word would be misunderstood and attacked, so he too built a defense, a hedge. Adam, the first human, erected a badly constructed hedge and caused problems. Yet, to engage in the process is necessarily human. Job, an ancient and a non-Jew according to much of the tradition, did it and Moses, the Jew who received the Torah and initiated the chain of tradition, did it. Each of the divisions of scripture, Torah, Prophets and Writings, make a hedge, or to de-personify them, have hedges built into the text. It is of the nature of Scripture to be explained and interpreted. Finally, the sages, the heirs to Moses and the interpreters of scripture in the author's day, erect hedges. The author of ARNA himself is continuing the process of interpreting and explaining, that is, of making a hedge. The hedges made by God and prophets concern God and defend God against scriptural statements which might be misunderstood. The hedges made by Adam, Torah, Moses, Job and the Writings all concern male-female relations, sexual relations or ritual purity. The hedge erected by the sages concerns the time for prayer and is a classic example of a Rabbinic rule constructed more strictly than a Biblical rule to avoid any infraction. The choice of examples reflect two of the traditional triad of sins thought characteristic of Gentiles and characteristically avoided by Jews (idolatry, murder and illicit sexual relations).

God's hedge is found in Dt. 29 where destruction of the land is promised if Israel sins. The destruction will be so severe that strangers passing by will ask, "Why has the Lord done thus to this 1and." (Dt. 29:23) God has already provided an answer to that question in the succeeding verses which charge that Israel broke the covenant and committed idolatry. The author of ARNA addresses an urgent question of theodicy brought on by the ruins of the Temple which existed in his day. In his view God himself in scripture anticipated questions about his justice and provided an apologetic answer, an answer which was extremely useful in the period after the destruction of the second Temple, and which also provided a model for the apologetic work done by later generations of scholars. 
After God, Adam the first human put a hedge around his words. The section concerning Adam's hedge is much longer than any of the others because it is replete with digressions and haggada. Stories and interpretations of scripture concerned with Adam were popular in Rabbinic lore and have been freely woven into the narrative with some even repeated.

God ordered Adam not to eat from the tree of the knowledge of good and evil (Gen. 2:16-17). Adam in turn told Eve not to touch the tree (Gen. 3:1), thus creating a hedge about God's command. The serpent then tricked Eve by touching the tree and shaking it until its fruits fell; Eve saw the serpent unharmed and ate. "Hence it has been said: If a man puts an (excessive) hedge around his words, he shall not be able to stand by his words. Hence it has also been said: Let no man add to what he hears." Adam's sin is also explained by the story that the serpent ate of the tree and did not die and so Eve concluded that "All the things about which my master ( $a b b \hat{i}$ ) admonished me at first are false." Both the excessive hedge and the disregard of the "Rabbi's" instructions led to sin for Adam and Eve and by implication will lead to $\sin$ in the author's world too. An alternate tradition, that the tree cried out in protest and so the serpent did not touch it, may be a defense against the criticism that the hedge Adam put about his words led to Eve's touching the tree and so to sin. Though the section in general advocates making hedges, Adam's hedge manifests the dangers inherent in this process.

Adam himself sinned by disobeying God, that is, not accepting and acting according to Torah. The disobedience of Adam is conveyed by two parables concerning a woman's disobedience to her husband. Lust after kingship and rebellion against authority are developed by several comments and stories: Titus stood at the altar and foolishly challenged God; the serpent wanted to be king over the whole world and so tempted Adam and Eve; the serpent was jealous of Adam who was being served like a king by the ministering angels. A series of Psalms associated with each day of creation stress God's majesty and power. Eve is convinced by the serpent that her "Rabbi," her master, has lied to her, so she rejects his instructions. The conflict which led to the first sin seems centered around a desire to be king as opposed to obeying the real king, God.

A number of traditional accounts of creation and the effects of Adam's sin are scattered throughout the chapter. The contrast between God's creation and sin vividly captures the contradictions 
of human existence and the dangers facing humans in their response to God. Implicitly, obedience to God's word (Torah) as expounded by the sages is proposed as the corrective to Adam's sin with all its consequences.

\section{Torah and Moses}

After God and humans, Torah itself made a hedge about its words (ch. 2). ARNA has probably moved Torah to third place in the sequence, away from the other two divisions of scripture (the Prophets and writings) in order to give it special prominence. ${ }^{4}$ Torah, which is God's revelation as a whole, is closely associated with its author, God, and its recipients, humanity.

The hedge which Torah made about its words is found in Lev. 18:6 and 19: "None of you shall approach any one near of kin to uncover her nakedness while she is in her menstrual uncleanliness." The verb "You shall not approach" is stringent and absolute; to avoid sin in relations with women, the law forbids most contact. Naturally, the detailed interpretation of this hedge leads us into Rabbinic rules concerning relations with wives, female relatives and women in general. Husbands and wives are not to embrace nor lie side by side during menstrual uncleanness; men are not to be alone with their mothers-in-law or daughters-in-law; in public a man should not talk with or walk behind a woman, or even his wife, for appearance sake.

The author asserts that a series of detailed customs governing male-female relations derive directly from scripture and are a hedge built into scripture to prevent humans from even approaching a transgression of the difficult and delicate laws governing ritual purity in marital relations. The disputes among the sages show clearly that scripture is in fact being interpreted, but the author holds that these interpretations are part of Scripture itself; written and oral Torah are simply Torah.

The difficulty and importance of obeying the commandment to refrain from intercourse during the woman's menstrual uncleanness is reinforced by the story of an otherwise pious husband whose early death is explained by infraction of the regulation not to lie side by side. The serious implications of infraction against even one minor commandment are reinforced by an interpretation of Song 7:3 "Your belly is a heap of wheat hedged in with lillies." The minor commandments are the heap of wheat or alternately the lillies which are tender. These commandments are kept in the privacy of one's home and are easily broken. They hedge Israel in 
and see that Israel remains faithful. As in previous sections, emphasis placed on voluntary obedience and the importance of Torah as one indivisible whole.

The hedge which Moses built about his words continues the theme of relations with women and it uses the tactics of Adam's hedge. Moses changes a command given by God into a more strict demand. God Said: "Go to the people and consecrate them today and tomorrow." (Ex. 19:10) Moses told them: "Be ready by the third day," (Ex. 19:10) and ARNA interprets this to mean that Moses added a third day of purification. Moses the founder of the Hebrew nation, succeeds where Adam, the founder of the human race, failed. The reason offered for the third day of purification, that a woman might discharge semen on the third day and render someone ritually impure as they receive the Torah, presumes the Rabbinic law which considered semen no longer a life force after three days and so no longer a source of uncleanness. ${ }^{5}$ Consequently, Moses is shown changing even the direct command of God to achieve harmony with Rabbinic law.

The very fact that Moses changed a command of God provokes a serious and extended reflection which takes up most of this section and strikes at the ambiguity of "making a hedge." ARNA introduces this discussion with the thematic statement:

This is but one of the things which Moses did of his own accord. He reasoned by inference and his judgment coincided with God's: He kept away from his wife.... He kept away from the tent of meeting....He broke the tablets of the Commandments, and his judgment coincided with God's. The author clings to the assertion that Moses reasoned and decided independently, but he hastens to add that his judgment coincided with God's, that is, he was correct in his interpretation of the implications of the law and its real meaning. The presentation of the three other cases when Moses acted independently is qualified by apologetic traditions which say that in separating from his wife and in breaking the tablets Moses did not act on his own (a denial of the original point of all these materials!) but only acted when directly ordered to do so by God. Moses' separation from his wife seems to contradict the positive command to increase and multiply (Gen. 1:28). The breaking of the tablets with God's word on them seems blasphemous and so it is put last and qualified by a mass of apologetic material. In its final form ARNA is profoundly uneasy with the statement that Moses decided independently. Second century authorities concerned with establishing Rabbinic practice and Torah as central to Judaism (Akiba, Meir, Judah ben Bathyra 
and Eleazar ben Azariah) are cited to show that God told Moses what to do. These commentators understand Rabbinic law as directly revealed by God and do not accept the interpretation that Moses decided for himself. The doctrine of the oral and written Torah, both given at sinai, ${ }^{6}$ is precisely an attempt to establish that "interpretations" were explicitly revealed by God himself.

In an elucidation of the hedge about Torah, Moses who received Torah on Sinai is obviously a key figure. The examples of Moses' decision making and behavior are culled from events connected with the giving of the Torah on Sinai. More significantly, all of Moses' decisions manifest respect and awe for the Torah or for God himself, the giver of Torah. Moses tries to prepare the people to receive the Torah by ritual purification and to protect them from sin by smashing the tablets. He profoundly alters the pattern of his own existence by deciding to separate from his wife and stay out of the tent of meeting. Moses is a model for how Israel should respect and guard God's Torah.

The review of cases in which Moses reasoned for himself and decided on a course of action which was approved subsequently by God addresses the substantial issue of how Torah is to be interpreted and lived. These stories teach that humans may and must play an active part in discerning the meaning and implications of God's commandments. Implicit in them is a defense of the creation of Rabbinic rules and laws not set forth in scripture. Moses, first person in the chain of tradition, gives an example for all subsequent generations. This is a very frank and daring defense of the Rabbi's authority to decide the meaning and practice derived from divine law and a justification of the intense study of Torah carried on in Rabbinic schools.

$$
\text { Job, Scripture and the sages }
$$

Job, who was a "blameless $(t a m)$ and upright man, who fears God and turns away from evil," (Job $1: 8$ ) made a hedge about his words, or more accurately his behavior, by keeping "himself far from things which lead to transgression, from what is hideous and whatever seems hideous." That Job was tam, that is blameless, whole, perfect, leads to the assertion that he was born circumcised, since circumcision makes a male Jew complete (ch.2). Twelve others from Adam to Zerubbabel who were also born circumcised are listed after this comment. The author of ARNA argues against the usual opinion that Job was a Gentile and includes him, by a divine intervention, within Israel. An example of Job's careful avoidance 
of occasions of $\sin$ is drawn from his relations with women, a subject which has come up in the hedges of Adam, Moses and Torah. Job 31:1 says: "I have made a covenant with my eyes; how then could I look upon a virgin?" The interpretation, that Job would not look even at an unmarried woman whom he might marry, provokes a corollary and a reason. The corollary is that he would all the more refrain from looking at another man's wife. It states explicitly what is forbidden by the commandments, coveting another man's wife, and by implication emphasizes the strictness of Job's behavior. This is explained by the reason: "If I should look upon her today and on the morrow another man comes and weds her, it will turn out that I have been looking upon another man's wife."

In contrast to the hedges which humans build to protect themselves in matters of sexual behavior the prophetic books concentrate on God himself. Descriptions of God use metaphors, but God exceeds the limits of the metaphors. For example, "The Lord goes forth like a mighty man," (Is. 42:13) must by understood so that God is "not merely like one mighty man but like all the mighty men in the world." 7 Amos 3:8, "the lion has roared" and Ez. 43:2, "the sound of many waters," are interpreted similarly. ARNA concludes "But the eye is shown what it can see and the ear is permitted to hear what it can hear." The hedge protects God's transcendence which can never be directly seen or understood by humans and it protects humans, giving them only what they can bear of God. More prominent than either of these hedges is the hedge the Rabbis erect about the words of the prophets here, as they emphatically assert that God is greater than the metaphorical language used of him.

The hedge which the Writings made about their words is found in the warning against the wayward woman in Prov. 5:8, "Keep your way far from her, and do not go near the door of her house." This warning is applied to the two concerns which have predominated in the discussion of the hedges: relations with women and the correct interpretation of Torah. ARNA continues its stress on Torah by interpreting the "her" in the verse to mean minkt, heresy; a person is warned against associating with or even listening to sectarians. A second paragraph, based on Prov. 9:2 that she has prepared a meal, may allude to christian common life or worship (Acts 1-5) and it warns that once a person is in the circle of heretics they will reclaim what they gave him. A second interpretation of Prov. 5:8 reinforced by Prov. 7:26, "For many a victim has she laid low," contains the standard warning against prostitutes. 
The hedge of the Writings, like the hedge of the Torah, demands caution and restraint in any behavior which might lead to sin.

The sages, like the Torah and the Writings, put a hedge around their words through regulations which keep the believer far from sin (ch. 2, end). Their teaching, that a man should recite the Shema before midnight (m. Berachot 1:1, the first mishna of the entire collection and a symbol for the whole?), guards against a person sleeping through the night and failing to say the shema before dawn, the last moment it may validly be said. ARNA, true to its stress on study, urges that a person go the the study house and even if he does not read Scripture or Mishna, at least he should say the shema there.

The hedges made by God, Adam, Torah, Moses, Job, the Prophets, the writings and the sages reinforce the authority of the chain of tradition and the necessity for study of it. Not only has Torah been handed down from God and Moses, but the tradents have preserved Torah's meaning. As they affirm that hedges are built into scripture and that the rules derived from scripture are fully Torah themselves, the rabbinic authorities who created this section of ARNA show the twentieth century observer that they were indeed interpreting and justifying those interpretations as coming from God. Since God himself and Scripture itself made hedges, subsequent authorities can do no differently. The types of hedges made by the eight authorities correct two major tendencies toward sin: the tendency toward misperception of God and heresy and the tendency toward sexual licence. All of this supports a Torah centered way of life founded on study of and obedience to the Torah and it demands that the task of guarding and promoting this way of life be carried on through the study and close fraternal relations characteristic of an ancient school.

The final phrase of the saying of the Men of the Great Assembly, "Raise many disciples," continues the central concerns of the Rabbinic way of life (ch. 3). A dispute between the Schools of Shamai and Hillel about who should study initiates the discussion. The school of Shammi restricts study to the talented, meek, aristocratic and rich; the school of Hillel opens study to everyone because even sinners have been drawn to Torah. The rest of ch. 3 is filled with sayings and stories about Rabbi Akiba with special emphasis on generosity to the poor. At first glance most of the sayings appear irrelevant to the topic at hand (except the interpretation of Qoh. 11:6, "In the morning sow your seed and in the evening withhold not your hand," applied to raising disciples), 
but $J$. Goldin has shown that Akiba is presented as the archetype of the student who is poor and begins study late, and that giving alms to the poor is carefully coordinated with study as part of living Torah. 8 This same balance will be found in the teachings attributed to the pairs.

\section{Simeon and Antigonus}

Simeon the Righteous' saying, "On three things the world stands--on Torah, on the Temple service and on acts of loving kindness," is used to explain the transition from worship at the Temple to study of Torah and good deeds. An extended description of the loss of the Temple also gives expression to the mourning which accompanied this event (ch.4). Each phrase of Simeon's saying is quoted separately. ARNA understands Torah specifically as study and teaching of Torah by sages. Hos. 6:6, "I desire loving kindness and not sacrifice, the knowledge of God rather than burnt offerings," supports this interpretation. The second half of the verse identifies study of Torah as more beloved than burnt offerings. "Hence, when a sage sits and expounds to the congregation, Scripture accounts it to him as if he had offered up fat and blood on the altar." ARNA replaces the lost Temple sacrifices with study of Torah and continues its emphasis on study, but it does not attempt to explain why the destruction occurred.

ARNA expands its discussion of Torah and action by taking up the well known problem of whether to interrupt study to join a marriage or funeral procession, a very serious duty. ${ }^{9}$ The evidence presented is mixed. First, a moderate rule is given: leave study to join a procession if too few people are in the procession. This rule assumes that the command to process must be fulfilled, but it is better fulfilled by a non-scholar. Secondly, Judah bar Ilai is presented teaching his disciples to join a marriage procession in imitation of God's attendance on Adam and Eve at their wedding. The fundamental need for marriage and begetting children in marriage is reinforced by a citation of Gen. 2:23 on the creation of Eve. Rabbi Judah's argument defends the importance of marriage, yet ARNA so places these materials as to stress the (equal or greater?) importance of studying Torah. The tension is commented on, but remains. These discussions of value and principle pertain especially to full time scholars and students connected with an organized school.

In explaining the second phrase of simeon's saying, "on the Temple service," ARNA cites the common belief that agricultural fertility depends on proper worship in the Temple. Dt. II and 
Haggai 2:15-16 (where the prophet recalls scarcity before the Temple was built) are cited. Hag. $1: 9$ is used to show why the Temple was destroyed and 2:18-19 gives a promise of prosperity if it is rebuilt. Mention of the Temple brings up the anguish of its loss in 587 B.C.E. and again in $70 \mathrm{C.E}$. along with problems of theodicy and hopes for the future.

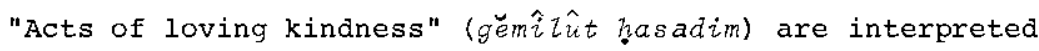
through Hos. 6:6, "I desire loving kindness (hesed) and not sacrifice," as a replacement for the sacrifices and worship no longer possible because of the loss of the Temple. The commentary on this phrase of Simeon's saying implicitly answers the problem raised above concerning the difficulties engendered by the loss of the Temple. This major shift in Jewish religious practice is justified by a three step argument in ARNA. The fundamental importance of loving kindness to the existence of the world itself as well as human existence is established by citing Ps. 89:3, "The world is built with loving kindness."10 Acts of loving kindness are not just deeds people do; they are intergral to and constitutive of the world itself. Secondly, Rabbi Joshua asks Johanan ben Zakkai how sins will be atoned for now that the Temple (and the sacrifices of the Day of Atonement) are at an end. Johanan replies that acts of loving kindness are an effective atonement and cites Hos. 6:6. Thus the most solemn and crucial Jewish ritual is replaced by this bold interpretation and the way is opened for adjusting other aspects of Judaism to make up for the loss of the Temple. Finally, Daniel is cited as an example of a Jew living without the Temple who engages in acts of loving kindness rather than sacrifices: "He used to outfit the bride and make her rejoice, accompany the dead, give a perutah to the poor, and pray three times a day--and his prayer was received with favor." What Daniel did after the loss of the first Temple, a pious Jew can do after the loss of the second Temple. Loving kindness was instrumental in the creation of the world, atones for sins and replaces the worship of the Temple as the center of a Jew's life.

ARNA concludes ch. 4 on Simeon's saying with the story of Johanan ben Zakkai's escape from Jerusalem, the story of the high priests throwing the keys of the Temple back to heaven, some verses which speak of mourning, and finally a discussion of the three things in which God made humans differ from one another. This final group of three forms an inclusion with Simeon's tripartite saying at the beginning of ch. 4. The story of Johanan's escape has at its core an account of the founding of the Rabbinic school 
at Jamnia.11 The final materials provide background to the loss of the Temple and stress again what it led to, a new Jewish way of life.

The saying of Antigonus of Soko (ch.5) with its Greek background, is made to refer to the dispute over resurrection of the dead and the rise of the sects. It functions as an explanation of how disputes arose within Judaism and as an apologetic for the Rabbinic belief in resurrection of the dead. Antigonus' saying makes an analogy between the master/slave and God/believer relationships. "Be not like slaves who serve their master for the sake of their allowance" refers to the normal situation in the GrecoRoman world in which a master committed himself to maintain a slave who worked for him. "Be rather like slaves who serve their master with no thought of an allowance" refers to the less common and less desirable relationship which prevailed especially when food prices were high: the master would make the slave hire himself out, in addition to his regular work, to earn money for food. 12 The final clause, "and let the fear of heaven be upon you," reinforces the application by analogy to the relations of humans with God. Respect for God and acceptance of one's situation on earth should lead one to worship and obey God, whether one receives rewards and happiness or not.

Since the relationship of humans and God must include God's justice toward humans and since reward for the just after death and the resurrection of the dead were major foundations of the Pharisaic and Rabbinic world views, it is almost inevitable that Antigonus' saying about reward be turned to that problem. In ARNA the very text of the saying has been altered with the addition, "and you will receive a reward, both in this world and in the world to come, as if you had done it yourself." ARNA then relates the saying to the dispute among Jewish sects over whether there is a resurrection from the dead. According to the author of ARNA Antigonus' disciples reasoned that he did not teach resurrection from the dead and so they "withdrew from the Torah," a statement made from a later polemical, Rabbinic stance. Two sects arose, the sadducees from Sadok and the Boethusians from Boethius.

The author of ARNA understands resurrection to be implied by Antigonus' saying and defends it against a natural challenge. The saying also serves as an occasion to explain the existence of a1ternate views. Note that the presentation of Antigonus' disciples and disciples of those disciples is arranged in a sorites, a common Greek rhetorical form. ${ }^{13}$ 
The author of ARNA is eager to lay the foundation of his own belief and explain the emergence of his opponents as a mistake. As in the chain of tradition as a whole, Rabbinic beliefs are seen as original and unchanged. This whole section identifies the Rabbinic school of thought and defends its validity by attacking alternate schools.

The Pairs

The early part of the chain of tradition ends with five pairs of teachers. The first two pairs have balanced teachings. Jose ben Joezer of Zeredah speaks of listening to the sages and Jose ben Johanan of Jerusalem talks about care for the poor in one's house and relations with women. Similarly, the second pair, Joshua ben Perahyah and Nittai the Arbelite, speak of having a teacher and fellow students and of keeping away from evil. In each case the first of the pair teaches study of Torah and the second good deeds.

Jose ben Joezer's tripartite saying (ch. 6) encourages welcoming and listening carefully to the teachers of the law: "Let your house be a meeting place for the sages, and sit in the dust at their very feet, and thirstily drink in their words." ARNA explains that the sages should be so familiar with one's house that they arrange to meet there. And of course, the householder ought to sit on the floor (the usual position for a student) and listen with awe. Surprisingly, ARNA also counsels that if a scholar visits the house asking to be taught, the householder ought not refuse him. This reversal of roles may project an ideal situation in which all people are able to teach one another.

The bulk of ch. 6 is filled with stories of Eliezer and Akiba as models who overcame obstacles to study Torah. The stories about Akiba stress his late start in the study of Torah, his poverty as a student and his eventual success at learning Torah bit by bit. The narrative about Eliezer chronicles his father's initial opposition and then eventual acceptance of his role as student and teacher, his initial poverty as a student and his brilliance as a youthful expounder of Torah.

The stories concerning the difficulties faced by Akiba and Eliezer when they wanted to study suggest that a person who wants to study will overcome age, poverty, family obligation and parental opposition. They also show the power of learning and its cumulative effect for one who learns, as well as the necessity for humble attitudes and a willingness to learn. The story of Eliezer's studies with Ben zakkai in Jerusalem as well as the added 
stories of the three wealthy men who attended the sages, sisit Hakkeset, Nakdimon ben Gorion and Kalba Sabua, paint an ideal picture of the center of Judaism before the destruction of the Temple and of the prominence of the Rabbinic school and teachers even then. Everyone, even the rich leaders, assembled to learn and all were eager students and pious in their good deeds and giving of alms.

The saying of Jose ben Johanan of Jerusalem (ch. 7) provides a balance and complement to that of Jose ben Joezer. Jose ben Joezer treats study and the master-disciple relationship. Jose ben Johanan teaches conduct toward the poor and among members of the household. In the previous saying the home was treated as a center for learning and in this saying it is a source of sustenance for the poor and a harmonious base for life. The first two clauses, "Let your house be opened wide and let the poor be members of your household," are more closely tied to one another than they are to the third, "Talk not overmuch with women," though this clause too is related to behavior in the household.

"Let your house be opened wide" means that a house should be open or have doors on all four sides, as Job's did, so that the poor may easily enter. The first clause is understood in terms of the second. The second clause, "Let the poor be members of your household," might be literally understood to mean that the poor should move in as family members. ARNA demurs and says "Not actually members of your household." Rather, the poor, like the sages in the previous saying, should be familiar with your house and constantly meeting each other on the way there. ARNA stresses generosity and zeal in caring for the poor and the needy traveler through the examples of Abraham and Job. The home, the center of life, is to be mobilized for the care of the poor and opened to them unrestrictedly, for it is a center for charity.

The word for poor, $\hat{a} n \hat{i}$, is close to the word for humble, tannaw, and the two meanings are related because a household of humble people (especially the wife) lives more harmoniously and welcomes the poor more readily. Consequently ARNA generates a new saying, cited twice with commentary: "Teach the members of your household humility."

The final clause of Jose's saying, "Talk not overmuch with women," has been expanded to continue "even with your own wife, and needless to say with your fellow's wife. For so long as a man talks overmuch with women he brings evil upon himself, neglects the study of Torah and in the end Gehenna is his portion." ARNA 
comments on this with an anecdote about a man bringing home the story of a dispute in the study house to his wife and thus bringing shame on himself and the other man. ARNA stresses domestic harmony and the threat to it from gossip.

The commentary on the three causes of Jose ben Johanan's saying focuses on charity to the poor, peaceful and orderly domestic relations through humility and restraint in relations with women, even one's wife. In tandem with the previous saying of Jose ben Joezer it gives a rounded picture of the attitudes and activities which make up the Rabbinic ideal: Torah and good deeds.

The form and contents of the sayings of Joshua ben Perahyah and Nittai the Arbelite, the second pair, (chs. 8-9), are balanced and complementary as were the sayings of the previous pair. Each saying has three clauses with the first two closely connected. Joshua's concerns relations among teachers and students; Nittai's warns about relations with evil neighbors. In the commentary ARNA stresses that a student should thoroughly study all branches of learning (Mishna, Midrash, Halaka, Haggada) with one teacher so that the teacher will have ample opportunity to cover everything. By contrast, a student with many teachers is compared to a man whose attention is fragmented among several fields. "Get yourself a companion" means someone with whom you constantly associate, both when you study and when you eat, drink and sleep. Qoh. 4:9-10 provides the reason for getting a companion: "Two are better than one because they have a good reward for their toil. For if one falls, the other will lift up his fellow." Companions in study will correct one another's errors. To this basic text are added two well known series of texts showing that God blesses different sized groups of scholars who study Torah. The blessing on even one scholar studying is illustrated by a parable of a son studying without his father's prompting. In general, the interpretations of the first two clauses of Joshua ben Perahyah's saying describe a school: learning is a communal activity; truth and accuracy are assured by interaction among teachers, students and colleagues.

Interpretations of the third phrase of Joshua's saying, "Judge everyone with the scale weighted in his favor," consist of a series of stories about pious ones $(h \bar{a} s \hat{\imath} d \hat{\imath} m$ ) found in very suspicious circumstances yet correctly given the benefit of the doubt by others. Though this clause of the saying is not explicitly about Torah, it does describe the proper relationship among companions who are closely associated with one another, such as the members 
of a school. It also presents an ideal type of observant Jew doing good under difficult circumstances.

Nittai the Arbelite's saying instructs the listener about dealing with evil in society and in life. One should avoid evil people and keep an eye out for possible disasters. The saying is structured like the previous one by Joshua ben Perahyah and its content complements Joshua's: the world at large and its evils are not consonant with the more harmonious world of Torah and scholars. One should "flee from an evil neighbor" because when plagues come to the house of an evil person (the narrative assumes that this will happen) they will undermine the common wall separating his house from the just man's (cf. Lev. 14:33-45). Mention of evil leads quickly to a discussion of sins and their punishments with reference to famous Biblical sinners. ARNA cites the slander spread by the spies (Num. 14), Miriam in her opposition to Moses (Num. 12) and Gehazi who told a lying tale (2 kings 5). The example of Miriam is greatly elaborated because of her association with Moses. Finally, Uzziah is cited.

The second clause of Nittai's saying, "Do not associte with the wicked," is similar to the first. ARNA cites three Scriptural examples of one person leading another into sin. The main message is that one should exercise care in those voluntarily associated with. The third clause, Jal tity $\tilde{a}^{\lrcorner} \bar{e} s$ min hoppurianut can be translated in two ways: "Do not shrug off all thought of calamity" and "Do not lose hope of the final reckoning." The text has interpretations to fit both meanings.

The comments on Nittai's saying are varied and at times uncoordinated. They balance the previous saying about relations among teachers, students and colleagues within the Rabbinic school. Lacking the overarching theme of Torah this saying treats the whole of society which includes the wicked and the disasters which can come upon a person in the normal course of things.

The sayings of Judah ben Tabbai and Simeon ben Shetah (ch. 10) are addressed to judges and concern fairness in examining witnesses and making judicial decisions. Both are treated briefly, perhaps because they are not directly related to Torah and good deeds, the main interests thus far in the chain of tradition in ARNA. ARNA does bring in Torah to a limited extent when it interprets "Do not play the part of chief justice" to mean that a person in the study house should ask the meaning of a statement of halaka rather than hastily dispute it.

Shemaiah's saying, "Love work, hate lordship and seek no intimacy with the ruling powers," receives full commentary in ch. Il 
while Abtalyon's saying, which warns against deciding anything not in accordance with Torah and thus misleading one's disciples receives only the briefest treatment. This imbalance may be caused by an understanding of Abtalyon's saying which unites it closely to Shemaiah's and makes further comment superfluous; still Abtalyon deals with masters and disciples and teaching and we would expect fuller treatment. The fact that the connection with Torah is not developed may explain the more brief development of the commentary .

The first clause of Shemaiah's saying, "Love work," is illustrated by ten sayings and stories which relate work to Torah, Sabbath observance and obedience to God's word. This is a popular theme and the materials collected here are not tightly organized. oddly enough, the second clause of Shemaiah's saying, "Hate Lordship," is directed at a proper attitude toward Torah and not Jewish difficulties with occupation governments or their own leaders. Four sayings, one anonymous and the others by Akiba, Ben Azzai and Jose, all center on not exalting oneself above Torah. The third clause, "Seek no intimacy with the ruling powers," receives a plain interpretation centering around the readiness of foreign governments (and robbers) to seize the property of or use those known to them.

Abtalyon's saying explicitly mentions the teaching of Torah, but this major theme of ARNA strangely is not developed here in the brief comments.
"Sages, watch your words lest you decide something not in accord with the teaching of the Torah, and incur the penalty of exile and be carried of to a place of evil waters; and your disciples also who come after you de- cide in your name something not in accord with the teaching of the Torah, and they incur the penalty of exile and be carried off to a place of evil waters.

The clause "lest you decide something not in accord with the teaching of Torah" is added by ARNA, consistent with its great emphasis on Torah. It also has the enigmatic interpretation: "'Evil water' means just that"; this probably refers to heresy. For the rest, a verse is quoted to show that the heathen nations are the evil waters and that mingling with them will get people carried off to forced labor. These comments relate to Shemaiah's mention of work and foreign governments, but they are surprisingly underdeveloped. 
The final pair in the chain of tradition are Hillel and Shammai. Hillel was the most popular sage in the Rabbinic tradition and the variety of materials marshalled in ARNA, ch. 12 (in contrast to the brief chapter on shammil bespeak that popularity. Ch. 12 begins with a citation of PA 1:12-14. Within the chapter two Hebrew sayings, PA $1: 12$ and 14 and then two Aramaic sayings, PA 2:6 and $1: 13$ are commented on. The rest of Hillel's sayings from PA $2: 4 \mathrm{~b}-7$ are cited at various points in the commentary. Hillel's first saying begins, "Be of the disciples of Aaron, loving peace and pursuing peace." The central tradition is that Aaron used to shame the wicked into behaving and reconcile people who were angry with one another. Aaron's effect on people produces a series of stories about their great mourning for him, in contrast to the mourning for Moses who was less beloved because he had to act as judge. Moses was so struck by the mourning for Aaron that he asked for a death like Aaron's. This statement leads to some legendary accounts of Moses' death in which he resisted the angel of death, the angel of death had to search for him and God put his soul under his throne.

Two comments should be made concerning the interpretations made about peace, Aaron and Moses. Peace is a favorite theme in miarashic literature and a number of stories and comments have been gathered here. Hillel, like Aaron before him, is pictured as a gentle, patient man beloved by the people. Second, the mention of Aaron leads to treatment of Moses, his relations with Aaron and his death. Implicitly, Hillel, the great teacher of Torah, is linked to Moses, who received the Torah from God. (Later Hillel is also compared to Abraham.) The themes of peace and greatness associate Hillel with Aaron and Moses and place him in their category. The favorite theme of peace serves the dominant theme of Torah. Note, too, that the long haggadic digressions on Moses attest to his popularity in story and imagination, but Moses is put in his place in relation to Aaron, a theme common in the literature. 14

The last two phrases of Hillel's first saying receive more brief comment. "Loving mankind" produces the reflection that because the people at the tower of Babel loved one another they were only dispersed, in contrast to the inhabitants of sodom who were destroyed because they hated each other. "Drawing them to Torah" is exemplified by Abraham who brought Gentiles to Torah. In both cases punishment or reward is associated with the saying and this 
same theme is continued in the following: "If not I for myself, who then? And being for myself, who am I? If not now, when?" This strange expresssion stimulates reflection on laying up merit for the world to come and on the opportunity to repent available to the living and not the dead.

Another saying, not found in PA, is cited and commented on: "If you will come to My house, I shall come to your house; to the place My heart loves, My feet lead Me." It is applied to one who goes to the study house and is rewarded in the world to come and to one who makes a pilgrimage to Jerusalem and is protected by God's presence. The themes of reward, punishment and pilgrimage are continued in the final section of the chapter which contains several Aramaic sayings, including PA 5:22-23 (here attributed to Hillel). A final story about a priest who did not eat food according to the rules of the sages and who was rebuked by Rabbi Joshua confirms the view that the sages have authority over priests and that their interpretation of the Torah is the basis for reward and punishment in this world and the next.

In the final chapter of this section, ch. 13, Shammai's saying, "Make your (study of) Torah a fixed practice; say little and do much; and receive all men with a cheerful countenance," contradicts the usual caricature of shammai as an impatient old man and reflects a pro-Shammai picture of a teacher urging study of Torah, eager performance of good works and harmonious personal relations. The commentary on this saying interprets $q b l$ to mean learn accurately or carefully, practice and teach.

Abraham practicing generous hospitality to his three angelic visitors (Gen. 18) is cited as the major example of doing much as ordered by the second clause and this parallels cheerful giving in the third clause of the saying. An example of the opposite of this is Ephron (Gen. 23).

Shammai comes off rather well in this chapter in comparison with some of the caricatures of him elsewhere. The materials must come from a time or group when it was not important to downgrade Shammai in comparison with Hillel. Were these materials very early, something hard to prove, they would come from a shammaite source. The themes of his saying tend to balance and relate study of Torah and good works which have dominated the discussion thus far.

Summary of ARNA

Torah, the study of Torah and good deeds which flow from obedience to Torah dominate the chain of tradition as it is 
explained and defended in ARNA. Torah produces a way of life which fits the model found in ancient schools in the Greco-Roman world: study, preservation of a tradition, interpretation of that tradition and behavior consistent with it. The chain of tradition and the hedges put around Torah establish the authority of Torah by identifying Torah with its interpretation and application. All come from God and exist as an inextricable unity; disobedience to a rule of the Sages is a denial of the whole integral structure and a danger to the harmony of life under Torah, a life preeminently of masters and disciples united in study and practice.

A Torah-centered way of life rests upon assiduous study of Torah and study requires close attention to the master--disciple relationship, communal study, methods for clarifying uncertainties in scripture and law and a rational mode of carrying on discourse. In addition, the more ordinary virtues of hospitality, generosity, compassion, sexual restraint and patience receive emphasis. The themes in ARNA project, in an unsystematic way, a humane, devout and God-centered school and society built on Torah.

The Torah has produced heroes and models. Moses, the receiver of Torah, enjoys frequent mention and exemplifies intimate acquaintance with Torah and God. Adam, the first human, communicates the human predicament in its primal form, especially the tension between God's gifts and human disobedience. Aaron, Abraham and Job each offer encouragement and instruction to the believer. Among post-Biblical figures, Hillel is outstanding as teacher and human being. The author of ARNA cherishes the presence of early named authorities, Simeon the Just, Antigonus of Soko and the pairs, though he knows little about them. Among later scholars, Akiba and Eliezer stand out.

The themes outlined above have an internal unity and coherence not evident in the structure of ARNA. Students who read the section on the chain of tradition come away knowing the origins of their school, what is expected of them and how to respond. The lack of rigid and logical development of themes matches the irregular and changing demands of life, even of a life centered on Torah from heaven.

Part II: ARNB

ARNB exhibits a structure and thematic core similar to ARNA. Clearly they both arose from one tradition but each developed independent wording, content and order in certain chapters or sections within chapters. To avoid repetition, reference will be 
made to the presentation of ARNA when the themes of both versions are substantially identical. Nevertheless, care will be taken to present ARNB as a unified whole. Major differences between the versions will be pointed out, but detailed comparisons and nuances of interpretation will appear in ch. 5 .

Since the foundation of the chain of tradition is the revelation of God to Moses on Mount Sinai, ARNB introduces the chain with a discussion of Moses' status in relation to God and his place within the events at Mount Sinai. "No one who glorifies himself is (truly) great unless someone greater than he glorifies him. The king over the kings of kings, the Holy One, blessed be He, glorified Moses, and the king over the kings of kings sanctified him..." This statement both praises Moses and puts him firmly in his place. The Bible and the Rabbis treated the man who had spoken to God with great awe and told many stories to elucidate his special and even unique status among humans. Fittingly, ARNB affirms the wonder and sanctity of Moses and implicitly of the meeting with God at Mt. Sinai. But the same comment establishes God's primary and Moses' secondary role in the extraordinary events at Mount Sinai.

The subsequent dispute concerning Moses' purification on Mount Sinai reinforces the main point, moses is merely human. The subject of purification is continued in an account of the purification of Aaron and his sons as priests, in the rite of the red heifer and in a list of seven things which require a seven day period of purification (flux, menstruation, death, etc.). These associated ideas link together the lawgiver with the priest and sinai with repeated events of ordinary life. ARNB's introduction to the chain of tradition is more brief and less centered on Torah than ARNA's.

The whole chain of tradition from Moses to the Men of the Great Assembly is recited in preparation for a series of comments on each member of the chain. For most members a Scriptural verse is given. The verses in ARNB vary in most cases from those cited in ARNA. This variation is the same as that found by $W$. Sibley Towner in his study of the enumeration form in the Mekilta and indicates that the verses were added to the chain after it was already in existence. ${ }^{15}$ The desire to establish the authenticity and authority of the chain of tradition would easily lead to the addition of Scriptural verses. Also, the extended comments on the sayings of the Men of the Great Assembly and those following them encourages some elucidation of the early links in the chain here. 
Moses stands out, as he did in ARNA, as the recipient of Torah from God: "Not from the mouth of an angel and not from the mouth of a Seraph, but from the mouth of the King over the kings of kings, the Holy One, blessed be He, as Scripture says: "These are the statutes and ordinances which the Lord made between him and the people of Israel on Mount Sinai by Moses!" (Lev. 26:46) Another verse is given to show that God himself wrote out the commandments for Moses.

Eli and Samuel are added to the chain of tradition in ARNB and they increase the members of the chain of tradition to sixteen. Given that fourteen is probably a traditional number for the members of the chain (see ch. 5), and that other sources lack them, it seems that ARNB added these names. Why they would be added is not clear. Eli was a priest (1 Sam. 1:9) and Samuel was a Levite (1 $\mathrm{Ch} .6: 18-23)$ and their presence in the early part of the chain corrects the omission of these sacred classes which are consistently neglected in Rabbinic tradition for polemical reasons. Note that simeon the Just is not identified as a high priest, but as the last of the Men of the Great Assembly. Perhaps the editor of ARNB sees Eli as the last of the Elders and Samuel as the first of the Prophets. Or at a later date, after Rabbinic authority was established and the priesthood a thing of the past, the editor may have been anxious to keep alive the memory of the lost priesthood and Levitical class by including them among the conveyors of the tradition. 16 The additions are literarily infelicitious because they interrupt the harmonious sequence of generic classifications, Elders, Judges and Prophets. Also, Eli's failure with his sons and loss of the priestly house makes him an ambiguous figure to include in the chain.

ARNB parallels ARNA in its treatment of the first clause of the saying of the Men of the Great Assembly, "Be deliberate in judgment." It discusses interpretation, canon and memory, but more briefly than ARNA. On the second clause concerned with making a hedge about Torah, ARNB retains the original chronological order of those who made a hedge: God, Adam, Job, Moses, Torah, Prophets, Writings and Sages. ARNB introduces its list of eight who made a hedge about Torah with a paragraph which warns against the dangers of making an excessively large hedge, a warning proper to the hedge made by Adam: "No one should make the fence more important than what is to be fenced in--for if the fence falls down, then it will cut down the plants. For this is what we find in connection with Adam..." The editor of ARNB has chosen the only example 
of a hedge which caused harm, most probably because he had seen abuse of the process in his own setting. Since Adam causes problems by making his instructions to Eve too restrictive, and since Rabbinic interpretation of the hedge was precisely as regulations which protected the Biblical commandments, the introductory paragraph may reflect a protest against excessive zeal and strictness in making laws.

God's hedge guards against the objection brought by nations when they see the destruction of the land (Dt. 29:23). ARNB expands on the question in Scripture, "Why has the Lord done thus to the land," with a series of hostile charges made to Moses by the nations of the world concerning Babel and Sodom: "Because He is the ruler of the world, He kills whomever He wants and leaves alone whornever fle wants." These ancient events are alleged to be preludes to the destruction and first exile visited upon Israel itself. The editor has identified the first and second destructions and the questions which each provoked. God is protected by Dt. 29 from the allegation that he is arbitrary both in antiquity ("What did the men of the [generation of the] flood do to him that he made them float like leather bottles in the water?") and in the editor's own day when the Temple lay in ruins.

ARNB has an extended treatment of Adam and his hedge, which is nevertheless more brief than ARNA's. Like ARNA, ARNB shows that Adam's hedge was defective because it let the serpent outwit Eve. There is a lament over the serpent who could have been such a boon to humankind, for even such a sinister creature as a serpent would have been a benefit in paradise. Two parables show that Eve was gullible and careless. ARNB is organized differently from ARNA in that its account of Adam and Eve cites Gen. 3:1, 2, 3,5 and 6 in order, thus producing a brief commentary on the beginning of Gen. 3. Other themes may be discerned: the serpent suggests that God's grudging nature caused his prohibition of the tree. This common Rabbinic theme may be a response to an ancient polemic against the Jews or to a common misunderstanding of Gen 3.17 The serpent also says that if Eve eats she will be able to create worlds and kill and revive, that is, she will be a god as described in the previous section on God's hedge. ARNB also stresses the immediate awareness of sin and its effects in that Eve sees the angel of death coming toward her and Adam feels his teeth set on edge. The life and death issues and ambiguities which link God, the serpent, Adam, Eve and evil predominate. 
After Adam the first human treated is Job, the Gentile, and not Abraham his contemporary (ch. 2). Job's hedge concerns sexual behavior toward women, a topic treated in the Noachite commandments and pertinent to Gentiles. The editor of ARNB includes all of humanity in the hedge-making process by citing Adam, the common progenitor, and then Job, a Gentile, and Moses, the recipient of Torah. Job $1: 8$ and $31: 1$ demand, as in ARNA, modesty in looking at any woman, especially another man's wife. Then ARNB cites Job 31:2 concerning Job's portion from God and interprets it to mean that one should be satisfied with one wife, like Adam. Since polygamy was permitted in the Bible, looking at an unmarried woman would be permitted, but Job's stringent behavior is explained by his position on marriage. This argument suggests an ongoing polemic against polygamy in Rabbinic literature.

The very reserved Rabbinic attitude toward women and relations with, women appears in both versions of ARN. This theme corresponds to Eve's susceptibility to temptation and influence on Adam in the previous section and also fits the polemic against polygamy. This theme of relations with women continues in the following sections on Moses and Torah.

Moses' command to the people to abstain from sexual relations for three days instead of two and the three other cases where he decided for himself are presented briefly and without the extensive polemical material found in ARNA. However, after three of the four cases the editor cites a verse to show that God agreed with Moses' decision. The four cases in ARNB show the sanctity and uniqueness of Moses' call. He commands all to abstain from sexual relations before the revelation on sinai. Because he was so close to God, Moses abstains permanently. In breaking the tablets he keeps Israel from being condemned for breaking its contract with God and finally, Moses does not approach the tent of meeting until called. Moses is seen as very close to God and yet assuming nothing in his relationship with God. Throughout, male-female relations are used as a symbolic vehicle for speaking of relations with God.

ARNB next shows that scripture itself, that which was revealed to Moses on Sinai, also puts a hedge about its words in each of its three parts, the Torah, Prophets and Writings (ch. 3). Making a hedge is not an accretion to or modification of scripture, but part of Scripture itself. The hedges proposed by Torah and the Writings concern relations with women, as did previous hedges. The Torah safeguards the prohibition of sexual relations with one's 
wife during the menstrual period and the Writings warn against being enticed by a prostitute, a common theme in Wisdom literature. In addition, the wayward woman is interpreted as heresy, another common Rabbinic theme. The prophets used metaphors to speak of God not so much to safeguard God, but "so that the ear be unoffended and able to hear." ARNB itself makes a hedge about the prophets so that their metaphorical language will not be misunderstood.

Finally, the Sages put a hedge about their words by saying a man should recite the Shema before midnight, even though it is a violation only if it is not done before sunrise. ARNB envisions a man in bed reciting the shema (and then possibly studying) in contrast to ARNA which imagines a person stopping off at the study house. ARNB further stresses the need for obedience by showing the dire consequences of disobedience and the temptation which follows, as developed through Qoh. 10:8, "He who digs a pit will fall into it; and a serpent will bite him who breaks through a wall."

Like ARNA, ARNB begins its comments on "raise many disciples" (ch. 4) with a dispute between the schools of Shammai and Hillel concerning who ought to be taught. But ARNB bases its position on prudent foresight: if one teaches all the students who come, some will turn out well. Qoh. 11:6, "In the morning sow your seed and in the evening withhold not your hand," is applied to this point as well as to actual sowing, giving to charity and begetting children. A loose chain of sayings and interpretations of goh. 11:6 fill out the picture of what a good disciple ought to be. Both teachers and students must be charitable, endure poverty and be models of good and prudent behavior. ARNB is organized in a radically different way from ARNA, ch. 3 which proposes Eliezer and Akiba as models of these virtues.

Simeon's saying that the world stands on Torah, the Temple service and deeds of loving kindness (ch. 5) occasions an explanation of the Temple's destruction and its replacement by Torah and good deeds in Jewish life. ARNB implies that the destruction of Jerusalem and the Temple was caused by neglect of Torah when it cites four Biblical cases where neglect of Torah caused destruction and exile. The examples concern the northern tribes, Judah and Benjamin, and also Jerusalem and Israel (the people and the land). Each example is supported by a Scriptural statement that the people have disobeyed or rejected God's Torah. As is sometimes the case, ARNB stresses action (here obedience) rather than study of Torah (ARNA). ARNB reinforces the covenant theology that 
survival depends on obedience and that disobedience will bring destruction and exile. This line of argument both explains the loss of the Temple in $70 \mathrm{C.E}$. and exhorts the readers to a better life.

In explaining the next phrase, "on the Temple service," ARNB presumes that the Temple has been destroyed and so it evokes an aura of "the good old days." "While the Temple service existed, the world was blessed, low prices were prevalent and grain and wine were plentiful; people ate until satisfied and domestic animals ate until satisfied." ARNB expounds this comment using Hag. 2:15-16 (found in ARNA) and then develops a phrase by phrase intexpretation of Hag. $1: 6$ and Hab. 3:17, which details the effects of the loss of various Temple rituals; the midrash ends with the traditional hope that the Temple will be rebuilt in the future. These extended midrashim prepare for the next two chapters $(6$ and 7) which describe the destruction of the Temple.

In ARNB the account of the Temple's destruction is occasioned by the mention of the Temple service in Simeon's saying. Unlike ARNA, ARNB interrupts its commentary on simeon's saying and substantially expands the account of the loss of Jerusalem and the Temple with stories of the siege and of the vengence visited upon Titus, its destroyer. After the story of Johanan's escape from Jerusalem and interview with Vespasian which leads to the founding of the Rabbinic school, ARNB (ch. 7) returns to the sufferings in Jerusalem, the final attack, Titus' blasphemous entry into the Temple and challenge to God and Titus' humiliating and horrible death. Mourning for the loss of Jerusalem overshadows the replacement of the Temple with study and good deeds, which is taken up in the following chapter.

In Ch. 8 ARNB applies Hos. 6:6 both to the words of Torah and to acts of loving kindness. Holocausts are the more important category of offerings and are replaced by the words of Torah. Sacrifices belong to a lesser category and are replaced by acts of loving kindness. These transformations are broadened by 1 sam. 15: 22 which says, "To obey is better than sacrifice," and by a remark of Rabbi Simeon, "More precious to Me is study of the words of Torah than burnt offerings and sacrifices." Although ARNB is interpreting the phrase "acts of loving kindness," it first explains that the Temple sacrifices have been replaced. Then loving kindness is expounded by a catena of four Scriptural verses which show that loving kindness fills the earth and extends above the sky. It is not merely an aspect of life, but dominant in the cosmos. (In ARNA it was instrumental in creation.) Finally, Johanan 
ben Zakkai's teaching to Rabbi Joshua that loving kindness atones in place of the Temple and the dispute about whether to continue studying or join a funeral and marriage procession complete the discussion of study of Torah and acts of loving kindess.

The dispute about whether to join a marriage procession mentions that God adorned Eve as a bride. This, plus the general topic of hesed, leads to a long digression (chs. 8-9) on the creation of Adam and the natural relations of males and females. Ch. 8 cites Ps. 139:5, "You have formed me behind and in front," and ch. 9 cites Gen. 2:23, "Bone of my bones." Much of the material concerns Adam and Eve and is found in other sources. Probably the popularity of such materials led to their inclusion here. The effect of this long digression is to turn attention from the grief associated with the destruction of the Temple and toward the creation of life, marriage and sexual attraction. In addition, Adam and Eve's sin shows the radical ambiguity of human existence which manifested itself also in the destruction of the Temple.

Like ARNA, ARNB uses the saying of Antigonus of soko, (ch. 10) to explain the emergence of the Sadducees and Boethusians as groups who rejected teaching of resurrection because they misunderstood the saying of their master, Antigonus. In the second half of ch. 10 ARNB also has a commentary on each clause of the saying, something lacking in ARNA. It gets into the difficult question of partial reward in this life and its relation to reward in the next life. In addition, it discusses the motives of love and fear, opting for fear as the better motive. ${ }^{18}$ The discussion is very compressed and plagued by manuscript difficulties, but it lays part of the foundation for the Rabbinic school's way of life.

The Pairs

ARNB interprets Jose ben Joezer's saying at great length, giving a chapter to each clause. Even so, comments under the first clause refer to the whole saying and it is clear that a large group of traditional materials has been arranged without sharp divisions between parts of the saying. In ch. 11 ARNB encourages welcoming the sages and their disciples because they bring blessings on the house. This is proved by three scriptural examples of blessings coming on a house because of the presence of Jacob, Joseph and the ark. The sages are implicitly presented as the contemporary equivalents of major Biblical figures; they are explicitly said to be of more value than the ark, which contained only the two tables of the commandments, presumably because the sages "contain" 
the whole Torah, written and oral. A second interpretation of "Let your house be a meeting place for the sages," stresses the respect, fear and awe that should be shown the sages, like that of Joshua toward Moses. The third and fourth interpretations explain what a "meeting place" means. The fifth interpretation repeats the second with the men of Jerusalem's respect for Ezekiel (Ez. 20:1) replacing Joshua and Moses as the Biblical example. The theme of Ez. 20, God's fidelity to Israel and rebuke of the men of Jerusalem who question his word, implicitly equates the teachings of the sages with the word of God which must be treated with awe and respect. Further Biblical passages show the value of associating with a wise teacher.

Chs. 12 and 13 recount the stories about Akiba and Eliezer, found also in ARNA, which show the attitudes and exertions necessary for success in study of Torah. ARNB presents the same materials on Jose ben Johanan's saying concerning generosity to the poor with the notable addition of a series of interpretations of Is. 58 which defines the "homeless poor" (58:7) and enumerates the curses and blessings attendant on generosity or its lack.

For the next two pairs, Joshua ben Perahiah and Nittai the Arbelite and Judah ben Tabbai and Simeon ben Shetah, ARNB attributes the saying of the second nember to the first and vice versa (compared to the attributions found in PA and ARNA). No obvious reason explains the transpositions, though one suggestion may be made. The preceding saying by Jose ben Johanan concerned treatment of the poor, the household and women. By its transposition ARNB has continued the discussion with a saying concerning relations with neighbors ("Flee from an evil neighbor..."). The last clause of Nittai's saying (according to the text of ARNB), "Judge with the scale weighted in his favor," leads smoothly into the sayings by Judah ben Tabbai and Simeon ben Shetah which concern legal process.

The materials collected to comment on Joshua's saying (chs. 16-17) have the same general thrust as that found in ARNA, but the Scriptural examples vary and ARNB is more brief. This lack of a common tradition in details argues to uncertainty about the exact meaning of the saying, especially since it does not immediately relate to Torah, the main theme of both versions.

ARNB begins its commentary of Nittai's saying (chs. 18-19) by two additions to the saying: "Provide yourself with a teacher for wisdom, and get yourself a companion for mishna." The companion is to help in oral repetition and memorization; the teacher provides 
guidance. Comments on the first two clauses of the saying are generally parallel. Like ARNA, ARNB illustrates the third clause, "Judge everyone with the scale weighted in his favor," with a series of stories. Each version has its own stories (with one in common and one roughly similar). These variations can be explained by the extreme imaginativeness and improbability of the stories. Though this clause is not explicitly about study of Torah, it does govern the relationships among companions and between master and disciples (Rabbi Joshua and his disciples). Even this generalized instruction is focused on a problem created by the close association of master, disciples and colleagues in a school.

The sayings of Judah ben Tabbai and Simeon ben Shetah (ch. 20) are reversed, as was noted above. They are treated with great brevity, as in ARNA. The observation that an official learns to cling to power fits better in ARNA in connection with the instruction "Do not play the part of chief justice," rather than in connection with "Again and again examine the witnesses..." in ARNB. Shemaiah's saying (chs. 21-22) receives extensive commentary and Abtalyon's hardly any at all, just as in ARNA. The first clause of Shemaiah's saying, "Love work," is illustrated by 14 stories all beginning with the stereotyped formula, "Great is work because..." Eight of the stories are common to both versions, but the order of the items and attributions to sages vary considerably.19 No consistent principle orders the stories though some themes unite two or three items. In some, work is related to Torah, Sabbath observance or obedience to God's word. The materials have been loosely edited as is customary with popular themes and materials.

The second clause of Shemaiah's saying, "Hate lordship," is first applied to a proper attitude toward Torah, as in ARNA. Then ARNB has a comment more appropriate to the lemma, that lordship buries those who wield it, and cites three Scriptural examples of rulers who died before their elders: Joseph, Joshua and Solomon. ARNB, ch. 22, also has a long digression on the fates of the just and wicked. This discussion, in the names of Jose and Akiba, is unconnected to the context except at the very end. Both versions are similar in treating the last phrase of Shemaiah's saying and Abtalyon's whole saying.

The last sentence of ch. 22, "Hillel and Menahem did not differ; Menahem went forth and Shammai entered," serves as a transition to the next chapter which treats Shammai and the subsequent 
ones which deal with Hillel. Who Menahem was and what this tradition means has been the subject of much controversy. His name may have been placed here by the editor of ARNB who was puzzled by the mention of Menahem in other traditions and wanted to ensure that he was not left out. Thus Menahem is included but not clearly identified. (See ch. 5 for a discussion,)

ARNB contains two further peculiarities in the transition to the last pair. There is no introductory formula saying that shammai and Hillel took over from them (Shemaiah and Abtalyon) and Shammai's saying precedes Hillel's, contrary to the order in PA and ARNA. The introductory formula may have been dropped through homoeoteleuton or a similar manuscript confusion. The change in the order of names must be deliberate and Finkelstein makes a reasonable case that the order shammi--Hillel is original, since later generations would probably not have put Hillel in second place. ${ }^{20}$ since the section on Shammai does not caricature him, but presents him in a favorable light, his precedence here is logical, even if we do not say with Finkelstein that this is an early Shammate source. Another possibility is that the editor wanted Hillel, the sage viewed by later generations as the founder of their school, in the final and climactic position. The section on Hillel then leads smoothly into the account of Hillel's deathbed acknowledgement of Johanan ben zakkai (ch. 28) which introduces Johanan as the successor to Hillel.

Shammai, (ch. 23), receives the same positive treatment in ARNB that he received in ARNA. In commenting on "Make your study of Torah a fixed practice," ARNB adds to the interpretation of $q b l$ the meaning "equally" or "consistently" and applies it to judgments about the law. One is not to be lenient with others and strict with oneself or the opposite.

Chs. 24-27 contain a wealth of sayings and stories by and about Hillel. The order and contents are roughly those found in ARNA without any significant changes in thematic stress. As always Hillel serves as a popular focal point for discussions of Torah and virtue as found among Biblical figures and the sages.

\section{Summary}

The major themes found in ARNB resemble closely those found in ARNA. Both versions of ARN share a common core of traditions derived from an early point in their developments. Each speaks most directly to a school of Rabbis, teachers and students, studying Torah, interpreting its laws and living according to its 
precepts. Each version makes its points in varied ways, but no great differences emerge. J. Goldin's insight that ARNA stresses Torah on a number of occasions when ARNB stresses good deeds stands up to scrutiny. 21 However, Torah and study of Torah still dominate both versions.

ARNB is notable for its development of some scriptural passages such as Qoh. $11: 6$ in $\mathrm{ch}, 4$ and Hag. 1:6/Hab, $3: 17$ in $\mathrm{ch} .5$. It has more material on the loss of the Temple in chs. 6 and 7 and it examines the nature of humanity and its plight in chs. 8 and 9. (Conversely, it develops materials concerning Adam less estensively than ARNA when Adam comes up in the section on the hedges.) In ch. 21 ARNB, true to its emphasis, includes a long praise of work. These and other occasional themes, such as purification in ch. 1 , dot the text of ARNB, but they do not change its central emphasis noted in the treatment of ARNA.

Now that we have seen how the two versions of ARN use and develop the chain of tradition, we must examine the chain itself as it occurs in PA and ARN. The chain of tradition has some peculiarities of structure with a complex background and purpose; it is a genre which will further elucidate the meaning of the first section of PA and ARN. 


\section{CHAPTER FIVE}

THE NATURE OF THE CHAIN OF TRADITION

Since the chain of tradition from Moses to the sages of the first few centuries, C.E. dominates and organizes the first part of ARN, we shall compare the several versions of the chain, suggest its original form and draw inferences about its purpose from its development and from comparison with other examples of this genre. ${ }^{l}$ The chain of tradition is set forth in four different versions. The most familiar is $P A$, ch. 1 and the beginning of $\mathrm{ch}$. 2. ARNB quotes the chain as a whole from Moses down to the Men of the Great Assembly; then it cites the chain lemma by lemma with commentary. The links in the first part of the chain from Moses to the Men of the Great Assembly differ in the two recitals. In ARNA the chain is not quoted as a whole, but rather cited and explained link by link. The following chart shows the variations schematically. 
First Half

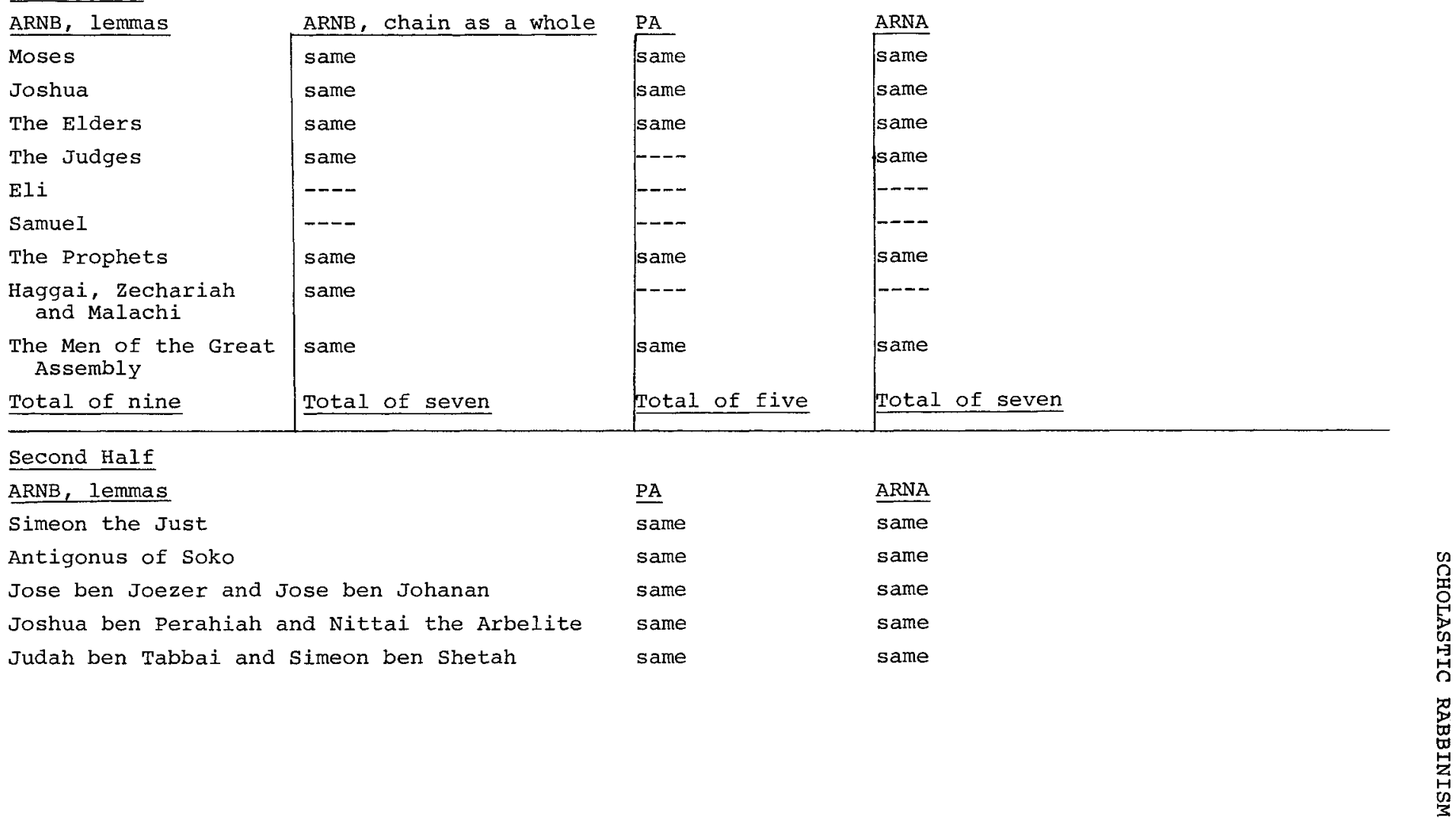




\begin{tabular}{|c|c|c|}
\hline ARNB, lemmas & $\underline{\mathrm{PA}}$ & ARNA \\
\hline Shemaiah and Abtalyon & same & same \\
\hline $\begin{array}{l}\text { (no lemma: Shammai, then } \\
\text { Hillel treated in the text) }\end{array}$ & Hillel and Shammai & same \\
\hline $\begin{array}{l}\text { (Johanan ben Zakkai "took over" in } \\
\text { ch. 31. Johanan treated in } 28-31 \text { ) }\end{array}$ & $\begin{array}{l}\text { (Johanan in } 2: 8 \\
\text { out of order) }\end{array}$ & Johanan ben Zakkai \\
\hline Total of seven plus Johanan & $\begin{array}{l}\text { Total of seven } \\
\text { plus Johanan }\end{array}$ & Total of eight \\
\hline \multicolumn{3}{|l|}{ The Princes } \\
\hline ARNB, in ch. 32 separate from the chain & $\underline{P A}$, in sequence & $\begin{array}{l}\text { ARNA, in ch. } 22 \text { separate } \\
\text { from the chain }\end{array}$ \\
\hline Rabban Gamaliel & same & same \\
\hline Simeon his son & same & same \\
\hline Rabban Gamaliel & $\begin{array}{l}\text { Rabban Simeon ben } \\
\text { Gamaliel }\end{array}$ & $-\cdots-$ \\
\hline Rabbi & same & ---- \\
\hline Rabban Gamaliel & $\begin{array}{l}\text { Rabban Gamaliel his } \\
\text { son }\end{array}$ & $-\cdots-$ \\
\hline Rabban Gamaliel & ---- & ---- \\
\hline Rabbi Judah the Prince & --- & ---- \\
\hline
\end{tabular}


Structure and Development of the chain

The first half of the chain of tradition, down to the Men of the Great Assembly, contains seven members in ARNA and ARNB, (chain as a whole), nine members in ARNB (lemmas) and five members in PA. Since Eli and Samuel occur only in ARNB, it seems likely that they were added. (See a more full discussion in ch. 4.). PA alone lacks the judges and Haggai, Zechariah and Malachi; since PA, ch. 1, has added Gamaliel and Simeon after Hillel and Shammi and then closed the chapter with an inclusion (see ch. 2 above), it is likely that two names were dropped when two were added. The other two lists have seven members. The number seven is common in Rabbinic lists and groups. PA, ch. 1, has fourteen names, twice seven. L. Finkelstein has claimed that the chain of tradition originally contained fourteen names, a traditional number for such a 1ist. The chain of tradition would go from Moses to the last pair, Hillel and Shammai; Eli and Samuel were added later in ARNB (lemmas) and PA, ch. 1 , was modified to include two later Princes of the second century. This hypothesis must await the end of this chapter for its final testing. For the present, we may note that there is some data to support the number seven and also fourteen and that several other particulars must be examined before any original form of the chain may achieve probability.

PA with its list of five initial recipients of Torah down to the Men of the Great Assembly has a loose parallel in the Iliad (2:102 ff.) where the scepter of rulership, fashioned by Hephaistus, is given by zeus to Hermes who passes it on to Pelops, who in turn passes it on to Atreus, and he to Thyestes and he to Agamemnon. The recital of the group of five is followed by a speech of Agamemnon (a functional parallel to the saying of the Men of the Great Assembly). H. Fischel points out that this passage was a popular example in several rhetorical handbooks and may have had an indirect influence on the ordering of the chain in PA. ${ }^{2}$ Fischel's hypothesis is weak because the contexts and the exact purposes of the two passages are different. The Iliad passage is an aside in a narrative; the chain in PA dominates the first part of the collection of sayings. The Iliad's chain establishes conventional political authority; the chain in PA establishes teaching authority and the veracity of a tradition and school. Groups of five are common in the next section where Johanan ben zakkai has five disciples. It may be that a common culture has slightly influenced the editor's sense of propriety; more likely, the number five emerged in the editing of the whole of $\mathrm{PA}, \mathrm{ch} .1$. 
The verb used to indicate that the tradition has moved from one link in the chain to another varies at the beginning of the chain, from Moses to the Men of the Great Assembly. PA and ARNB say that the Torah was "passed on" $(m s r)$; ARNA says that each member of the chain "received" or "took over" ( $q b l)$ the Torah. From Antigonus of soko on all versions use "received, took over" and all use it of Moses receiving Torah from God. The reason for the variation in terminology is not clear. Finkelstein has suggested that "received" is original and has a more general connotation: these figures were among the recipients of the tradition, but not the only ones to receive it. "Passed on" is exclusive, indicating that the tradition was passed on on $1 y$ to the next person(s) in the chain. According to Finkelstein the change to "passed on" occured in the second century in an attempt to exclude the priests from authority. ${ }^{3}$ This interpretation of the verbs seems strained. Fischel points out that both verbs are used in Greco-Roman examples of the sorites and that "passed on" is the more usual verb because it leads to a more simple pattern: A to B, B to C, C to D, etc. "Received, took over" leads to the more complex pattern: B from $A$, C from B, D from C, etc. ${ }^{4}$ The more complex pattern prevails in the chain of tradition and its dominance may have been initiated by the first link, that Moses received the Torah from God. This passive construction is required since God is not handing on something he received, but initiating the chain. A desire for consistency probably led to the final removal of "passed on" in ARNA.

Two peculiarities associated with Simeon the Just and the first pair, Jose ben Joezer and Jose ben Johanan could indicate some dislocation in the chain. Simeon the Just is not said to have received; the text merely says that he was "among the last of the Great Assembly." Since the previous sentence already said that the Men of the Great Assembly had received Torah, it is not strictly necessary to repeat that statement for simeon who is one of them. The first pair, who follow Antigonus of Soko, are said to have received (Torah) from them. Some have suggested that simeon and Antigonus are later insertions and that the first pair originally followed the Men of the Great Assembly. ${ }^{5}$ However, "from them" is so stylized a phrase that it may have worked its way into this position even though it was not appropriate.

The next problem in sequence occurs in the transition to the last pair, Shammai and Hillel, as recounted in ARNB. The last sentence of the chapter on Shemaiah and Abtalyon (ch. 22) is a transition to Shammai and Hillel: "Hillel and Menahem did not 
differ; Menahem went forth and Shammai entered." This same sentence is found in $\mathrm{m}$. Hag. $2: 2$ and it may have been added to ARNB from there. ${ }^{6}$ (It is not found in PA and ARNA.) Menahem remains an unknown figure and his reasons for going forth are not given. Some suggest that he is the Essene who predicted Herod's reign; 7 others identify him with Menahem ben Juda ${ }^{8}$ or Menahem ben Signai of m. Eduyyot $7: 8 .{ }^{9}$ All identifications must grapple with supposed reasons for his going forth and hypotheses about what he went forth from. The Talmuds offer a variety of opinions. 10 Most connect Menahem's going out with Pharisaic disputes over leadership of their assembly (Sanhedrin). Since we have only this one sentence, on which all theories are based, no certainty can be reached. The Rabbis traced their communal ancestry most directly back to Hillel and the disputes between the schools of Hillel and Shammi. It may be that the editor of ARNB was puzzled by the mention of Menahem in the Mishna and wanted to include anyone relevant to this crucial period in the chain of tradition. Thus, Menahem was included, but not identified.

ARNB contains two further pecularities in the transition to the last pair: there is no introductory formula saying that shammai and Hillel "took over from them" and Shammai's saying precedes Hillel's, contrary to the order in PA and ARNA. The former is probably an error in transmission and the latter has been explained in ch. 4: the order may be original; the editor wanted Hillel in the climatic final position; and Hillel leads smoothly into the introduction of Johanan ben Zakkai at Hillel's deathbed in ch. 28 .

In all three sources Johanan ben Zakkai is said to have received the Torah, but only in ARNA, ch. 14 is this statement in proper sequence. PA has displaced Johanan to the middle of ch. 2, after the princes (see ch. 2 above) and ARNB, ch. 31 has added the statement that Johanan "received" after the main body of Johanan materials. Johanan is the last person of whom the technical term "received" is used. He may have been added by Rabbinic authorities who opposed the growing power of the hereditary princes in the second century. However the princes eventually dominated and Rabbi Judah the Prince, editor of the Mishna, removed Johanan from proper sequence in $P A, c h . I$ and placed him in ch. 2. A slight displacement also occurred in ARNB, chs. 28-31. This solution assumes that Johanan ben Zakkai was added to an organized chain of tradition during the second century. If the chain dates from the organization of the Mishna in the early third century, then both versions of ARN may have reorganized the chain of 
tradition to place Johanan ben Zakkai in proper chronological order, contrary to the order in the Mishna.

Rabbi Judah the Prince extended the chain of tradition in PA by adding Gamaliel and Simeon his son after the last pair, Hillel and Shammai. The technical term "receive" is not used but the sequence of names and the final saying (1:18) which recalls simeon's saying at the beginning of the chapter implies that the chain continues through ch. 1 . Third century authorities added Judah the Prince, himself, $(2: 1)$ and his son Gamaliel III $(2: 2-4 a)$. The extension of the chain at the end of ch. 1 is confused by the sequence Rabban Gamaliel $(1: 16)$, simeon his son $(1: 17)$ and Rabban Simeon ben Gamaliel $(1: 18)$. Finkelstein argued that Gamaliel II was dropped because of the controversy surrounding his leadership and his supposed Shammaitic tendencies.11 But Gamaliel's supposed Shammaitic tendencies are very controversial and Judah the Prince would have been likely to emphasize his authoritative approach to leadership. D. Hoffmann held that Gamaliel II is meant ${ }^{12}$ and if this position is correct, then there is a gap between Hillel and Gamaliel II as well as mention of two Simeon's together or the citation of one under two titles. It is probably impossible to determine who is meant. The literary structure of PA, ch. I shows that the two simeon's in 1:17-18 are understood as one and that the final saying is so placed because it forms an inclusion with $1: 2$. This, along with the identity of names in the four generations of leaders (Gamaliel and simeon twice each, suggest that the editors of PA are not concerned with filling up the centuries with exact genealogies, but with naming the famous figures associated with Torah.

In both versions of ARN some of the princes listed in PA can be found but not in sequence after Hillel or Johanan ben Zakkai. They are cited after the treatment of the early sages (Akabya ben Mahalaleel et al.) and before the four who entered the garden (Ben zoma et al.)13 In each case the sayings are part of a thematic group of sayings: seven sayings on Torah make up ch. 22 of ARNA and ten sayings or groups of sayings, mostly on Torah, conclude ch. 32 of ARNB. In each case the princes end a chapter and the treatment of the collection of sayings by early sages.

ARNB mixes up the references to Gamaliel II and III and repeats Judah the Prince twice because it inaccurately follows the chain of tradition as it was expanded in PA. (See also ch. 7 below.) ARNA has only Gamaliel and Simeon his son (PA $1: 16-17$ ) without the second simeon saying which closes PA, ch. 1. ARNA 
seems to have these two sayings as originally positioned in the tradition. The later editors of ARNA did not add the sayings by Rabbi and his son (PA 2:1-4a), perhaps because the sayings heavily emphasize works, contrary to ARNA's greater emphasis on Torah. Rabbi is included in ARNA by being given his own chapter (18) after the treatment of Johanan ben Zakkai and his disciples, but ARNA does not continue the formal chain of tradition beyond Johanan ben Zakkai. Judah the Prince is parallel to him, but the final editors preserved no clear sequence. ARNB has Johanan, the early sages, Gamaliel, Simeon and Judah the Prince in a loose sequence and one could argue that the formal chain of tradition is being continued. But the lack of any repetitive phrases or clear structure to indicate this makes it a weak hypothesis. ARNB collects the number of sayings of late first and second century sages in these chapters and they do form a very loose sequence, but the addition of PA 2:1-4a in the name of Gamaliel and Judah the Prince seems to be influenced by $P A$ in the third century. The editor who originally organized these materials continued the spirit of the chain by quoting early and authoritative teachers, but he did not formally continue the chain of tradition.

The Genre of the Chain of Tradition

The preceding detailed study of the chain of tradition has shown its literary sources and structure and something about its development. For its nature and purpose to become fully clear we must examine parallel lists and structures, especially in GrecoRoman literature, and try to understand the larger genre of which the chain of tradition is an example. Much of the evidence has been gathered by $\mathrm{E}$. Bickerman and more recently by $\mathrm{H}$. Fischel. 14 Some recent work on genealogy will also be reviewed.

During the Hellenistic period and well into the Roman period lists of founders of philosophical schools and the succeeding generations of disciples and heads of the schools were common. Diogenes Laertius organized his Lives of Eminent Phizosophers learly third century, C.E.) by schools of philosophy and then by a succession of masters and disciples. Bickerman suggests that the Rabbinic chain of tradition was precisely to establish and validate the origins of the Schools of Hillel and Shammai as similar to Hellenistic schools of philosophy, all of which encompassed a way of life. ${ }^{15}$ As early as the second century, B.C.E. Sotion had 
composed a list of the "Succession of the Philosophers." Suidas noted two centuries later that Epicurus had fourteen successors and other authors used these lists. Lists of other officials were also common. In the second century, C.E. Sextus Pomponius compiled a succession of Roman jurists which included pairs, as in the Rabbinic chain of tradition. ${ }^{16}$ Celsus compiled a succession of physicians as part of his encylopedic summary of medical and other knowledge. 17

Lists of religious officials were also common. Bickerman notes that successions of priests, who were the hereditary guardians of tradition, were kept in Egypt, Babylon and Persia, as well as in the Bible ( $1 \mathrm{Chr}, 24--25$ ). Eupolemus (2 Cen., B.C.E.) as quoted in Eusebius, has what appears to be the beginning of a chain of prophets: "Moses prophesied forty years; then Jesus, the son of Nave, thirty years, and he lived 110 years, and pitched the holy Tabernacle in Silo. And afterwards samuel rose up as a prophet...."18 Eusebius' account continues with the history of Israel. We may infer that Eupolemus had produced a longer list of prophets, but we are not certain.

The structure of these chains of tradition are part of a larger rhetorical and literary device, the sorites (climax, gradatio), popular during the first two centuries, C.E. Fischel divides the sorites into six major groups, with the chains of tradition part of a group called transmissional sorites. ${ }^{19}$ The presence and popularity of this form in the larger Greco-Roman world provides a natural background for the Rabbinic chain of tradition. More remote analogues may be found in genealogies and king lists, common for millenia in the Near East. Though the chain of tradition differs significantly from genealogies both formally and functionally, they overlap in that both are lists of persons over several generations who have a significant relationship to one another and whose relationship is of functional importance to the community. We shall examine selected results of two recent studies of genealogies by Marshall D. Johnson and Robert R. Wilson. 20 Wilson has used recent anthropological studies to understand the form and function of oral and written Near Eastern genealogies in their origins and development. A linear genealogy covers one line of descent through several generations. Most Biblical genealogies are of this type (p. 198) and the chain of tradition is analogous in structure to this type of genealogy. Most linear genealogies are nine to twelve, or at most ten to fourteen, generations deep. The genealogy will sometimes stop with an intermediate founding ancestor 
or skip older generations back to the founder (pp. 21-26). Long lists, like the king lists in genealogical form, serve to anchor in the past a claim to power, authority or status.(p.26). Similarly, the chain of tradition is of the same length, treats older generations by groups until it gets back to Moses and Joshua and anchors its claim to authority in God and the Torah he gave to Moses on Sinai.

Johnson subjects Biblical genealogies and especially the New Testament genealogies of Jesus to detailed analysis. Finkelstein has suggested that the chain of tradition originally had fourteen links, just like the (three) groups of fourteen in Matthew's genealogy of Jesus $(1: 1-17) .^{21}$ The fourteen are Moses, Joshua, the Elders, the Judges, the Prophets, Haggai, Zechariah and Malachi and the Men of the Great Assembly (7); Simeon the Just, Antigonus of Soko and the five pairs ending with Hillel and Shammai (7). Finkelstein contends that EIi and Samuel were dropped from the list in PA and ARNA and that in PA the Judges and Haggai, Zechariah and Malachi were dropped so that Gamaliel and Simeon his son could be added and the number fourteen preserved. Johnson points out that the number fourteen is not explicitly mentioned in the Rabbinic sources, in contrast to Matthew, and the variations in the lists indicate that the number fourteen was not significant for the editors (pp. 205-206). Johnson is correct for the texts which are before us in that all have variations and additions to the hypothetical original. The best case can be made for PA, ch. 1 which has fourteen links to the chain and is closed with an inclusion $(1: 2$ and $1: 18)$. ARNA has Johanan ben Zakkai in sequence and ARNB has Eli and Samuel in its chain.

Groups of seven and fourteen can be found in Biblical genealogies: Gen. 4:17-24 has seven generations before the flood, a tradition also found in Mesopotamian materials. ${ }^{22}$ Both Finkelstein and Johnson (without knowledge of Finkelstein) cite 1 Chr. 5:29-41 where twenty-three high priests are listed. ${ }^{23}$ The first group in this list comprises fourteen priests ending with Johanan, who was the first to serve in Solomon's Temple. The second part of the list extends to the Exile. Finkelstein appends Neh. 12:10-11 with six high priests during the exile, ending with Jaddua to form a list of twenty-nine. Finkelstein suggests that Jaddua begins a new era and so we have two groups of fourteen: Exodus to Temple and Temple to Exile. Finkelstein's scheme, which combines two lists, is strained. Though there is schematization in the Bible, Matthew and PA-ARN, only in Matthew is the number fourteen 
explicitly stated. It is, however, possible and even probable that Rabbinic writers could have arranged groups of seven in the two halves of the chain at various stages of its development.

In all the materials compared here, lists are important and have functions in the community. Groupings within the lists can be important, but rigid numbers are often not adhered to. As Wilson notes of oral genealogies, they remain fluid and responsive to community needs. 24 Even in literary form both Biblical and Rabbinic materials underwent adjustments according to historical developments and community needs. Only Matthew turned a genealogy into an enumeration form with a set number of items.

Purpose

Most directly and immediately the chain of tradition establishes the legitimacy of the leaders of the Rabbinic and Pharisaic schools as successors to the leaders of Judaism back to its founder Moses. This leadership is centered around Torah, which was given to Moses on Sinai and passed on. Consequently, the prime duty of the members of the chain was to teach Torah accurately and effectively. The chain of tradition implies that the school of the Rabbis, that is, their teachings, thought, and way of life, stands at the center of Judaism and holds it together. In the tradition contained in PA and ARN Judaism is a school and the appeal is made to the listeners to become students of Torah. In this function, $P A$ and ARN are similar to the Greco-Roman school literature which contains chains of tradition and other stories and sayings (to be explored further in $\mathrm{ch}$. 6) which describe and stabilize a philosophical tradition. The schools, as will be seen in ch. 6, included a way of life and a claim to authority over its adherents lives based on continuity in teaching and leadership. This authority could extend farther than the confines of the school, since schools resembled other religious and social organizations in antiquity and often served several functions. Just as sophists often became leaders in society, it is likely that prominent Rabbis also became leaders in their cities and used their association with the tradition and Torah as a basis for more general leadership in Jewish society. The chain of tradition implicitly claims that the revelation given at sinai is present and effective. The chain of tradition, like the genealogies and lists reviewed earlier, establishes stable relationships and continuity within Jewish society, even though its primary and first focus is on the Rabbinic school. Especially in PA, it is clear that the chain of tradition was used 
to legitimate the Prince's power and authority as leader in Palestine during the late second and third centuries, just as king lists, lists of jurists and lists of priests did in other parts of the East. Though we cannot reconstruct all the uses to which the chain of tradition was put and relate them to the variations in its form found in $P A$ and the two versions of ARN, we can know that it strongly suggests a school setting for its origin and the establishment of teaching authority as its purpose. 
CHAPTER SIX

THE SCHOOI OF RABBAN JOHANAN BEN ZAKKAI

AND HIS DISCIPLES: A NEW WAY OF LIFE

The collection of stories and sayings concerning Johanan ben Zakkai and his disciples is pervaded by Hellenistic rhetorical and literary forms associated with the lives of philosophers and the accounts of their schools. The list of Johanan's five disciples, each characterized by an epithet, the role of Johanan as head of the school, the presentation of a typology of learning, the story told by Eleazar ben Arak to console Johanan on the death of his son, the question concerning the good and bad ways, the stories about Hillel and other sages, the mention of the Epicurean in Simeon's saying and the stress on human virtues (hospitality, frugality, self-control, harmony, etc.) found in this section all have parallels in Hellenistic literature, especially among the chriae and teachings of philosophical schools. ${ }^{1}$ The presence of these parallels to Hellenistic literature argues for a substantial Hellenistic influence on the sages' way of presenting themselves in this part of ARN. Both here and in PA the Johanan section has antecedents in both Jewish and Greco-Roman traditions. The ideals and modes of expression of the sects and schools, as well as their very existence, bespeak the atmosphere of the Empire and an adjustment of local society and structures to the pressures of another culture.

H. Fischel and others have argued for a strong Hellenistic influence on the Pharisees. ${ }^{2}$ s. Lieberman has developed evidence from the Talmud to show the extent of Greco-Roman influence from the third century onward. ${ }^{3}$ The very nature of Pharisaic and Rabbinic institutions derives from Greek associations. 4 The conception of the Great Assembly and the organization of the sects, in so far as we know them or at least later generations' 5 presentations of them, are a type of Greco-Roman association. ${ }^{\text {The struc- }}$ ture of the first section of ARN, the chain of tradition, has parallels in Greco-Roman literature.

The exact type of Greco-Roman influence on Rabbinic literature and the channels it travelled cannot be known precisely. Epigraphic evidence indicates that Jews in the first century were using Greek. ${ }^{6}$ s. Lieberman shows that the Rabbis and people knew some Greek from at least the third century on. ${ }^{7}$ Most probably Palestinian Jews had a functional knowledge of Greek for business, 
for dealing with Greek speaking neighbors and officials and for speaking of the Hellenistic realia which had become part of their lives. ${ }^{8}$ Within such a context the more educated might be functionally fluent in Greek. Consequently, Greek stories, modes of expression and popular wisdom could easily influence the literary products of scholars. S. Lieberman notes that the Rabbis quote aphorisms, rather than technical philosophical terms and that they probably "drew their information from personal conversations with philosophers and other intelligent people." ${ }^{9}$ After pointing out the many Greco-Roman cultural influences on Rabbinic literature, Lieberman summarizes:

"We do not know exactly how much Greek the Rabbis knew. They probably did not read Plato and certainly not the pre-Socratic philosophers. Their main interest was centered in Gentile legal studies and their methods of rhetoric. But the Rabbis knew enough Greek to prevent them from telling stories (i.e. making up things) about Greek principles and their civil laws. Jewish opinion on the non-Jewish world was the product of knowledge and not of ignorance, and this knowledge was undoubtedly a great asset."10

It may be that further research into the social world of the Eastern Roman Empire will illuminate the relations between Rabbis and other social groups as well as the structure of Palestinian society. For the present we know that contact occurred and that it is manifest in the section on Johanan ben zakkai.

\section{Greco-Roman Associations and Schools}

The school in the Greco-Roman world was one of a variety of associations. Associations were so numerous and varied in both the city and the country that they cannot be clearly categorized. ${ }^{11}$ The terms used for associations and the members of the associations are many: orgeones, thiasos, schola, eranistai, synodos, colzegium. Each word has many meanings. Trade guilds or associations often had religious titles. ${ }^{12}$ Colzegia could be burial societies or religious societies or both; thiasos, secta and synodos are sometimes used for collegia and schools. 13 Thiasos, which most often means a religious association, is also used of trade associations. 14 In addition, associations often had multiple purposes. A craft guild might engage in the protection of the craft, but it might also be a social group. Burial societies met regularly and had rules for their banquets. A street or neighborhood of a city might 
have a society for the regular worship of a deity and the organization of a festival. 15

Hellenistic schools, usually associated with a philosophical way of thought and life, overlapped many of the characteristics of associations sketched out above. However, R. Alan Culpepper lists nine particular determinants of a school:

1. Groups of disciples which emphasized friendship and fellowship.

2. A founder who was an exemplary wise man or good man.

3. They valued the teachings of their founder and the traditions about him.

4. Members of the school were disciples or students of the founder.

5. Teaching, learning, studying and writing were common activities.

6. Communal meals, often in memory of the founder.

7. Rules or practices regarding admission, retention of membership, and advancement.

8. Some degree of distance or withdrawal from the rest of society.

9. Oxganizational means to insure their perpetuity. 16

Culpepper distinguishes a general movement or sect from a school, but concedes that a school may be part of a movement or sect and that all have characteristics in common. 17 He analyzed the school of Hillel in so far as the data allow, and he notes that Johanan ben Zakkai also had a school. ${ }^{18}$ The data which match Culpeppers list are scattered throughout ARN, but they are especially concentrated in the section on Johanan ben Zakkai and will be subjected to special analysis.

Materials concerned with study, teaching, masters and disciples, fraternal relations and authority argue strongly that a group centered around a school generated the fundamental traditions in ARN. This hypothesis allows for other goals; for example, worship, table fellowship, leadership in the community, etc. but the proper nature of the group addressed and described in ARN is scholastic. The literary materials in ARN resemble the doxographic works which detail the lives, teachings and disciples of Greek philosophers. 19 ARN is not a biography; neither is it a sayings collection like PA. It has a combination of stories, sayings and exegeses which have organization and purpose. The collection gives an ideology to the Rabbinic school, establishes the school's authority and propounds the fundamental teachings of the school concerning study 
and behavior. 20 It is noteworthy that one of the main topics of study, halaka, is almost never presented in ARN. Rather, the scholastic attitudes and the atmosphere for serious study are promoted here as a presupposition for the study of Torah in all its forms. In addition, we find praise for wise men, stories of the sages as examples, moral sayings concerning community order, especially the relationships of scholars with one another, and stories which celebrate various virtues, such as hospitality, cleverness, brevity of speech and self-control. ${ }^{21}$ Behavior was especially important because ancient schools and philosophies aimed at producing good people and also were themselves closely knit groups of teachers and students requiring order and discipline. 22

\section{The Scholar in society}

In maintaining that $\mathrm{ARN}$ is addressed to the teachers and students united in a Rabbinic school, I do not wish to deny that some Rabbis had other roles in society. ARN does not give a complete description of the Rabbis nor does it recount how they lived, but rather how they ought to live as members of the school. 23 Scholars, wise men, the educated, rhetors, scribes, sophists and philosophers often accepted responsibility for political leadership and diplomatic negotiation in their cities or kingdoms. In a time when few learned to read and write, the educated filled many roles in society and especially the most prominent could rise to positions of great power. In the Hebrew Bible the kings are surrounded by counselors and wise men. Whether "wise man" was a professional title has been disputed recently, ${ }^{24}$ but surely educated and capable people surrounded the kings and kept the records of the kingdom. In the Greek and Roman world philosophers and sophists advised leaders and attained positions of power from fifth century Athens on. During the second and third centuries, C.E. sophists were often prominent, rich and powerful. They led embassies, were high administrators for the Emperors and were consulted on important decisions. These roles were based on their fame as orators, teachers and authors. 25

The roles of the sophists and rhetors of the second and third centuries correspond to some of the characteristics and activities assigned to the Rabbis. We read of leading teachers going on embassies, taking part in the civic affairs of their home cities and exercising leadership over Judaism. The prince was chosen by heredity in the late second century, but Rabbinic authors hoped 
for a scholar-prince. Power and influence were divided among and a source of tension for the prince and leading teachers. ${ }^{26}$ In addition, the Rabbinic school and leadership arose in the East, the same part of the Empire which produced many famous sophists. Rabbis like sophists, were sometimes freed from certain taxes. Particular cities became famous centers for study or as the homes of respected teachers in Palestine and elsewhere. Many disputes arose among well known teachers. The coincidence of these features in both Rabbinic and Roman educated circles argue for a broad cultural milieu common to them all. H. Fischel has proposed the hypothesis that the Pharisees and Rabbis were part of a scholarly, bureaucratic, administrator class which arose in many places during the Hellenistic period and which shared many roles and modes of expression in common. ${ }^{27}$ This class tended to develop an ideology which separated them from other ways of life and initiated new members into their society. 28

Fischel's hypothesis is not fully proved and the role of the Rabbi in society is only partly clear. Associated with the role of the Rabbi is his status in society. Rabbinic documents, including ARN, speak of Rabbis engaged in trades. They also reject strongly anyone deriving benefit from Torah, either by taking money or seeking power. ${ }^{29}$ on the other hand, many sayings encourage full time involvement with Torah and reprimand scholars for attending to worldly affairs. ${ }^{30}$ The very dispute over the occupation of the Rabbi and also some texts which note the role of the prince in supporting some scholars prove that the situation was complex and that no balanced description of the situation survives. Since the majority in Palestine and the whole Roman Empire were relatively uneducated subsistence farmers, those able to read and write automatically moved into a separate class. Eliezer left his family to become a scholar. Even the scribe making out documents for the illiterate was a skilled craftsman. ${ }^{31}$ R. MacMullen points out that society everywhere in the Empire was extremely vertical without a middle class. Those who rose above small crafts and subsistence farming either attained wealth as landowners or attached themselves to the rich. ${ }^{32}$ G. Bowersock points out that those who succeeded as sophists and rhetors because of their oratorical and literary talents were patronized by the rich and became part of their society. 33

We can only speculate on the social, status of the Rabbis. An offhand comment in sifre Deuteronomy alludes to the distinctive walk, speech and dress of the students of the sages. ${ }^{34}$ Scattered 
evidence which cannot be dated exactly suggests that some Rabbis fulfilled leadership functions and some devoted themselves totally to teaching in a school setting. Since the economic structure of Palestine resembled that of the rest of the Eastern Empire it is likely that the Rabbis tended to form a special class, separate from society. Those who owned land, like Rabbis, were wealthy land owners. Records of animosity between the Rabbis and the Am Ha-aretz may reflect this. The requirements of constant study and of teaching in a school would foster a special way of life; in addition, anyone devoting full effort to intellectual matters must in fact differ from the majority of his fellow citizens, especially in a society so highly agricultural. This hypothesis does not deny that some Rabbis may have supported themselves by a trade and that individuals reached different degrees of fame and therefore varied status in society. It does suggest that the Rabbis both as scholars and as leaders lived a distinctive life with special potential.

Finally, a warning. The similarities between Greco-Roman and Rabbinic literature do not demand that we conclude to any direct contact between these literatures. Judaism reached back to the Bible and the monarchy for an indigenous tradition of wisdom which even then had international roots. Just as Plato and Aristotle wished to train statesmen, so Jewish wisdom produced advisers and leaders. It is clear that both wisdom and scribal traditions entered the Rabbinic stream flowing from the disaster in 70 . Attention to Greek and Latin models will alert us to traits shared by many ancient traditions and also to particular values not stressed in the Bible, such as poverty, austerity, lowly toil, health, etc. 35 Comparison of the two corpora will demonstrate how common themes were spread among cultures and were Judaized in their locations, names and other particulars; more importantly, Scripture was added and some of the more sharp sarcasm found in Greco-Roman sources blunted. ${ }^{36}$ Many of these common traditions have been modified and integrated into the section on Johanan ben Zakkai and his disciples.

\section{The School of Johanan ben Zakkai}

Stories and sayings from Johanan ben zakkai and his disciples are remarkable for the brief space given to Johanan and the extensive space given to his disciples. The introduction to Johanan is followed only by a brief saying. other sayings about Johanan are scattered about both versions, most notably the story of his escape from Jerusalem which is attached to Simeon the Righteous's saying. 
ARNB, ch. 31 does have a collection of materials attributed partly to Johanan, but it is added almost as an afterthought. The comments attached to his disciples' sayings contain several stories about Hillel which cement the relationship between the pre- and post-destruction leaders of Judaism. Nevertheless, Johanan remains an enigmatic and only partly developed figure. It may be that he is implicitly praised both in his disciples and in the recognition of his role at a crucial juncture in Jewish history. But his greatness is not directly extolled as it is for Hillel and to a lesser extent Eliezer and Akiba. Rather, Johanan's disciples and his relations with them, that is, his school, take center stage. Just as the story of Johanan's escape from Jerusalem leads primarily to the founding of his school at Jamnia (cf. ch. 4), so the materials gathered under his name explain and promote the foundation of that school.

\section{ARNA}

ARNA is the only source to connect Johanan ben zakkai directly to the chain of tradition with the formal statement "Johanan ben Zakkai took over from Hillel and Shammai." (Cf. ch. 5 on the chain of tradition for a discussion of the sources.) Johanan is first identified as a disciple of Hillel. The text recounts that Hillel had eighty disciples, a number which emphasizes Hillel's greatness and influence. Of them Jonathan ben Uzziel was the greatest/oldest and Johanan the least/youngest. 37 To explain how this least/ youngest disciple could be heir to $\mathrm{Hillel}$, the editor next recounts that Johanan ben Zakkai studied everything, Scripture, Mishna, Gemara, etc., including all their fine points of interpretation. 38 Strangely, after this strong introduction, Johanan is represented only by one saying (PA 2:8): "If you have wrought much in your study of Torah, take no credit for yourself, for to this end were you created." To this saying ARNA has added the clause "for men were created only on condition that they study Torah," a repetition of the main point of the saying and consistent with ARNA's emphasis on study of Torah.

The list of Johanan's five disciples immediately follows his saying. The epithets given to them refer to their knowledge of Torah (plastered cistern, oasis, stream, threefold cord) and their holiness (saint, happy she who bore him, fears sin). Neusner has suggested that the choice of the five may represent a composite of the group at Jamnia: Eliezer, a Pharisee; Joshua ben Hananiah, the newly emerging Rabbinism; Jose, a priest; Simeon ben Nathanel, 
an Am Ha-Aretz; and Eleazar ben Arak, mysticism. ${ }^{39}$ whatever their origin, the five form a tight and typical group of early sages and they are an implicit continuation of the chain of tradition after Johanan ben zakkai. The form of the list is an enumeration, often used in Rabbinic literature and elsewhere. Such lists of disciples are known in Greek school literature. The epithet applied to Eliezer, " a plastered cistern which loses not a drop," has a functional equivalent in Diogenes Laertius where zeno compares his successor Cleanthes to "hard waxen tablets which are difficult to write on, but retain characters written on them." 40 All of this material argues for a school setting.

The enumeration of the five disciples is followed by a dispute about who was the greatest: Eliezer, mentioned first in the list or Eleazar, mentioned last. The dispute parallels the previous contrast between Johanan and Jonathan ben Uzziel. The received opinion is that Eliezer is the greatest disciple of Johanan, a generalization substantiated by his prominent place in the halakic tradition. Abba saul contradicts the opinion and says that Eleazar is greater. The next two pericopae support this position because Eleazar gives the best answer to each question about the good and bad ways and he alone succeeds in consoling Johanan on the death of his son. The chapter ends with an explanation of why Eleazar did not live up to his potential, that is, he went to a beautiful spot, Emmaus, rather than staying with the scholars in Jamia. In one sense, ARNA, ch. 14 is a search for the greatest disciple and especially an exploration of Eleazar's merits and destiny. It implicitly teaches that natural talent must be developed in the richest environment for study, the company of other scholars. This theme was treated several times in the comments on the chain of tradition.

The school atmosphere continues in the famous discussion among Johanan ben Zakkai and his five disciples concerning the good way and the bad way. The question is a general ethical one, but with Hellenistic overtones. "Go out and see which is the good way to which a man should cleave." Goldin points out that the use of "cleave" ( $y i d b a q)$ is unusual here and that the search for a way fits the milieu of Hellenism with its religions and philosophies. 41 ARNA judaizes the question by adding the motive clause, "so that through it he might enter the world to come." From the answers given we can see that the question was understood as a request for the greatest or most comprehensive of the virtues. This listing of virtues (a liberal eye, a good companion, foresight, 
etc.) is a popular form in Hellenistic literature, including the New Testament. 42 strikingly no one says that "the way" is study of Torah or obedience to God's commandments, an answer that would have been obvious in the materials connected with the chain of tradition. The direction of the question and the atmosphere it generates produces a more Greco-Roman answer.

The answers given in the dialogue are difficult to evaluate and plagued with variants. Eleazar's answers, which are designated as best, are whole heartedness or good-heartedness ( $\bar{e} b$ tôb) and meanheartedness or bad heartedness ( $\bar{e} \bar{b}$ ral). The exact meaning of these expressions is not clear. Melamed suggests that they mean something as simple as a cheerful disposition and a sour disposition. ${ }^{43}$ How these expressions comprehend all the other answers is not immediately clear. The answers of Joshua and Jose, a good companion and a good neighbor, are close to one another. Jose's answer is given variously in the sources and, as a summary, ARNA suggests three possibilities: a good neighbor, a good impulse and a good wife. 44 The pithy and enigmatic character of the answers fits the style of proverbial saying both in the Bible and in Greek rhetorical literature and Eleazar's answer is judged best by Johanan. In the attempts to console Johanan on the death of his son, which immediately follow, Eleazar's parable about the king's subject who had an object on deposit and was relieved to return the deposit, is similar to the stoic ideas that children are held in trust by their parents. 45 All these materials glorify Eleazar as the greatest of Johanan's disciples and necessitate the final story about his move to Emmaus as the explanation for his subsequent lack of achievement.

The next three chapters in ARNA (15-17) take up the sayings of Eliezer, Joshua and Jose. The sayings of Simeon and Eleazar are added on at the end of ch. 17 without comment. Stories of Hillel as an example of patience, a discussion of the evil impulse and chastity, thoughts about possession of Torah, the example of the sages, exhortation to virtue and reflections on the fate of Jews after the destruction of the Temple and on sudden reversals in life dot this section. Most of these materials show the continued influence of Hellenistic rhetorical literature which is associated with schools. At the same time, all the sayings except simeon's end with mention of God or the next world.

The first two clauses of Eliezer's saying concern humane behavior toward others: "Let the honor of your fellow be as dear to you as your own. Be not easily angered." The second clause 
is followed by three stories illustrating the patience of Hillel in contrast to the impatience of Shammai. 46 Hillel's psuedo-rational explanations of nature (Why are the Babylonians' heads long?) and Shammai's impatience are common motifs in Hellenistic chriae about philosophers. 47 Hillel is proposed as the ideal sage and as the model to be followed by all Rabbis. The view that Hillel founded the Rabbinic movement is presumed and Hellenistic modes of expression continue. The invocation of Hillel once again designates Johanan and his school as successors to Hillel and his school. Joshua ben Hananiah's saying, like the others in this section, promotes humane virtue and the avoidance of vice, ending with an implicit reference to the world to come. "A grudging eye, evil impulse and hatred of mankind put a man out of the world." A grudging eye is both a common lack of generosity and also refusal to share one's learning, a constant concern of ARNA. An extended discussion of the evil impulse ranges over its origin in humans at puberty to its dominance of the body. The evil impulse leads to immoral sexual behavior and so the Biblical Joseph and Rabbis Zadok, Akiba and Eliezer are the subjects of stories which illustrate chastity in the face of temptation. These chriae plus parables about the strength of the evil impulse are typical of the stories told about virtuous wise men. The final clause against hatred of mankind produces a definition of whom to love and hate: one is to love masters, disciples and the Am Ha-Aretz; one is to hate sectarians, apostates and informers. ARNA uses acceptance of Torah as the dividing line between those inside and outside the community. ARNA's emphasis on Torah continues in its comments on Rabbi Jose's saying: "Let your fellow's property be as dear to you as your own. Make yourself fit for the study of Torah, for it will not be yours by inheritance. Let all your actions be for the sake of heaven." The first clause is interpreted to mean that one should share his learning with another who asks to be taught. The passing on of leadership from Moses to Joshua, who was unrelated to him, illustrates the second clause. The mention of inheritance and the concern with property attract three stories about young women impoverished or made captive in war. These stories and the reflections of Johanan ben Zakkai on meeting the daughter of the wealthy Nakdimon ben Gorion, reduced to poverty after the destruction of Jerusalem, establish the transitory nature of wealth and the dangers surrounding our physical well being. The final clause, "Let all your actions be for the sake of heaven," receives the 
concise interpretation, "for the sake of Torah." The general proclivity to relate sayings to Torah in ARNA is very much in evidence in this section.

The sayings of the last two of Johanan's disciples lack commentary for no clear reason. Simeon's saying contains reference to the Shema and Eleazar's encourages Torah study, themes found elsewhere in ARN, but they receive no elaboration here. The sayings of the first three diciples do form a triad of tripartite sayings, but it is doubtful that this is the controlling structure since the tradition of five disciples is so strong. Both Simeon's and Eleazar's sayings concentrate on one's attitude before God; Simeon counsels reverence and promptness in the daily prayers and Eleazar reminds us that it is for God we work. Eleazar's saying ("Be diligent in the study of Torah, and know how to answer an Epicuros. Let not one word of the Torah escape you. Know in whose presence you are toiling, and who is author of the covenant with you.") is notable for the mention of the Epicuros or Epicurean. Goldin suggests that the four clauses were originally tripartite and read: "Be diligent to learn how to answer an Epicurean, know in whose presence you are toiling and faithful is your taskmaster (balal berritkā)," a reading found in the Geniza manuscripts. 48 Study of Torah could easily have been added to "Be diligent" to form a stock exhortation. Further, Epicurean was probably meant literally in the original version of the saying. 49 only later did Epicurean achieve the wider meaning of sceptic or heretic in general. Such an interpretation is consistent with the school setting of ARN for the Rabbis would probably have been aware of other schools of thought and their teachings.

Ch. 18 neatly parallels ch. 14: "In like manner, Rabbi Judah the Prince used to list the excellences of the sages: of Rabbi Tarfon, Rabbi Akiba, Rabbi Eleazar ben Azariah, Rabbi Johanan ben Nuri, and Rabbi Jose the Galilean." Each is characterized by an epithet and the characteristics of the first three are developed at length. All the comments refer to the sages' learning and skill at collecting and in expounding Torah. Then, another 1ist of epithets attributed to Isi ben Judah gives characteristics of eight sages. The last two from the list above are repeated. This chapter is a later composition designed to give Rabbi Judah the Prince a place in ARNA comparable to Johanan ben Zakkai's. Like so much else in ARN, it upholds continuity of learning and authority within the Rabbinic school. 
In contrast to ARNA, no lemma linking Johanan ben Zakkai to Hillel in the chain of tradition introduces the section on Johanan and his disciples (ch. 28). Such a statement is made in a separate collection in $\mathrm{ch}$. 31. That the chain of tradition continues is implied by the opening sentence, "Hillel the Elder had eighty pairs of disciples." Pairs is not used in ARNA; ARNB pictures the last of the five pairs in the chain of tradition continued by an enormous group of pairs. Immediately, though, the text refers to individuals, saying that Johanan is the least/youngest of the disciples. The characterization of Johanan as the least/youngest prepares us for a striking contrast in Hillel's deathbed scene where Hillel praises Johanan even though he was initially left outside. The introduction of Hillel's disciples, followed by the "appointment" of Johanan as the greatest by Hillel, establish Johanan's authority as leader of the new post-destruction school and as heir to Hillel. The deathbed scene in Rabbinic literature is a literary form which may date from the second century and is often used to affirm and guarantee the passing on of authority and tradition and to announce the appointment of a successor to a leader. Here and typically in deathbed scenes the disciples enter the dying man's room, the master begins the action by a question, the master makes a prediction, appoints a successor (here implicitly) and imparts a blessing (here Prov. 8:21). 50

After reviewing Johanan's curriculum of study, ARNB introduces his sayings with the statement that he used to say five things. But only two sayings follow. Five is a favorite number in this section (Hillel's five Aramaic sayings in the previous chapter and Johanan's five disciples in the following chapter), but whether the list ever contained five sayings in unknown. Johanan's disciples are presented as in ARNA: the list of five disciples with epithets, the dispute over the greatest and the explanation of Eleazar's lack of later prominence (ch, 29). The dispute over the good and bad ways is placed last as a preparation for the disciples' individual teachings.

The comments on Eliezer's saying (ch. 30) resemble those in ARNA, but those on Joshua's differ in that ARNB interprets a "grudging eye" simply as lack of generosity, unrelated to Torah. In addition, the evil impulse enters a person at birth (not at puberty as in ARNA) and this theme does not receive a long development in ARNB. ARNB quotes simeon's saying third and puts Jose's fourth so that Jose's and the final saying, Eleazar's, which both 
mention Torah, will be together. In commenting on the third clause of Jose's saying, "Let all your actions be for the sake of heaven," ARNB does not mention Torah, as ARNA does, but rather tells two stories about Hillel in which he takes washing and going to the toilet as fulfilling commandments. These stories are typical Hellenistic chriae in which a striking action of the master teaches the disciples. ARNB also has less mention of Torah and more of works than ARNA, a constant tendency in the two versions. 51

The stress on Hillel and also on Johanan as founders of the school continues in ARNB, ch. 31. Chapter 31 is a loosely structured collection of sayings by these two early and prominent Rabbinic leaders. (In ARNA some of Hillel's sayings are found in ch. 28, a different context which is also a loose collection of sayings.) Ch. 31 begins in the ordinary fashion of the chain of tradition: Johanan took over from Hillel and Shammi, he enunciated a saying (PA 2:8) and the saying is commented on. We have already discussed in ch. 5 the dislocation of Johanan from the chain of tradition.

A series of seven sayings attributed to Johanan ben zakkai follows. Though the number of sayings is not noted at the beginning of the sequence, groups of seven are very common. The sayings are loosely linked by topics and associations. The first of the sayings advises against tearing down pagan altars; the second is anti-messianic and the third refers to building and tearing down the Temple. All three counsel prudence and moderation and presume a setting in the Roman Empire as well as a polemic against radical action after the loss of the Temple. Young men and children are mentioned in sayings 3,4 , and 6 . Property owners are viewed negatively in 4 and 7 . Wise men (or sages) are dealt with in 5 and 6 and implied in 3 lold men are to be listened to) and in 4 (children are to be brought to words of Torah.) one further point: the fourth saying instructs us to keep children from pride. S. Lieberman has suggested reading mhgywn rather than mglwn, based on the Talmud and later commentators. 52 We would then be instructed to keep our children from the study of Greek logic. If this suggestion is valid, the saying is a response to the Greco-Roman culture surrounding Israel. 53

The rest of $\mathrm{ch} .31$ consists of sayings of Hillel drawn from PA 2:4-7. These sayings occur in different contexts in PA, ARNA, ch. 28 and here. The texts of the sayings vary and ARNB omits PA $2: 5$ and 6 . PA $2: 7$, "The more wives, the more witchcraft, etc.," 
fits in well with the rhetorical flavor of this section. 54 The final clause of the saying, "If one acquires for himself knowledge of Torah..." makes a smooth transition to the next two sayings which are also on Torah. The second of this pair mentions gold vessels which draw the following saying comparing gold and glass vessels and then another comparing glass and regular (ceramic) vessels. The chapter is closed by three enumerated groups of three things, all folk proverbs. These sayings are collected here by catchwords and associations, just like the sayings of Johanan earlier in the chapter. Ch. 31 presents both Johanan and Hillel as wise men who are known through their human, down-to-earth Proverbial wisdom. The sayings promote the purpose of the author of ARNB who stresses wise and ethical activity with great sages as models.

\section{Conclusion}

The bulk of the sayings and stories contained in the section of ARN concerned with Johanan ben Zakkai and his disciples pertain most directly to a school setting. Masters and disciples, study, fraternal relations and sages as models pervade these chapters. Johanan appears as the head of a school which continues the school of Hillel and is itself the origin of the Rabbinic school in all of its variety in later generations. Many of the sayings and stories have parallels in Greco-Roman school literature, or at least are functional equivalents of materials found there. Yet, ARN remains a Jewish document with Torah firmly in the center and Biblical exegesis as a close support. ARNA puts an extra stress on study of Torah while ARNB gives a slight emphasis to good works. Most of the traditions in these chapters are common to both versions of ARN and to $P A$, though order, wording and emphasis have been altered. 


\section{CHAPTER SEVEN}

\section{THE SAYINGS OF THE EARLY SAGES}

Both versions of ARN use the commentary form when dealing with the members of the chain of tradition and Johanan ben Zakkai. A whole saying is followed by lemmas and comments. This genre breaks down in subsequent chapters on the early sages (ARNA, chs. 19-30; ARNB, chs. 32-35) and is replaced by collections of attributed sayings linked by themes, names and catchwords. This is especially true of ARNB which uses lemmas and commentary only once in ch. 34 for a saying of Rabbi Nathan. ARNA has some commentary, some collections of sayings and an intermediate form consisting of a saying followed by associated material which functions as a commentary but which lacks a lemma or an interpretative remark (such as zeh, kësad, minnay $\hat{i} n$ ).

Not only does format change in the later chapters of both versions of ARN; each version differs sharply from the other in structure, organization and purpose. The order of sayings found in $P A$ exerts little influence on this part of $A R N$, and as has long been recognized, $A R N$ is not commenting on the text of $P A$ as we have it in the Mishna. Rather, the sayings of PA appear along with many others and they are for the most part indistinguishable from the other sayings in ARN because they are not the subject of a commentary nor are they set apart in any way. ARNA does have several chapters where a few of the sayings from PA head the chapters and possess a commentary, but chs. 22 and 27-30 are simply collections of sayings. ARNB is almost wholly collections of sayings and it includes more sayings from PA than ARNA.

The sayings from PA used in this section of ARN can be seen in the chart on the following page. 


\begin{tabular}{|c|c|c|}
\hline ARNA & ARNB & omitted in both \\
\hline $3: 1,5$ & $3: 1,2,3,4,5,6$ & 7,8 \\
\hline $9,10 \mathrm{~b}$ & $9,10 \mathrm{~b}$ & $10 a$ \\
\hline 11 & 11,13 & 12 \\
\hline $14-16$ in ch. 39 & $14-16$ in ch. 44 & \\
\hline & $17-18$ & \\
\hline $4: 1,2,3$ & $4: 1,2$ & \\
\hline $5 a$ & $4 a, 5 a$ & $4 \mathrm{~b}, 5 \mathrm{~b}$ \\
\hline 6,9 & $6,7,8,9,10$ & \\
\hline 11,12 & $11 a, 12,13 a$ & $11 b$ \\
\hline $13 \mathrm{~b}$ in $\mathrm{ch} .41$ & $13 \mathrm{~b}$ in $\mathrm{ch} .48$ & \\
\hline $14,15,18$ & $14,15,16,17,18$ & 19 \\
\hline $20 a$ & $20 \mathrm{~b}, 20 \mathrm{c}, 21,22$ & \\
\hline
\end{tabular}

This chart does not show the order of appearance of the sayings in the two versions of ARN, since this order varies considerably. Several sayings do not occur in the section of ARN being studied in this chapter, but among the enumerations. A few sayings occur in neither version of ARN; a larger number occur in just one version.

L. Finkelstein has proposed a source theory to explain the genesis of this section of ARN and PA. Collection 3 gathered five sages who lived around the time of the destruction of the Temple: Akabya ben Mahalaleel, Hananiah, Prefect of the Priests, Nehunya ben Ha-Kana, Hanina ben Dosa and Dosa ben Harkinas. ${ }^{1}$ Their sayings along with others are found in PA 3:1-14, ARNA, chs. 19-22 and ARNB, chs. 31 (end), 32 and 34 . Collection 4 contained the four who entered the orchard to learn mystical lore: ${ }^{2}$ Elisha ben Abuyah, Ben zoma, Ben Azzai and Akiba. Their sayings, along with others, are found in PA 3:17-20, ARNA, chs. 23-26 and ARNB, chs. 33 and 35. Several of these sages head chapters in ARNA and this phenomenon provides the most evidence for Finkelstein's theory. However, the variety of order in all the sources, including ARNA, demands numerous explanations to account for changes in the hypothetical original collection. We shall proceed through each version of ARN, examining its present shape and purpose. It is clear that the collections hypothesized by Finkelstein were not determinative for the editors of ARN, who used the material for their own purposes. Still, the presence of the names of the four who entered the orchard is striking, especially since Ben zoma and Ben Azzai are not that prominent and Elisha ben Abuyah later became an apostate. Consequently, some attention will be given to 
Finkelstein's hypothesis as a means of clarifying the order found in ARN as we have it.

$$
\text { ARNA, Chs. } 19-30
$$

ARNA, ch. 19 begins with the intriguing saying of Akabya ben Mahalaleel which points out the lowly origins of human life. The second and third clauses read: "Whither is he going? To a place of darkness and gloom. What is he destined to be? Dust, worm and maggot." The third clause might imply denial of resurrection, so ARNA concentrates its commentary on that clause. The sayings, stories and parables in this chapter are associated by theme and name and together they function as a commentary on Akabya's saying, though they lack the formal characteristics of one. The first sentence begins, "Rabbi simeon says," as if to quote an independent saying, but simeon instead comments on the first three clauses of Akabya's saying and adds an appropriate quote from Job 25:6, "Surely man is a worm! And the son of man is a maggot." Rabbi Eliezer ben Jacob then contributes a brief exegesis of the verse from Job and Rabbi simeon ben Eleazar a parable about a tannery pipe in a palace as an image for the human body. ARNA aggressively accepts the negative image in Akabya's saying and applies it to the low condition of human origins and to bodily destiny immediately after death.

After these negative comments, Rabbi Eliezer (note the repetition of the names Eliezer and Simeon in ch. 19) is quoted from his deathbed. ${ }^{3}$ He orders his disciples to watch over each other's honor, a contrast to the lowliness theme, and to remember before whom they stand praying so that they may merit the life of the world to come. This is a more optimistic admonition than Akabya's. A second story of Eliezer's last teachings on his deathbed continues the theme of death and destiny after death which fills this chapter. His final teachings subtly counteract the negative impression of humanity which precede by speaking about purity and immersion pools.

Ch. 20 begins with a long paragraph attributed to Hananiah, Prefect of the Priests, and concerned with taking the words of Torah to heart. The evils that come upon one who disobeys Torah are expounded by an exegesis of Dt. 28:48 and seven exegeses of Song 1:6. The evils are associated with external enemies of Israel and have a strongly anti-Roman tone, similar to the tone of the saying of Nehunya ben Ha-Kana, a sage who does not appear in ARNA. 
In fact, the names and sayings of Hananiah, Prefect of the Priests and Nehunya ben Ha-Kana are confused and changed in the versions of ARN as this chart makes clear.

$\underline{\mathrm{PA}}$

3:2 Hananiah, Pre-

fect of the Priests

Pro-government saying (omitted)

3:5 Nehunya ben Ha-Kana (omitted)

Yoke of Torah saying
ARNA

ch. 20 Hananiah, Prefect of the Priests

Words of Torah saying (free variant)
ARNB

ch. 31, end. Nehunya, Prefect of the Priests.

Pro-government saying

ch. 32 Nehunya ben Ha-Kana.

Yoke of Torah saying.

Several notes are in order. At the end of ch. 31, ARNB has Nehunya, Prefect of the Priests, in all manuscripts even though it is an evident error. Hananiah and Nehunya are easily confused by the metathesis of the first two letters of their names. ${ }^{4}$ Some sources for the text of ARNA have Nehunya ben Ha-Kana rather than Hananiah, Prefect of the Priests. ${ }^{5}$ The suppression of Hananiah's pro-government saying ("Pray for the welfare of the Empire which rules over us constantly, because were it not for the fear it inspires, every man would swallow his neighbor alive,") can be explained as the action of some later editor who was shocked at its extreme position. (Note that Hananiah's saying has a dim view of human nature, similar to that in Akabya's saying.)

Hananiah is presented as the author of a saying which is a free variant of Nehunya's saying in PA and ARNB: he who is preoccupied with Torah will be freed of preoccupations with various kinds of evil such as hunger, unchasity, etc. He who is not preoccupied with Torah will have to deal with those evils. To prove the latter statement ARNA quotes Dt. 28:46-48 on the curses which will come on Israel if they do not serve the Lord. The end of verse 48, that Israel will serve its enemies in hunger, thirst, nakedness and in want of all things, is developed at length to show the evils which the heathen government (Rome) has brought on Judaism. ARNA's usual exhortation to study Torah has been linked with fierce resentment of the demands made by the Roman Empire on a subject people: "At a time when one longs for drink and cannot find even a drop of vinegar or a drop of bitters, the heathen nations demand from him the finest wine in the world." After this outburst, ARNA returns to its main theme of attention to and obedience to Torah with a series of seven interpretations of song 
1:6, mostly centered on the clause "My mother's sons were incensed against me" which is related to various acts of disobedience to Torah. Ch. 20 is unified by the theme of neglect of Torah which leads to sin and then to punishment.

Dosa ben Harkinas's saying in ch. 21 continues the theme of ch. 20, neglect of Torah. Dosa lists four wasteful ocupations, "morning sleep, midday wine, children's prattle and sitting in the gathering places of the Am Ha-Aretz" which "put a man out of the world." ARNA has transformed this folk saying on the dangers of idleness into a warning against neglect of Torah. Each of the wasteful occupations is described in a formulaic way which ends with "he neglects the study of Torah." Each item is supported by a scriptural verse. The verses cited for the second and fourth phrases receive further exegesis. Ch. 21 concludes with a prayer of Akiba thanking God for bringing him to study rather than to loitering on the corner.

Chs. 20 and 21 strongly recommended a constant study of Torah as the opposite of evil. Ch. 22 is a series of seven sayings, six of which are concerned with the necessity of good works as a basis for Torah or wisdom. Thus, ch. 22 balances the emphasis in the previous chapters. The first two sayings, by Hanina ben Dosa (PA 3:9), place fear of sin and works over wisdom. A question to Johanan ben zakkai produces a comparison of wisdom to a craftsman and fear of sin to his tools. This theme continues in two sayings of Eleazar ben Azariah (PA 3:17). The chapter ends with the sayings of Gamaliel and Simeon his son from the end of PA, ch. 1 . Gamaliel's saying does not relate to the theme of the chapter, but seems to have come here by association with his son's which does fit. 6 The commentary form which predominated in the previous chapters has been dropped in favor of a collection of sayings juxtaposed to one another.

Chs. 23-26 are each headed by one of the four sages who entered the garden or orchard, that is, studied mystical lore. ${ }^{7}$ The order of the sages differs in ARNA and PA/ARNB. Finkelstein hypothesizes that originally Elisha ben Abuya headed the list, but that he was displaced when he became an apostate.

$\begin{array}{lll}\text { ARNA } & \frac{\text { ARNB/PA }}{\text { Akiba }} & \frac{\text { Hypothetical Original }}{\text { Blisha ben Abuyah }} \\ \text { Elisha ben Abuyah } & \text { Ben Zoma } & \text { Ben zoma } \\ \text { Ben Azzai } & \text { Ben Azzai } & \text { Ben Azzai } \\ \text { Akiba } & \text { Elisha ben Abuyah } & \text { Akiba }\end{array}$


ARNA simply switched the first two names. PA and ARNB put Akiba, the most prominent, first and Elisha the apostate last. ${ }^{8}$ Finkelstein's hypothesis is weakened by Akiba's position in PA, ch. 3 and the other three in ch. 4. In ARNB, Elisha ben Abuyah is separated from the other three by a complete chapter. ARNA with the four in sequence at the head of chapters provides the greatest strength to Finkelstein's theory. The four sages determine the structure of ARNA, but not of ARNB and PA.

Ch. 23 in ARNA begins with a saying of Ben zoma who asks and answers four questions; this is the same form found in Akabya's saying in ch. 19. The fourth of the clauses of Ben zoma's saying receives a brief commentary which is followed by a group of seven sayings; the previous chapter, too contained a group of seven sayings. All these sayings except one are concerned with study of Torah, in this case the preferability of studying Torah as a child. Both ch. 23 and also ch. 24 have links with ch. 22 so that even if they originally came from different sources, here in ARNA they form one complex whole centered around Torah.

The order of the four questions and answers asked by Ben zoma varies in $P A$ and the two versions of ARN. Ben zoma asks who is wise, rich, etc. and answers each question with a statement and a Scriptural verse to prove it. The order of the questions is as follows.

$\begin{array}{lll}\text { ARNA } & \text { ARNB } & \text { PA } \\ \text { wise } & \text { wise } & \text { wise } \\ \text { humble } & \text { honorable } & \text { mighty } \\ \text { rich } & \text { mighty } & \text { rich } \\ \text { mighty } & \text { rich } & \text { honorable }\end{array}$

Both versions of ARN have arranged the list so that the final member of the list leads into a related comment. H. Fischel suggests that ARNA has changed "honorable", a traditional Greco-Roman category, to the more Biblical category "humble".9

The fourth type in ARNA, "mighty," is defined as one who subdues his evil impulse. This popular theme prompts the citation of Prov. 21:22 and several related interpretations. The remainder of $\mathrm{ch} .23$ is devoted to a group of seven tradents, each reporting one or more sayings. The sayings concern study of Torah, especially the advantages of studying as a youth. ARNA once again returns to its favorite topic, study of Torah, just as it has done in previous chapters. 
Ch. 24 continues the themes of study of Torah in youth and good works found in the previous two chapters. It contains eight sayings all attributed to Elisha ben Abuyah. The first four follow a common pattern: "one in whom there are good works, who has studied much Torah, to what may he be likened?" Two similes follow coupled with a question about one who has no good works but studied Torah. The attribution of these similes to Elisha is ironic, for he was a sage who knew Torah, but who did not act well in apostasizing. Good works are compared to a solid foundation and to a bridle, both of which Elisha lacked. The fifth saying concerns studying Torah as a child, the subject of the previous chapter and also of Elisha's saying in PA 4:20a. The sixth and seventh concern the danger of forgetting Torah and the eighth causing another to carry out a commandment. This final saying is expanded by an ironic parable about the need to keep Torah as a valued possession, something which Elisha also failed to do. ARNA has attributed a large number of sayings to Elisha, in contrast to $P A$ and $A R N B$ which reduce his role, and it has put him to work in support of Torah despite the outcome of his life.

In ch. 25 Ben Azzai has three groups of statements interrupted by stories of Johanan and Eliezer on their deathbeds. The first two groups of Ben Azzai's concern good and bad signs for a person, especially in relationship to death. The theme of death attracts the stories of the deaths of Johanan and Eliezer. The group of Ben Azzai's sayings (five in number) at the end of the chapter includes his saying quoted in PA 4:2. It should also be noted that $H$. Fischel has found many parallels to this chapter in Greco-Roman literature as well as for Ben Azzai's whole corpus of sayings. He also finds many parallels to Ben zoma's sayings and to all of the materials associated with the four entering the garden. ${ }^{10}$ These materials, like those associated with Johanan ben Zakkai, have an especially intense Hellenistic flavor and are filled with materials concerned with study, Torah and master-disciple relationships.

The first two groups of Ben Azzai's sayings concerning good and bad signs for a person at death, arouse the ambiguities by humans faced with death. Even a model sage like Johanan ben Zakkai expresses his fear and uncertainty about judgment. Once again, Johanan is associated with verses about Moses which are related to reward and punishment. In the stories of Rabbi Eliezer's last iliness the focus shifts dramatically to the passing on of Torah, a major theme of deathbed scenes in Rabbinic literature. ${ }^{11}$ Eliezer 
shows that his mind is still sharp and rebukes the younger sages for failing to learn much of the law, all the while lamenting how much he himself had forgotten. In the final group of sayings Ben Azzai exhorts his listeners to be quick to carry out a minor commandment and to flee from sin. These are the sayings traditionally attributed to Ben Azzai, but the editor of ARNA has added them on only after he has finished discussing the subjects of most concern to him, death and judgment. Ben Azzai's final admonitions may be seen in the context of judgment: "Be quick to carry out a minor commandment" and "One transgression leads to another transgression."

Ch. 26 begins with five sayings by Akiba, followed by one more commenting on what he said. The second half of the chapter is also five sayings including two by Akiba. Though composed of sayings, like previous chapters, this one is less unified than they. Ch. 26 is more like chs. 27-30 in lacking tight organization. Akiba's first statement, a modified version of PA $3: 13$, lists five hedges: "A hedge about honor, not to be frivolous; a hedge about wisdom, silence, etc." The next saying, a string of six admonitions, has verbal links to the hedges and to the following saying where a discussion of the advantages of the Holy Land is continued. The fourth saying is an abbreviation of $P A$ 2:5, there attributed to Hillel, and the fifth like the fourth concerns the conditions and attitudes necessary for study. A saying by Simeon ben Eleazar expands on three of Akiba's admonitions: on the Holy Iand, idolatry and banquets. (See simeon in ch. 28 also.) The final five sayings of the chapter detail several sins and ways of vitiating Torah study. The themes are familiar (Torah, marxiage and food) but no one theme unifies the chapter except perhaps the dominant presence of Akiba. Ch. 26 discusses some subjects which are repeated, but in a desultory fashion. Its sayings are organized like those is chs. 27-30 which follow.

ARNA, chs. 27-30 is a collection of sayings with some commentary interspersed. It has no parallel in ARNB or PA. Sayings are linked to each other by similarity of names, words and themes. Some attributions differ from other sources. Some sections have thematic unity, with Torah predominating in many places, but not to the usual extent. Many of the sayings are found also in ARNB, especially in chs. 32-35, but they are arranged and used very differently there. Some blocks of material do retain a common shape in both versions, but their origin and purposes are impossible to discover. Strikingly, sayings from PA are quoted infrequently here. Ch. 27 has several. Ch. 28 has one saying of Hillel in the middle 
of the chapter. Chs. 29 and 30 have one saying each at the head of the chapter. This contrasts with ARNB which has many sayings from PA built into chs. 32-35. Clearly, the author of ARNA was not commenting on $\mathrm{PA}$ or even using it extensively; rather he gathered together sayings which he wished to include in his work and placed them after the traditions common to the whole tradition and before the enumerations of chs. 31-4l.

ARNA, ch. 27 begins and ends with sayings which speak of honor and which are followed by commentaries which use Exodus themes. Rabbi Jose speaks of honoring Torah and Eleazar ben Shammua of the honor among masters and disciples. The verse quoted by Jose brings with it several exegetical comments concerning Pharoah's punishment at the Red Sea and Eleazar's saying is illustrated by the honor of Moses, Aaron and Joshua. In between lie eight sayings by five sages on the themes of Torah, laws and constant study. The chapter is dotted with several sayings from PA, especially PA, ch. 4 , but also chs. 2 and 3. As a whole ch. 27 continues the main theme of ARNA, Torah study of Torah and it encourages such study by pointing out the honor which pertains to the state of student (and master). Succeeding chapters are less unified.

Ch. 28 contains four sections: a series of nine superlatives by Rabbi Nathan; a group of seven sayings by various sages; two sayings by Hillel (the only from $P A$ ); and two long sayings on three types of scholars and on balancing Torah with worldly matters. Though Torah occurs in all four sections, it does not dominate them. The nine superlatives begin with "There is no love like the love of Torah" and contains negative comments like "There is no arrogance like the arrogance of Elam." In the next section of seven sayings simeon ben Eleazar encourages residence in the Holy Land as he did in ch. 26; Simeon ben Gamaliel speaks of peace in the home, Rabban Gamaliel on the difficulty of acquiring Torah and Rabbi Judah the Prince on reward in the world to come. Hillel's sayings (PA 2:4 and a paraphrase of 2:7) mention Torah and peace as well as other admonitions and observations on human nature. Finally, Eleazar ben Shammua distinguishes and describes three types of scholars and Judah ben Ilai recommends making Torah primary over worldly affairs, though his saying is coupled with a parable which recommends balancing the two and avoiding extremes. All these sayings continue discussion on themes and problems brought up previously in ARNA, especially Torah. However, they lack any compelling order or tight unity. 
Ch. 29, like ch. 30 , has a saying from PA at the beginning of the chapter only, though the body of the chapter contains some material found also in ARNB, chs. 33-34. The saying of Simeon ben Eleazar consists of five admonitions about how to relate to another in a crisis. Three sayings follow concerning preference for companions who rebuke you and diligence in the study of Torah. Diligence in study serves as a norm for distinguishing four classes of scholars and motivates a pair of sayings about thinking of Torah if awake at night. The second half of the chapter features Eleazar Hakkappar on two subjects, honoring fellow human beings (see also ARNB, ch. 34) and atonement. Honoring another for the sake of wealth and despising another for the sake of a holy work elicit the Biblical examples of Balaam with Balak and Moses with Pharoah, plus attendant commentary. The four means of atonement, repentance, Day of Atonement, suffering after the Day of Atonement and death, are each explained and related to a type of sin. The last penalty, death, forms an associative link to the first of the last four sayings concerning study of Torah and relations among humans and scholars. The final saying, a four part admonition about human relations, forms an inclusion with the first saying of the chapter. Though Torah is frequently mentioned in ch. 29, it does not draw the chapter tightly together. The sayings remain loosely associated with one another.

Ch. 30, like ch. 29, has one saying only from PA (4:9) which opens the chapter. The three parts of the chapter are held together by weak associative links. The initial saying concerns Torah and the one following is about good works, forming a balance of the two types of meritorious activities. The initial saying is by Nathan ben Joseph whose name also occurs within the second section of the chapter between Meir and Akiba. A long paragraph is attributed to each sage and each paragraph follows the same pattern: a rule is given concerning guilt and punishment for a class of sin. An example follows and then the question is asked: Which is the greater measure, the measure of reward or the measure of punishment? All three instances prove that the measure of reward is greater. Finally, Rabbi simeon speaks of the punishment of a liar and Jacob is adduced as a Biblical example in a brief midrash. The chapter ends with an unconnected group of four sayings about buying grain and feeding one's family.

ARNA, chs. 19-30, continues the theme of Torah and associated subjects such as study and perseverance, which became so familiar in earlier chapters. However, these chapters are not so dominated 
by Torah as the earlier chapters were, nor are they organized in as tight an order as the chapters of the chain of tradition or Johanan or his disciples. These later chapters continue the idea of the chain of tradition by citing many early sages at their core. These sages, many of whom lived about the time of the destruction of the Temple and the founding of the Rabbinic school, testify to the centrality of study and Torah and to the way of life which ought to emerge. They, like the teachers of the chain of tradition, are reliable sources of wisdom and truth and through them the Rabbinic school received its character and value. Their teachings range over a wide field and include observations on human behavior, categorization of human types and the consequences of sin. They and their teachings function as a supplement to the chain of tradition and founding of the Rabbinic school by Johanan and his disciples. Even the four who entered the garden and engaged in dangerous mystical explorations are made to serve the cause and among them even the apostate, Elisha ben Abuyah, ironically furthers the cause of Torah. The materials in these chapters derive from many sources. Even if Finkelstein has correctly reconstructed the core of two sources, these sources have been submerged into a larger plan and become part of a complex whole.

$$
A R N B, \text { Chs. } 32-35
$$

The sayings of the sages from about the time of the destruction of the Temple (Akabya et al.) occur in chs. 31 (end), 32 and 34 of ARNB. The sayings of the four who entered the garden are presented in chs. 33 and 35 (Elisha). At the end of ch. 31 the progovernment saying of Hananiah, Prefect of the Priests is quoted, not suppressed as in ARNA. However, it is attributed to "Nehunya, Prefect of the priests." Such a figure is unknown and the two names may be easily confused. (See ARNA above.) The saying has been placed at the end of ch. 31 so that it will not open a chapter.

Ch. 32 is a collection of sayings attributed to various sages. only one parable and one exegesis of a verse vary from this pattern. The structure of the chapter shows the importance of the sayings of Nehunya, Hanina ben Dosa and Akabya and the chapter is unified by themes of studying and doing Torah. Nehunya begins the chapter by promoting the yoke of Torah with the threat of the yoke of government and mundane matters as the alternative. ARNA, ch. 20 used this saying as the occasion for a long development of the evils of the Empire and the evils suffered by Israel. ARNB merely adds six 
sayings to make an initial group of seven. The first four explicitly concern Torah, the fifth seems to refer to the rewards of Torah; the sixth and seventh are by Ishmael and his father Johanan ben Baroka and concern reward and punishment. Five of the seven are found in PA.

Hanina ben Dosa's saying on fear of sin and works in relation to wisdom follows the group of seven. A parable supplemented by a Scriptural verse brings out its meaning, that works are the foundation of wisdom. The relating of works to study of Torah is a recurrent theme in ARNB with works often receiving more emphasis than in ARNA. Akabya's saying, which seemed so strange and possibly heretical that it was modified in $P A$, is taken from first place (as compared to PA and ARNA) and placed after Hanina's saying. Simeon ben Eleazar follows Akabya with two sayings (making a group of three) that function as commentary. But simeon's first saying is no less strange than Akabya's. Simeon asks four times "From whence did he ( $m a n)$ come?" and gives the answer that he comes from and returns to a place of fire, a compressed place, 12 a place no creature can see and an unclean place. S. Lieberman suggests that the first statement is typically Gnostic (that humans originate from light) and the next three are anti-Gnostic refutations emphasizing the humanity and lowliness of humans. 13 Whatever the interpretation, Akabya's questions provoke confusion and response. A second saying by simeon takes the safe course of urging good actions in this life while there is opportunity.

Ch. 32 is completed by a group of ten sages and their sayings; some of the sages are repeated, so there are only seven sages cited in toto. The editor of ARNB used PA $1: 16-18$ and $2: 1-4$ a but he became confused about the identity of the Princes listed there and could produce no clear sequence. He cites Rabban Gamaliel, Simeon his son (PA 1:16-17), then PA 1:18 in the name of Rabban Gamaliel (not Rabban simeon as in $P A$ ), producing an alternation of names. Rabbi Judah the Prince (PA 2:1) follows and then Rabban Gamaliel (PA 2:2) who is not here identified as the son of Rabbi Judah the Frince. Two other sayings are attributed to Rabban Gamaliel and then PA 2:4a is attributed to Rabbi Judah the Prince (not Gamaliel as in PA) along with some other sayings. The editor of ARNB has understood the Gamaliel following Judah the Prince to be Gamaliel II and then he has repeated Judah the Prince again after him to complete the chronological sequence.

The editor of ARNB uses this collection of sayings attributed to ten sages to stress Torah, keeping the commandments and God's 
will, sin and judgment, worldly occupation and praiseworthy public conduct. The thought of the section is loosely tied together, but has a generally coherent point and impact. ARNA, ch. 22 uncharacteristically stressed works, as a necessary prerequisite to Torah. ARNB moves implicitly along these lines.

Chapter 33 treats three of those who entered the garden: Akiba, Ben Zoma and Ben Azzai. Each is presented more briefly than in ARNA with only a few central sayings. In ARNB the Hellenistic flavor of their core sayings, shared for the most part with ARNA, is patent. Akiba begins with five hedges, six admonitions and five descriptions of those whose capacity for study and virtuous life is limited. Akiba's hedges recall the hedges at the beginning of ARN. The admonitions lack the theme of the superiority of the Holy Land which is expanded in ARNA. They merely warn against occasions of sin; the sixth is drawn from PA 2:5, "Where there are no men, strive to be a man." The third saying, in the name of Hillel in PA $2: 5$ and in the name of Akiba in both versions of ARN, describes those whose limitations make them unfit for the life of the Rabbinic school: "The timid cannot learn...The Am HaAretz cannot be an observant saint." Further sayings, collected in ARNA, do not appear here.

Ben Zoma follows Akiba's five unfit types of people with descriptions of four admirable types: the wise, honorable, mighty and rich. This group of questions and answers about how a type is defined matches the stoic literary form of paradox. ${ }^{14}$ The mention of the rich leads into the next saying, a sorites which in context functions against covetousness by warning about going into another man's orchard, touching, taking, etc. This enigmatic saying may have originally referred to care in entering into mysticism ${ }^{15}$ or been a polemic against Epicurean hedonism. ${ }^{16}$ Ben Azzai continues the theme of warning by designating a couple of good signs and a bad sign. This theme is found in Epicurean literature. 17 Next Ben Azzai warns against sin, noting that one sin leads to another. This warning is similar to the Epicurean and stoic rhetorical instruction on what to flee and choose. ${ }^{18}$ one other saying, about taking a lower place (Prov. 25:7 is quoted) also has parallels in Epicurean asceticism. ${ }^{19}$ Many of these parallels are commonplace in ancient wisdom, ethics and scholastic traditions and precise lines of influence cannot be claimed. Rather, the Rabbinic tradition existed within a larger cultural milieu and drew indirectly on many sources to expound and reinforce its insistence on Torah, 
study and good behavior. In this section behavior receives more emphasis than Torah.

Ch. 33 ends with seven sayings, initiated by that of Rabbi Nehorai and including PA 4:14-18 and 4:10. Nehorai heads a totally different group of seven sayings in ARNA, ch. 23. The sages include an Amora, Jannai, one of only three Amoraim quoted in ARNB. 20 Several themes are woven through the sayings: Torah, tranquility, the world to come and good behavior.

Ch. 34 begins with Dosa ben Harkinas who is associated with the sages found in ch. 32 (Akabya, Nehunya, etc.) in PA and in ARNA but who is here isolated from them among the four who entered into the garden. Why Dosa is found here is not clear. His saying occurs as one of an initial group of five sayings, two by him and three on assiduous study of Torah taken from PA $3: 2,3$ and 6 . The three sayings on Torah implicitly refer Dosa's general warning against midday wine, etc. to the specific danger that they will interfere with study of Torah. The theme of study of Torah continues through a good part of the chapter showing that the editor of ARNB interpreted Dosa's saying as an aid to that discussion.

The rest of ch. 34 contains a complex of sayings, names and themes found also in PA, chs. 3-4 and ARNA, ch. 29. It is possible to discern only some of the blocks of material and connections that have given the materials their present form. Presumably the authors of the two versions of ARN and of PA were drawing on com-mon sources, but the shape and purpose of those sources is lost to us. Levitas of Jamnia and Mattiah ben Heresh ennunciate three sayings which teach humility because of the low state of humans. It is possible that Levitas' saying originally followed the last saying of ch. 33 since they contain the same expression, "humility of spixit," (špl rwh in ch. 34 and šplwt rwh in ch. 33) If these two sayings were originally adjacent, then Dosa with his attendant sayings was inserted into his present position at a later stage in the development of the tradition. The next group of seven sayings, drawn mostly from $P A$, chs. 3 and 4 , continues the themes of Torah, its relation to works and study. Some attributions vary in other sources either because of similarity of names or other reasons; for example, the seventh saying about good works and Torah occurs in Elisha ben Abuyah's name in ARNA, ch. 24 but in Simeon ben Eleazar's name here. One may suspect that the editor of ARNB wished to confine Elisha to the final chapter of this section, ch. 35 . 
After the seven sayings on Torah and study comes the only passage of explicit commentary in ch. 34: Rabbi Nathan's saying on honor among disciples and masters (PA 4:12). The themes of masters, disciples and Torah above pertain to the school setting so dominant in earlier sections of ARN. The theme of honor draws in a discussion of honoring and reviling others according to God's wishes, a discussion found in ARNA, ch. 29, with Moses and Balaam as the examples. In ARNA, this passage is attributed to Eleazar Hakkappar, who immediately follows in ARNB. Eleazar Hakkappar and his son Eliezer close out chapter 34 with justice, judgement and the world to come, themes common to the end of a section in Rabbinic literature. Ch. 34 is marked by a diversity of theme, though Torah and associated subjects proper to a school dominate. The author of ARNB has woven together sayings from several parts of the tradition into a loose unity. In this he has acted similarly to the author of ARNA in chs. 27-30, using some common material, but going his own way.

The final chapter before the enumeration sayings, ch. 35, is reserved for the apostate Elisha ben Abuyah who is not dropped, but rather set apart. Unlike ARNA (ch. 24), ARNB does not give a whole chapter to Elisha. Rather, one saying is recorded with an explanatory parable. The saying concerns studying in one's youth, something Elisha did; but the parable ironically speaks of guarding everything in Torah, something Elisha failed to do. The rest of the chapter is then given over to sayings by several sages. The final three sayings by Judah and Jose at the end of the chapter return to the theme of Elisha's saying, studying Torah in one's youth, and form an inclusion with the beginning.

At the beginning of ch. 35 Elisha is followed by Reuben ben Astroboli to whom are attributed three sayings concerning trustworthiness and honoring parents. These topics stand in implicit contrast to Elisha's behavior. The center of the chapter contains a series of nine sayings attributed to different sages and mostly concerned with study and Torah. The two not related to Torah are associated with the sayings previous to them by theme or catchword. Some of the nine are from PA and others are found in ARNA, ch. 27, thus indicating that all sources have drawn upon a common fund of sayings and shaped them for their own purposes, just as happened in ARNB, ch. 34 and parallels.

After the nine sayings on Torah and assoicated topics Akiba enunciates five sayings, the first listing three human interactions to avoid and three to become involved in and the next four 
(all in the same pattern) cataloguing Scripture's punishments for four groups of sins. These lists of items are like exhortations and observations attributed to Akiba at the beginning of ch. 33 and they function as an interlude before the final five sayings on Torah. Of the five, two concern Torah and works and the final three concern studying Torah in one's youth to form an inclusion with the initial saying.

Chs. 32-35 are much less well organized than the first 31 chapters of ARNB, just as the later chapters of ARNA are less well organized than the earlier. Many sayings and groups of sayings are common to $P A$ and the two versions of $A R N$, but the authors and editors of each work have used the materials in independent ways. Because there was no organizing principle such as the chain or the group of five disciples of Johanan ben Zakkai, no common structure emerged in these later chapters of ARN. Sayings have often been collected in groups of three, five and seven and seldom do they have any direct commentary. Torah, study of Torah and matters proper to disciples and schools predominate in these chapters, but these themes do not control the subject matter. These chapters function as appendices to the earlier parts of ARN and PA, reiterating the necessity for Torah and for behavior based on Torah. In certain parts, especially those connected with Ben zoma and Ben Azzai, Hellenistic forms of expression make themselves strongly felt, as they did in the materials associated with Johanan ben zakkai and his disciples. The purposes and interests manifested in ARNA, chs. 19-30 and ARNB, chs. 32-35 continue those in the earlier chapters, but they are less urgent and more diffuse. 


\section{CHAPTER EIGHT}

\section{THE ENUMERATION SAYINGS}

The final chapters of $P A$ and ARN consist mostly of enumerations, that is, lists of items which begin with an interpretative remark stating the number of items in the list and describing the nature of those items. The final sections of each work, PA, ch. 5, ARNA, chs. 31-41, and ARNB, chs. 36-48, differ starkly from the preceding chapters because of the dominance of enumerations and consequently are often treated separately as additions. (PA, ch. 6 is universally recognized as a late addition to PA for liturgical purposes.) However, the enumerations are integral to the works as we have them and they will be related to what has preceded through theme and function. Some general comments on the nature and functions of enumerations in Biblical, Rabbinic and other literature will prepare for an analysis of the functions of enumerations in ARN. ${ }^{1}$

Most of the sayings in this section of ARN are enumerations with a scattering of non-numerical sayings. Most of the enumerations are anonymous because they are a listing of what is either in scripture or in nature. The items listed are not matters of learned opinion needing interpretation, but simply observations of the world around us or of scripture, open and patent to all. The enumerations are a type of list. Lists are used in many cultures to catalogue, present and preserve matters of importance and interest. Continuity, authority and education demand the construction of lists, such as the alphabet, numbers, lists of the Presidents of the USA and the top forty popular recordings. The chain of tradition is a list which is not itself reported in the name of any sage (though it contains numerous authorities); rather it is stated as a fundamental and obvious fact.

The enumerations share with the rest of PA and ARN an interest in those aspects of Judaism which are early and fundamental. Just as the chain of tradition goes back to sinai, the materials about Johanan ben Zakkai go back to the foundation of the Rabbinic school and the sayings of the early sages back to the formative period of Rabbinic Judaism, so the enumerations gather information about creation, Abraham, the Exodus, Jerusalem, the Temple, human nature and sin. The foundations of the world and of Judaism are presented and sometimes expounded through commentary and exegeses. All these subjects are connected to scripture through constant 
citing of proof texts and phenomena in Scripture which illuminate aspects of life. The enumerations serve as a review of all that is basic and essential in life as propounded in ARN as a whole.

W.M.W. Roth in a form critical study of enumeration sayings in the old Testament reviews both the old Testament and other ancient literature, including Rabbinic literature. He divides the enumerations into three major groups: Narxative Numerical Sayings; Reflective Numerical Sayings; Hortative Numerical Sayings. Narrative numerical sayings are characterized by their setting and are divided into genealogical groupings, social groupings and geographical groupings. Reflective numerical sayings treat nature, society, humanity, history, canonical scripture and theology. Hortative numerical sayings cover legal requirements, ritual requirements, covenant stipulations and wise counsel (typical of Proverbs). Roth contends that the enumerations exhibit a serious, philosophical tone aiming at mastery of life and world. ${ }^{2}$ He also characterizes the enumerations as a

"frame pattern, i.e. a pattern which frames several items into a coordinated whole. Its setting in life are those situations in human life when elementary items of information, knowledge, or ethics are to be grouped together as of equal importance. Broadly speaking it can be said that whenever human reflection is at work by way of ordering and classifying, the pattern of the numerical saying offers itself as that genre which most readily and adequately fixes the results of such reflection. Hence the pattern is basically a philosophic-didactic genre; philosophic, in that it is the outcome of a simple form of philosophy, attempting to understand and to master life and world, didactic in that such formulation is meaningful only if it aims at framing and fixing once for all the results of reflection, to be retained in oral or literary tradition." 3

Roth's conclusion concerning the enumerations found in Scripture, especially in the wisdom literature, correspond with the data found in ARN. The enumerations in ARN aim at mastering life and the world, but even more at mastering scripture itself which gives insight into and authority for the Rabbinic way of life and view of the world.

Deeper implications of lists for cognition and culture have been expounded by J. Goody. ${ }^{4}$ Goody's main thesis is that the development of literacy in a society changes both the ability of people to know and the actual way that they know. Specifically, 
the technology of the written list produces new learning because items graphically represented on a page in hierarchical order (vertically) or as equivalents (horizontally) form new categories and can be manipulated in new ways. The decontextualization of concrete items produces abstraction and reflection with resultant sharper classification, but also the reduction of multiple qualities to quantity. For example, lists of events (annals, chronicles, king lists) helped to produce history from the flow of events and from the imprecise grasp of the past contained in oral myths. Goody has found such phenomena in ancient Near Eastern literature and also in modern African cultures.

In his study of Rabbinic examples of the enumeration form W.S. Towner argues that the proverbial form of the enumeration (a list of things without corroborating prooftexts from scripture) precedes the exegetical form (with prooftexts) because the proverbial form is so widespread in time and place. ${ }^{5}$ The Rabbinic use of lists with prooftexts is a specialized form of the enumeration which fits general tendencies in Rabbinic culture and literature. Towner has used studies of oral tradition to show how the shift has taken place. Rule A suggests that two similar patterns (the proverbial and the exegetical) will assimilate to one another; Rule $B$ suggests that the stronger pattern (the exegetical form, in Rabbinic circles) will dominate the weaker; and Rule c suggests that early loose traditions will be regularized according to the dominant pattern (Biblical verses are often added to lists.) ${ }^{6}$

The exegetical enumeration forms are divided into six categories: common-sense analysis of an individual text (four groups of Israelites at the Red sea); hermeneutical analogy (in three places God warned Israel not to return to Egypt); lexical analogy (seven clouds: Stichwort); syntactical analogy (three things named after Moses because he devoted himself totally to them); legal analogy (three nonvoluntary "ifs" in Torah); and technical exegetical analogy (the five uncertain syntactical constructions in Torah.) Throughout these six functions of the exegetical enumeration, the form remains the same even though the functions become more technical and less haggadic, more mnemonic and less exhaustive in their listings. The haggadic functions (e.g., hermeneutical analogy) are closer to the earlier proverbial enumeration forms; the technical functions (e.g., legal analogy) are closely tied to the language of the text and to Rabbinic concern with preserving and interpreting the sacred words. Surprisingly, even these technical, mnemonic functions, which we would expect to be precise and unchanging, exhibit as much modification and development in 
transmission as the more haggadic functions. ${ }^{7}$ The many variations in the contents of the lists argue that Rabbinic enumerations are literary, at least as we have them now, and not primarily an aid to exact memory. All of the categories distinguished by Towner occur in $A R N$ where they serve various functions according to their context.

Most of the enumerations in PA, ch. 5 are found in ARN. The two versions of ARN contain many other enumerations common to both. Yet, each version has organized the materials differently and each contains much unique material. As Towner noted in the Mekilta, so here the number at the head of the lists and the remarks which characterize the items in the lists are very stable, but the members of the lists vary. In addition, some lists announce a certain number of items, but contain more or less than that number.

\section{$A R N A$}

ARNA, chs. 31-33, each begin with a major event or figure and each chapter is filled with material which expands on the topic and functions as a commentary or explanation. Ch. 31 begins with the ten words used in creation, ch. 32 with the ten generations from Adam to Noah and ch. 33 with the ten generations from Noah to Abraham along with further groups of ten concerned with the Exodus. Chs. 31 and 32 are devoted entirely to teachings and exegeses concerning creation and the flood. Ch. 33 speaks of Abraham's obedience and charity and then enumerates the ten trials of Abraham; it notes that in Egypt there were ten miracles for Israel and ten plagues for the Egyptians and at the sea the same. The ten plagues on the Egyptians are developed at length though only six are described. The chapter ends with dialogue between Moses and Israel in which Israel resists crossing the sea. The groups of ten in ch. 33 themselves number seven, another favorite number in this section and Rabbinic literature. These groups of ten summarize the situation of humanity and the Hebrews up to the formation of the people of Israel in the wilderness at sinai.

Ch. 34 contains ten groups of ten, beginning with the ten trials with which Israel tried God in the wilderness. A brief exegesis of Dt. 1:1 provides warrant for the ten trials. The other groups of ten, all of which are followed by Biblical verses or words which support them, concern ten names of praise for God and ten names of contempt for idolatry, ten dotted passages in Scripture, ten descents and ten ascents of the Shekina, ten names for prophets and for prophecy (prophecy is called the Holy Spirit), 
ten names for gladness and ten who were called living. The references to God, idolatry, the Shekina, prophecy and the sins of Israel in the desert all recall God's revelation to Israel on Sinai which is the foundation of the people Israel. Torah is the revelation and all these enumerations indirectly point to aspects of Torah and revelation. In addition, ch. 34 contains a list of the eleven passages where $h y^{d}$ is used for $h w^{d}$ (only ten verses are cited), the two inverted nuns (Num. 10:35-36) and the suspended Ayin (Ps. $80: 14)$. They were attracted to this chapter by the list of ten dotted passages in Scripture and they all manifest the Rabbis' determination to safeguard the revelation given on Sinai.

Ch. 35 continues the groups of ten and the emphasis on fundamental aspects of Judaism. It presents three lists of ten things associated with Jerusalem and the Temple: miracles done for former generations in Jerusalem, things said of Jerusalem and miracles done for former generations in the Temple. The lists actually contain eight, fifteen and eleven items respectively. They manifest the desire to say as many marvelous things about Jerusalem and the Temple as possible, especially since their destruction. Items are gathered even if the limits of the traditional number ten cannot be maintained.

Ch. 36 completes the discussion of the basic phenomena which support and give shape to Israel. It begins with five groups who will neither gain life in the world to come nor be brought to judgment. (The number five is not explicitly cited.) The claim for each is validated by an appeal to scripture and variant opinions and explanations follow each. The discussion of life after death completes the sequence of subjects which began with creation in ch. 31. Ch. 36 ends with two groups of seven who will have no share in the world to come; both the number seven and the reference to the ultimate destiny of humans lead smoothly into chs. 37 and 38 which contain mostly groups of seven and are concerned with human types and human behavior.

Ch. 37 begins with seven things, one created superior to the other; for example, stars are superior to the firmament. The final comparison concerns the superiority of the ministering angels to humans. Mention of the ministering angels and humans leads to two further comparisons in which humans are said to be like ministering angels in three things and unlike them in three and then are said to be like and unlike demons in three things. These comparisons establish the relative places of the important elements of the universe and humans in particular. Humans may come to know who they 
are by locating themselves in the hierarchy of the universe and comparing themselves to angels.and demons. These reflections continue in the rest of ch. 37 which consists of ten groups of seven: seven types of pharisee, seven things beneficial to humans in small quantity, seven types of wisdom used to create the world, seven qualities (or virtues), seven levels to the universe, seven heavens, seven names for the earth, seven distinctions between the righteous and others, the seven hermeneutical rules of Hillel and finally the seven qualities which characterize the wise man (PA $5: 7)$. The last group of seven qualities is explicated by appropriate examples and verses from scripture.

The development of the nature of the universe and the qualities of a wise man (ch. 37) contrasts with a list of seven kinds of calamity which come upon the world for seven kinds of transgression (ch. 38). This saying is found in PA 5:8 immediately after a saying which ends ARNA, ch. 37. Four of the calamities and transgressions receive explanation through sayings or Biblical verses. The theme of $\sin$ in ch. 38 logically leads to repentance in ch. 39, which functions as an appendix to $\mathrm{ch} .38$. Ch. 39 begins with a list of five types who will not obtain forgiveness. PA 3:15-16 concerning judgment follow, along with other sayings on repentance and judgment. PA $3: 14$ on the dignity of humanity and a saying by Eliezer ben Zadok on the righteous and wicked complete the discussion. The chapter ends with three lists of six names each for the lion, serpent and Solomon; these are disconnected from the rest of the chapter. They are probably here in numerical order between groups of seven in previous chapters and the fours and threes which follow in the last two chapters.

The themes of judgment and repentance from ch. 39 are continued in the initial pair of fours which open ch. 40 . The list of four things which give humans reward in this world and the next are drawn from $m$. Peah $1: 1$ and $t$. Peah $1: 2$. These two groups are expanded by $t$. Peah $1: 2$ and other comments on virtue, sin and repentance. The heart of ch. 40 lies in seven groups of four most of which distinguish types of disciples and sages. The last of the seven groups lists four sages and the appropriate interpretation if one sees them in a dream. This last group of four prompts three groups of three (scholars, prophetic books and writings) which have a certain import when seen in dreams. The end of the chapter contains several sayings not organized into numerical groups. ${ }^{8}$ The final three sayings, all from PA $(5: 16 ; 17 ; 4: 11)$ discuss proper motivation for love, controversies and assemblies. 
All these sayings fit generally with the themes of human types and behavior, but they are not tightly structured into a whole.

The final chapter of ARNA, ch. 41 , begins with a characteristically heavy emphasis on study of Torah. PA 4:13, which also appears at the beginning of the final chapter of ARNB, mentions the crowns of priesthood, royalty and Torah. The author of ARNA has used the saying to point out that the crown of Torah is superior because it is open to all who study assiduously. Seven groups of three items follow, similar in theme and function to the seven groups of four in the preceding chapter. The groups of three characterize humans, scholars, physical phenomena associated with humans and finally earthenware and glass vessels. These themes continue in two groups of four: four times when cohabitation is harmful and four requirements to become an associate (hinted at already by the characteristics of vessels which are subject to impurity.) ${ }^{9}$ The final section of the chapter lacks tight organization according to numerical groups, as did the previous chapter. One possible group of three, some unnumbered sayings, two groups of five and one of six lead to a final controversy between the schools of Hillel and Shammai concerning the fate of the mediocre at the judgment, a fit theme for the end of a Rabbinic document of Torah and human behavior. As is traditional, PA $6: 11$ concludes the text.

\section{ARNB}

The enumeration sayings comprise fully one third of ARNB, a much larger proportion of the whole than in PA and ARNA. The enumerations are more loosely edited here than in PA and ARNA and they have a less sharp impact on the reader. Lists with ten items begin the enumerations and numbers descend to lists of three in the final chapters, but the descending sequence is interrupted frequently by lists of eighteen and twelve and by smaller sequences of seven, six and five items. Most of the material in PA, ch, 5 and ARNA, chs. $31-41$ is found in ARNB, chs. 36-48 but the order often differs and the lists are not integrated one with the other in the same way in all the sources. ARNB quotes Biblical verses more consistently and voluminously than ARNA. Though ARNB is less tightly edited than ARNA it does have some chapters and sequences of lists which fit logically together. Many other lists have been added because such lists were very popular and abundant in the tradition.

The comprehensive organization of ARNB, chs. 38-48 may be seen in the numbers which dominate the chapters: 
TENS: $36-39,40$ (?), $42 \mathrm{~b}, 43 \mathrm{a}$

SEVENS: 40 (?), 41,43 end, $45 a$

FIVES : 44

FOURS : $45,46 \mathrm{~b}$

THREES : $45,46,47,48$

Note that the descending order of numbers is not wholly consistent. In addition, many chapters have other numbered groups in them, especially ch. 43 which contains groups of ten, two, seven, three, eighteen, twelve, six, five, four and three.

Ch. 36 is constructed with six groups of ten which cover creation, the early generations up to Abraham and the Exodus up to the crossing of the Reed sea. Three of the six lists are itemized. The treatment of these lists is much more brief here than in ARNA, chs. 31-33. Ch. 37 contains eleven groups of ten phenomena, words or events found in scripture. Eight of the eleven are itemized with most supported by Biblical verses. The lists are: ten changes made in the septuagint (eleven are actually listed), ten things originally planned by God (Sabbath, Jerusalem, the light of the just, etc.), ten things created at twilight of the sixth day of creation, ten names for prophets, ten names for prophecy, and ten who were called men of God. The final five lists are introduced together and then three of them are itemized (ten descents, dotted passages, vigils, interruptions and generations in Torah.) The lists cluster around scripture and catalogue things found there. Ch. 38 repeats the types of material found in the previous two chapters: the ten trials in the wilderness, ten miracles at the sea (out of place?), ten names of praise for God, ten names for idols and ten things which are the equal of all transgressions (the Shema, tithes, etc.). These five lists of ten are followed by a list of the eleven places in scripture where hy $\downarrow$ is used for $h w^{\prime}$ (ten are actually given, as in ARNA, but one entry differs from ARNA). Lists of two men whose lives spanned twenty-four generations and seven men who covered the whole history of the world end the chapter. Lists concerned with early events in Israel's life at the beginning of the chapter and the two lists covering the span of world history at the end bracket several lists of items found in scripture. Ch. 38 lacks unified composition, though its contents continue the themes found in the previous two chapters.

Ch. 39 speaks of one theme, Jerusalem, in five lists of ten items each: ten miracles done in Jerusalem, ten at the Temple, ten names of praise for Jerusalem and ten of contempt and finally, ten things in which Jerusalem excels other lands. Each list is 
itemized and each actually contains ten items, in contrast to parallels in ARNA, ch. 35. The list of miracles at the Temple is followed by a further unnumbered set of eight wonders associated with the sounds and smells of the Temple. The first series of lists in chs. 36-39 concern mainly the fundamentals of the world and Israel, as they did in ARNA.

Ch. 40 describes the qualities of the wiseman and the contrasting characteristics of the clod, a list which contains seven items in PA 5:7 and ARNA, ch. 37. However, ch. 40 of ARNB announces that there are ten qualities which characterize them, actually lists eight in the saying and finally gives comments and explanations for nine qualities. The presence of lists of ten in the previous chapters has influenced the beginning of ch. 40 , as has the availability of extra descriptive characteristics for expanding the list and commentary.

Ch. 41 describes each of the seven calamities which follow seven kinds of sin (PA 5:8-9 and ARNA, ch. 38) and the four periods when pestilence is on the increase (PA 5:9b). The seven calamities are proven by Biblical verses. The four periods of pestilence are followed by seven statements (without an opening exegetical comment or number) designating in great detail the punishments for certain sins. As ch. 40 described humans when they behave well, so $c h .41$ describes them when they behave badly. The theme of humanity's misbehavior continues in ch. 42 which examines the origins of sin. After some numbered items concerning creation (three entered to be judged and four emerged: Adam, Eve, the serpent and the earth; the 12 hours of Adam's creation), the bulk of the chapter explains the ten decrees given by God against Adam, Eve, the serpent and the earth.

The recurence of groups of ten at the end of ch. 42 continues at the beginning of $\mathrm{ch} .43$ with three groups of ten: ten who prophesied and did not know it, ten names for the earth and ten things by which the world was created (wisdom, knowledge, etc.) The theme of the origin and structure of the universe continues in two brief lists, two things that continue 500 years (and are stable like the universe) and seven things that are superior one to another. The seven of the last list are followed by seven rich gifts of the just in the world to come and that list by three companies of the just. Mention of the just leads to several lists of those favored by God in Scripture: eighteen called servants, twelve called chose, six called beloved, and five called loved ones. The 
descending numbers of this sequence continue in two more lists, four called fire and the four banners at the throne of glory.

Ch. 43 continues with another sequence of descending numbers: twelve called living, six called full, and four who were told to ask, four of whom it was said "in good old age" and four called Cushites. The chapter ends with three groups of seven: seven names for lions, seven for a poor man and seven for a serpent. (ARNA, ch. 39 ends with six names for lions, serpents and solomon.) Groups of seven will occur again in ch. 45 . But first ch. 44 intervenes with three groups of five (one without an exegetical comment), some sayings on judgment and nine statements about Israel (again without exegetical comment.) The themes of these lists repeat concerns which arose earlier. For example, five expressions in Torah which need their syntax clarified, five instances of inference from the lesser to the greater in Torah and an unnumbered group of five places where reference to God was removed to avoid blasphemy. All are technical lists concerned with interpreting Scripture. The themes, judgment and the attributes of Israel (beloved, servants, etc.), have been seen before.

Ch. 45 continues the discussion of human nature and human types begun in chs. 40-41 and here as there a list of seven introduces the chapter. Seven types of Pharisee are listed but many of the designations are obscure and it is not even certain whether some are laudatory or pejorative. Immediately following are three characteristics of a disciple of Abraham, three of a disciple of Balaam (PA 5:19) and then PA 5:18, "If one leads the multitudes to virtue, through him shall no sin come; if one leads the multitudes to sin, through him shall no virtue come," which implicitly refers to Abraham and Balaam. As a further explanation of Balaam and Abraham, ch. 45 lists four who erred in vision (Adam, Cain, Balaam and Hezekiah) and three who conceived evil plans, contrasted with three who conceived good plans. This discussion of good and evil behavior concludes fittingly with three groups of three who engaged in certain behavior and then inherited or failed to inherit this world or the world to come. Ch. 45 ends as it began, with types: seven groups of four types including groups such as givers of charity, disciples, women, etc.

Ch. 46 begins with non-numerical sayings which distinguish assemblies and controversies which are and are not for the sake of heaven. After the significance of four groups of three figures who appear in dreams has been elucidated, ch. 46 continues the analysis of types of people and behavior using non-numerical 
sayings and then two lists of four. The chapter ends with a list of the three Torah scrolls kept in the Temple. Ch. 46, like ch. 38 previously, lacks coherence.

Ch. 47 contains seven lists of three items. Some are types found in Scripture (prophets, those who wept and God heard them) and some are observations of life. Ch. 48 continues the threes with ten lists of three. This final chapter begins with the three crowns of Torah, priesthood and royalty, as did the last chapter of ARNA, but here the saying is not oriented so strongly toward Torah as in ARNA. The other groups of three concern things which nurture the body, increase the sperm, increase excrement, etc. These folk observations are continued in the sequence of eleven sayings which contain a number but are not exactly enumerations: each saying claims that there are ten portions of something in the world, nine in one spot and one throughout the rest of the world. For example, "There are ten portions of foolishness in the world, nine among the Babylonians and one throughout the rest of the world." Jerusalem is both praised and blamed and the concluding claim concerns Torah: "There are ten portions of Torah in the world, nine in Jerusalem and one throughout the rest of the world." ARNB concludes with the exhortation of Judah ben Tema (PA 5:20a) to be strong and swift to do God's will and a saying about scholars increasing peace in the world which traditionally ends tractates. 10 The editors of ARNB did not completely tame the profusion of lists in chs. 36-48. There are several sequences of descending numbers which introduce the lists and some chapters have a controlling theme, such as human behavior, groups and types found in Scripture, Jerusalem, etc. Other chapters lack any discernable unity and many lists lack an appropriate context. Most probably the core of lists common to PA and both versions of ARN were added to from many sources and by many editors over a long period of time. Any plan or purpose originally embodied in these final chapters as a whole has been lost. 


\section{CHAPTER NINE}

\section{LITERARY CONCLUSIONS}

A number of brief generalizations concerning the relationship among the three texts, PA, ARNA and ARNB, will pull together the major data and conclusions established in preceding chapters. The similarities and differences among the texts compel us to posit a complex growth for these traditions. Several sections in each version will be examined to see what relation they have to the Palestinian and Babylonian Talmuds, since we know the approximate dates for these documents and something about their development and editing. Finally, some suggestions will be made concerning the oral and literary development of $\mathrm{PA}$ and the two versions of ARN in the light of ancient Mediterannean culture. These conclusions reached on the basis of the texts will serve as a foundation for hypotheses in ch. 10 concerning the historical setting and dates of the texts.

\section{simizarities}

The two versions of $A R N$ and Mishna Tractate Abot share a great fund of common sayings, stories and exegeses. Most of PA is Found in each version of $A R N$ and in the sections on the chain of tradition and on Johanan ben Zakkai's disciples PA serves for the most part as the text on which ARN comments. In all sections of ARN the two versions have comments, stories, exegeses and sayings not found in $P A$, and often not found elsewhere, which form the core of both versions. This common material is especially striking in the first two sections, the chain and the Johanan section. These first two sections also follow the same order and structure and seem to have the same purpose. The third section on the early sages varies greatly in order, structure and point in the two versions of ARN and in PA, chs. 3 and 4 . Though most of the sayings in $\mathrm{PA}$, chs. 3 and 4 are found in ARN, they have been rearranged into very different structures and used for purposes peculiar to each document. The two versions of ARN have some common material not found in $P A$, but the order of the materials (mostly sayings) and their functions differ greatly. The final sections of all these works, containing enumeration sayings, exhibit the same characteristics as thesayings of the early sages. The enumerations and other sayings presented in $\mathrm{PA}, \mathrm{ch} .5$ reappear for the most part in both versions of ARN but they are structured 
and handled differently. ARNA follows PA more closely and is edited more tightly than ARNB. ARNB has many more enumerations than ARNA, but the organization and purpose of the enumerations remain unclear.

Almost every chapter in both versions of ARN mentions Torah or a related theme and many chapters have Torah as the central theme. Themes unrelated to Torah occur in ARN and even dominate in parts of chapters, but these themes are isolated and have no coherent effect on ARN as a whole. The authors and editors of ARN chose and organized their diverse materials to explain Torah and encourage its study. Torah is, of course, not only scripture or the Pentatuech, but tradition, revelation, the commandments from God, the interpretations of the Rabbis, etc. Related themes are study of Torah, the master-disciple and disciple-disciple relationship, ethical behavior, virtues demanded by Torah or by a life of communal study, good works, deeds of loving kindness and their results such as peace. Various Biblical and Rabbinic figures exemplify Torah, study and virtue in sayings and stories, for example, Moses, Aaron, Hillel, Johanan ben Zakkai, Akiba, Eliezer, et al. Special emphasis is given to questions concerning God, apologetic questions, and the source of authority for Torah and its interpretation. ARN also develops the coordinate themes of obedience to God and obedience to the rules of the Sages which interpret the commandments of God. All of these themes and strictures are supported by exegesis of Scripture, parables, life experience and wise sayings. This complex of themes centered on Torah strongly suggests a school setting for ARN, a conclusion which will be summarized in the following chapter.

\section{Differences}

PA and each of the versions of ARN stand as independent and individual literary works, despite their many and deep similarities. In ch. 2 we already pointed out that PA is a sayings collection and that its wisdom sayings are organized to establish the authority of a continuous and coherent group of teachers and teachings and that it is centered around the major emphases of that group, Torah and Torah study. Virtually everything in chs. 1 and 2 furthers that aim and most of chs. 3, 4 and 5 are equally focused on the main theme and purpose. The two versions of ARN are longer and more diffuse than PA and so lack its spare and pointed form. Some parts and especially the chain of tradition 
is a commentary on PA. In later chapters elements from PA are simply mixed in with other similar sayings. Sometimes a saying from PA will initiate a series of relevant and related sayings, stories and exegeses and other times sayings from PA are not marked out from surrounding material in any other way. Certain sayings occur with variants, minor and major, in ARN. Consequently, though both versions of ARN are related to PA, they are not simply a commentary on it, especially not a commentary on Tractate Abot as it exists in the Mishna.

Some differences between the two versions of ARN can be easily discerned, especially digressions and collections of sayings proper to only one version. For example, ARNA adds extensive materials on Adam and his creation when treating his hedge in ch. 1 . Likewise, ch. 3 contains many stories and sayings concerning Akiba as an example of poverty in study. Stories concerning Moses and associated figures are added to the saying of Nittai the Arbelite (ch. 9) on an evil neighbor and to Hillel's sayings (ch. 12). Ch. 18 on Judah the Prince and chs. 27-30 are both collections assembled by the authors and editors of ARNA for their own purposes. ARNB expands on the events during and after the siege of Jerusalem (ch. 7) and on creation and male and female (chs. 8-9). It has a separate collection of sayings by Johanan ben Zakkai and Hillel in ch. 31 and many more enumeration sayings in chs. 36-48 than are found in PA and ARNA. In addition, each version has separate organizational principles in the sayings of the early sages (cf. ch. 7).

Less massive differences and nuances have been pointed out for many passages in chs. 4-6 above. The change of a word or phrase and the addition of a comment often turns a saying towards study of Torah or a related theme. An apologetic note may modify the thrust of a section, such as ARNA's assertion (ch. 2) that Moses did not really decide four things on his own, but acted on direct divine command. ARNA also changed the order of hedges in ch. 2 to place Torah in a more prominent place. ARNB relies on lengthy interpretations of scripture to make its point in chs. 4 and 5 .

$\mathrm{J}$. Goldin analyzed over a dozen passages found in both versions where ARNA emphasizes study of Torah and ARNB good works and "piety." 1 He also notes many other passages on the same topics and some passages found in only one or another version. Goldin is correct that the final forms of ARNA and ARNB manifest differ- 
different tendencies in many passages and it is especially clear that ARNA has turned some passages which refer naturally to good works toward study of Torah. That latex editors of ARNB have revised sayings to refer to good works is not so clear. Goldin's detailed study complements the analyses in previous chapters here. This study describes the overall emphasis on Torah, study and related themes common to both versions of ARN. Goldin demonstrates that later editors and authors of ARNA further developed and highlighted study of Torah as the essential for Judaism. Since ARNA enjoyed more currency in the tradition and was the version copied and read down through the middle ages, it is likely that the editors and copyists' interest in study manifested itself in modifications of the text.

\section{Relationship to the Talmuds}

Many of the stories, sayings, exegeses and parables found in the two versions of ARN are found elsewhere in Rabbinic literature. Consequently, ARN must be located within this larger literary tradition. Since a complete study of all the parallels between the two versions of $A R N$ and Rabbinic literature would fill more than one volume, some limited observations and explorations will be attempted here. Further parallels may be found in schechter's edition of ARN and Saldarini's commentary on ARNB.

The most logical place to begin a study of parallels to ARN would be the midrash. Both schechter and Saldarini cite many more parallels in the midrash than in the Talmuds. The contents of ARN are haggadic and similar to the contents of many midrashim. Consequently, ARN seems to have interacted with the midrash more than with the Talmuds. However, most of the midrashim lack firm dates and the processes which led to the collecting of their many exegesis sometimes produces a clear developmental sequence, but more often results in uncertainty.

The Talmuds will be more useful for our literary and historical inquiries into the development of ARN. We know that the Babylonian Talmud took shape from the third to sixth centuries and was further modified by the Seboraim and Geonim. Dependency in either direction can place ARN or its contents within the tradition. Though ARN is printed in the Babylonian Talmud, because PA lacks a Gemara, ARNA is not a proper part of the Talmud. Nor is ARN wholly derived from the Talmuds since it has only a limited number of parallels to them. We shall examine several sections of each version of ARN for Talmudic parallels. Our limited sample 
reveals that some traditions common to both are independent of one another in wording and form and others are virtually identical. In some cases the Talmud merely alludes to traditions which are fully developed in ARN. ARNA is a little closer to the Babylonian Talmud than ARNB, reflecting its association with the Talmudic tradition which caused additions to be made directly from the Talmud or from common sources and traditions.

Several examples of the relationship of each version of ARN to the Talmuds will be given. The first chapter of each version expands on the account of Adam's hedge with further accounts of creation and the sin of Adam and Eve. Version A especially draws together many stories, exegeses and explanations concerning this popular midrashic subject. Many of the subjects and observations in ARNA are found also in the Babylonian Talmud, but almost always in different words. This argues that both texts were influenced by current thought, but are not literarily dependent on one another; this is to be expected in a culture which was both oral and literary. Titus' entry into the Temple is paralleled by a more general story of a Greek king entering the Temple in $b$. Sukkah 56b; the ten curses placed on women are found in b. Erubin 100b. The decrees against Adam are recounted in b. Pesahim in different words. The idea of the excessive hedge erected by Adam is alluded to in b. Sanhedrin 29a as an idea already known. The story of Adam's sacrifice is told in different words in b. Abodah Zarah 8a. Both versions say that the serpent, had he not sinned, would have been a valuable pack animal but they vary in details of the tradition and its attribution. ARNA is closer to $b$. Sanhedrin $59 b$ and ARNB to $b$. Erubin 18a. Finally, both versions as well as ten other sources have a list of the events which took place in each of the twelve hours during the day Adam was created. Terminology and exact steps vary so that twenty-six different items are used. ${ }^{2}$ Most of the exegeses in this section are similar in all versions. ARNA is closest to, though not identical with, b. Sanhedrin 38b and ARNB stands independent. These results suggest that ARN has its own traditions, but that when additions have been made to ARNA, which was more actively read and copied in Rabbinic circles, they are influenced by materials in the Babylonian Talmud.

Both versions of ARN recount that Moses made a hedge about his words by adding a third day of purification for the Hebrew people at Sinai before the commandments were given (ch. 2). Then they add three more instances where Moses reasoned out an action and God agreed with him. Two Talmudic sources also have a group 
of three cases where Moses reasoned. The other cases are that Moses separated from his wife, broke the tablets and kept away from the tent of meeting. Their order is as follows:

$\begin{array}{llll}\text { ARNB } & \text { ARNA } & \text { b. Shab 87a } & \text { b. Yeb. 62a } \\ \text { third day } & \text { third day } & \text { third day } & \\ \text { separates } & \text { separates } & \text { separates } & \text { separates } \\ \text { breaks tablets } & \text { tent of meeting } & \text { breaks tablets } & \text { breaks tablets } \\ \text { tent of meeting } & \text { breaks tablets } & & \end{array}$

In both versions of ARN, the last three items are united under an introductory rubric which says that in three cases Moses reasoned for himself. In both Talmudic passages the introductory rubric lists the three items in the same order, separation, tablets, and third day, even though b. Shabbat does not follow that order in explaining each. Both versions of ARN use one of the cases as an example of the hedge; then they must add another case (keeping away from the tent of meeting) to make the following group equal three. ARNB and $b$. Shabbat have the same order for the first three cases. ARNA has moved the breaking of the tablets to last position so that it can add a group of apologetic materials to explain how Moses could do such a seemingly blasphemous thing. ARNA shows signs of later hesitations about these cases since additional materials explain that Moses did not really reason on his own, but was obeying commands of God implied by Scriptural passages. Both Talmuds cite Amoraic comments on these cases and present them with wording different from ARN. Moses' decisions are a popular tradition which each of the sources has modified and put to use in its own way.

In ARNA, ch. 3, which was specially edited to show Akiba as a model of study and good deeds, one story has a parallel in the Mishna and three have parallels in the Babylonian Talmud. The story of Akiba's judgment of a man who uncovered a women's head in the marketplace occurs in Baba Kamma 8:6. In three places ARNA makes the narrative more full or dramatic: the man's friend gives him detailed advice about what to do, the man's appeal to Akiba is more extensive and the ending is a dramatic confrontation, in contrast to the Mishna where the legal point is reinforced by another halakic example. It seems likely that ARNA has used a well known story, perhaps getting it directly from the Mishna, but has felt free to recast it slightly to fit its own character. ARNA, ch. 3 also has a series of three stories about good men. The first is about a charitable hasid who heard two spirits talking with one another in a graveyard and learned from them about the 
future. A fundamentally identical version of the story occurs in b. Berakot $18 \mathrm{~b}$ where the point is the obligation to pray when a member of one's immediate family is unburied. The second concerns an habitually charitable hasid who was lost at sea yet lived. Qoh. 11:1, "Cast your bread upon the waters," is used in the story. ARNA uses the story to encourage giving alms, a theme of ch. 3 . $B$. Yebamont 12la deals with the halaka about whether the wife of a man who has been lost at sea may remarry. Qoheleth Rabba groups this story under $11: 1$ along with other sea stories. Though Schechter (ad loc.) suggests that ARNA is a combination of the other two stories, the changes in the versions of the story suggest that each source has tailored the story to its own needs. Finally, a story about the charity of Benjamin the Righteous occurs in ARNA and $b$. Baba Bathra lla with minor variations. At some point the author or an editor of ARNA organized ch. 3 to make a special point (see ch. 4 above) and to that end collected together three traditional stories, using the Talmud or the traditions behind the Talmud as his source.

The story of Johanan's escape from Jerusalem occurs four times in Rabbinic literature: ARNA, ch. 4; ARNB, ch. 6; b. Gittin 56; and Lamentations Rabba $1: 5$ (31). These four versions fall into two parallel traditions: the two versions of ARN which have much in common and $b$. Gittin and Lamentations Rabba which have many similarities. Each version has its own peculiarities, especially Gittin/Lamentaions which have clear later additions. ${ }^{3}$ ARN carries an independent tradition which parallels the Talmudic.

In the descriptions of the siege of Jerusalem which follow the story of Johanan's escape (ARNA, ch. 4 and ARNB, ch. 7) each version of $A R N$ has arranged materials independently. Though some stories and exegeses are found in Talmudic sources, the forms and functions vary by source. At the end of ch.7, ARNA recounts that the doors of the Temple used to open by themselves during the night. B. Yoma $39 \mathrm{~b}$ recounts the same phenomenon, among several others, and says that Johanan ben Zakkai rebuked the doors so that they stayed closed, a detail lacking in ARNB. Both versions of ARN, b. Taanit 29a, and other sources, tell the story of the priests throwing the keys of the burning Temple back to heaven, saying that they had been unworthy. This story is told with minor variants in all versions. ARNA's application of Zech. 11:2 ("Wail, o cyprus tree, for the cedar is fallen.") to the Temple is also found in b. Yoma 39b. Finally, ARNA, ch.4 ends with the three things which distinguish one human from another, voice, taste and 
appearance, to form an inclusion with simeon the Just's three things on which the world stands at the beginning of the chapter. B. Sanhedrin 38 a has voice, appearance and mind with a different attribution and with a discussion of mind. The traditions associated with the fall of Jerusalem manifest no consistent dependence on Talmudic sources.

Both versions of ARN have stories concerning leading Rabbis. The beginnings of the careers of Akiba and Eliezer (ARNA, ch. 6 and ARNB, chs. 12-13) and a large group of sayings and stories concerning Hillel (ARNA, ch. 12; ARNB, chs. 24-27) are typical. The Babylonian Talmud has a reference to the golden crown called a "Golden Jerusalem" which Akiba had made for his wife (b. Shabbat 59b); it also mentions that he had 12,000 pairs of disciples $(b$. Ketubot 63a; b. Yebamot 62b), details found in ARN. The story of Eliezer's leaving his family and engaging in study occurs also in Genesis Rabba and Tanhuma, but not in the Talmud. Most of the Hillel ma-terials are unparalleled in the Talmuds, but the Moses traditions associated with him do have parallels.

In these few examples which have been reviewed, traditions common to both versions of ARN are most often not found in the Babylonian Talmud (nor the Palestinian). Digressions and elaborations of basic points, especially those unique to one version of ARN, are more often paralleled in the Talmud than common materials, but each source hones its contents in its own way. Neither the two versions of ARN nor their oral/written earlier stages manifest direct dependence on the Babylonian Talmud. Sometimes individual pericopae show a close relationship, especially in ARNA which was read and edited in the same tradition as the Babylonian Talmud.

These same phenomena continue in the section on Johanan and the section on the early sages. B. Baba Bathra 134a, b. Sukkah $28 \mathrm{a}$ and p. Nedarim 5:7 (39b) have material found in ARNA, ch. 14 and ARNB, ch. 28 concerning Johanan as Hillel's successor. ARNA and b. Baba Bathra (identical with sukkah) say that Hillel had eighty disciples of whom Johanan was the least/youngest and also list the subjects which he studied and then quote Prov. 8:21 apropos of him. ARNB and Nedarim say Hillel has eighty pairs of disciples (an analogy with the pairs in the chain of tradition) and in addition they recount Hillel's praise of Johanan from his deathbed. Nedarim lacks Johanan's curriculum and ARNB has it added on after Prov. 8:21. ARNB stands between ARNA and p. Nedarim and ARNA stands with the Babylonian Talmud. The Babylonian Talnud 
has put together a group of things which were said concerning Johanan ben zakkai and it is likely that the Talmud drew from ARNA. ARNB could have influenced the Palestinian Talmud or vice versa. In ARNA, ch. 14 much is made of Eleazar ben Arak's decision to leave Jamnia for Emmaus. B. Shabbat $147 \mathrm{~b}$ presumes knowledge of this story, but does not recount it. In ARNA, ch. 15 and ARNB, ch. 29 three stories which illustrate Hillel's patience are told. The order of the stories and details vary. In b. Shabbat 3ob-3la the same three stories are told in an abbreviated form. The sequence is the same with the addition of one story. ${ }^{4}$ since there is a common number for a group of stories and since the stories seem abbreviated in the Talmud, it is likely but not certain that Shabbat drew upon ARNA. Right after the Hillel stories comes the saying of Rabbi Eliezer, "Repent one day before your death," accompanied by an explanation. This material occurs in b. Shabbat 153a in an appropriate context with similar but not identical wording. Finally, only one of Johanan's sayings in ARNB, ch. 31 has a parallel in the Talmud: "If the young men say to you: Let us go and build the temple, do not listen to them..." occurs in the name of Simeon ben Eleazar in b. Megilla 37b; this attribution is derived from $t$. Abodah zarah 1:19. It is probable that this and other sayings were gathered into a special collection in ch. 31 to praise Johanan ben Zakkai further.

The section of ARNB containing the sayings of the early sages (chs. 32-35) has almost nothing in common with either Talmud. ARNA, chs. 19-26, its parallel, contains many sayings without Talmudic parallel. Among the stories, several deathbed scenes stand out. In ch. 19 Eliezer's meeting with his disciples and final teachings are paralleled by $\mathrm{b}$. Berakot $28 \mathrm{~b}$, but the two texts are very different. 5 Another independent story of his death and last teachings is told in ARNA, ch. 25. Eliezer's mind is proved sharp because he recognizes that his son is incorrectly preparing for the Sabbath. Consequently, his colleagues led by Akiba ask him a number of halakic questions and he laments the lack of learning among his contemporaries. The basic story occurs in a confused form in $\mathrm{p}$. Shabbat $2: 7$; in $\mathrm{b}$. Sanhedrin 68a Akiba rather than E1iezer instructs the son on correct preparations for the Sabbath, thus destroying the main action of the story. ${ }^{6}$ Finally, in ARNA, ch. 25 Johanan worries on his deathbed about punishment. The basic story occurs also in $\mathrm{b}$. Berakot $28 \mathrm{~b}$ along with the version of Eliezer's death found in ARNA, ch. 19. In b. Berakot Eliezer's 
final words concern prayer and study, the themes of $b$. Berakot here; the story of Johanan's death has joined it by attraction. 7

Finally, near the beginning of ARNA, ch. 26 stand six admonitions attributed to Akiba. Some of them, especially those concerned with vows, are presented in a different form in b. Nedarim 20a. Neither version can be certainly related to the other.

These selected comparisons between the two versions of ARN and the Talmuds, especially the Babylonian Talmud, seem typical of the whole. By far the majority of the traditions in ARN lack parallels in the Talmuds; consequently, ARN is not compiled from Talmudic materials or even heavily influenced by them, as are some later midrashim. In many cases ARN has its own independent traditions, which are likely to have formed the early core of ARN before the two versions became differentiated. When traditions in ARN and the Talmud are parallel, they each have their own wording and nuances which fit them to their own contexts. Occasionally traditons are virtually identical. In long digressions on traditional subjects (Adam, the evil inclination, etc.), the influence of Talmudic traditions can be seen and we may speculate that additons were made under the influence of the Talmud or of traditions that were being drawn into the Talmud. This is especially true for ARNA which interacted with the Talmudic tradition more than ARNB.

\section{Literary Origins and Development}

The history and date of ARN belong to the next chapter. However some observations and hypotheses about the nature of $\mathrm{PA}$ and the two versions of ARN may be made from the data assembled thus far. Though we have three fixed written texts now, the texts were more fluid in antiquity and at some early stage the traditions were passed on orally. A complete distiction between written and oral sources cannot be maintained because in antiquity much written literature was meant to be read aloud and was written under the influence of oral techniques. ${ }^{8}$ In Greek literature Homer is the most well known example of literature standing on the threshold between oral and written communication. Plato marks the move of philosophy from oral to written form with the consequence that abstraction plays a larger role. Oral communication is distanced from life and allows history and thought to be fixed in time and manipulated in more formal ways. Oral communication more effectively involves the listener in what is being said and elicits an appropriate response; written communication 
encourages precision and dispassionate analysis. Oral traditons change with each generation and remain eternally contemporary; written texts gradually become antiquated and spawn further interpretative genres.

The origins of oral traditions both before and after 70 C.E., their place and function in the tradition and the rise of the concept of oral Torah can be only imperfectly understood. Both $\mathrm{J}$. Neusner and Peter schäfer conclude that the Rabbis at Jamnia after 70 C.E. began earnestly and comprehensively to gather and transmit the traditions which formed the Mishna. ${ }^{9}$ This process culminated in the mnemonic patterns of the Mishna at the end of the second century. Schäfer points out that the concept of oral Torah and the contention that the oral Torah in general goes back to Sinai develops only at the end of the process in the third century. However, the processes of collection and memorization went on in the Rabbinic school during the second century. Thus, PA 1:1 speaks only of Moses receiving the Torah on Sinai and does not distinguish oral or written Torah. The Mishna itself in three places makes the claim that individual halakot derive from Moses on Sinai, 10 but it does not claim that its traditions in their entirety derive from Moses nor that the traditions have been passed on word for word. These claims arise slightly later than the Mishna. But the Mishna itself, which was first published orally through professional memorizers, 11 stands as evidence that oral traditions were carefully formulated for memorization. 12

$\mathrm{PA}$ and $\mathrm{ARN}$ in their written forms bear the marks of oral transmission, though not of precise formulation and memorization. They consist of a series of related sayings, stories and exegeses, each with a particular point but so structured as to convey meaning. The discussion is not carried on with precise concepts or dispassionate analysis, like that found in Greek philosophy. The sayings are proverbial, deriving from one of the most common and early types of spoken communication. The stories are popular forms recounting the origins, deeds and destiny of major Biblical and Rabbinic figures or encouraging virtue by example. The exegeses are the closest to a properly literary activity, but we know that the Bible was actively read, translated into Aramaic and interpreted. Consequently, much Biblical interpretation was oral and popular and the listing of Biblical verses in the enumeration sayings, and elsewhere, seems to be as old as the Rabbinic movement. 13 
This mixed oral and written character to the Rabbinic tradition, something that affected the early years of the Mishna also, means that there is no fixed or cannonical text of PA or ARN. That explains why few parallel sayings and stories reach verbal identity. To repeat a saying does not mean using exactly the same words in contrast to quoting exactly from a book. A.B. Lord has shown that over the years the same story is told with striking changes, though all within the framework of the story and traditional themes.14 Never is a story told twice word for word. The many traditions in the two versions of ARN which are substantially similar but not identical may be related through oral transmission. oral transmission also allows for modification of the traditions to fit new contexts in ARN, midrashim and the Talmuds. These modifications may have occurred in the writing of the texts and may also have been introduced by copyists.

This history of how the texts which we have became fixed is lost. We may speculate with some probability about the independence and relatedness of the texts and the stages of their development. We have noted that Tractate Abot as it exists in the Mishna differs from the Abot which is commented on or integrated into the parts of ARN. From the end of the second and beginning of the third century Tractate Abot underwent its own development within the Mishna.15 The two versions of ARN did not develop as adjuncts to the Mishna, like the two Talmuds. ${ }^{16}$ ARN went its own way, in contact with the midrashic traditions which were ultimately collected into the surviving midrashic collections. The two versions of ARN each modified the received form of PA to serve new goals.

The many traits common to PA and the two versions of ARN suggest that these three works had a common beginning within the Rabbinic tradition either as oral tradition or as a rudimentary written document. The material in PA and ARN was popular and imaginative and so it grew in at least three directions. In ch. 10 we will develop hypotheses concerning time, place and setting with proper cautions dictated by the paucity of evidence. The literary structures and relationships among the versions suggest only that diverse groups in different places must have preserved and augmented the two versions of $A R N$ and that they must have had time to develop and attain their present shape. The process of development was probably diffuse and its exact stages cannot be recovered. Previously we have seen that certain digressions and sections bear the marks of compilations on popular subjects and were probably added. Certain other themes and traits betray the 
hands of strong authors or editors who made sure that their major interests were communicated through the text. As whole works, the two versions of $A R N$ and PA suggest the interests and goals of scholastic groups. An attempt to describe them will occupy the next chapter. 



\section{HISTORICAL CONCLUSIONS}

Like most of early Rabbinic literature, ARN resists historical analysis. It is not the work of one author, though it has a certain unity and purpose and shows the influence of coherent organization at some stages of its development. It does not identify itself, by time and place nor does it state its origin within a named group. Any information about it must be deduced from our analysis of the text and thus will remain very hypothetical. Within these limits some observations may serve as a beginning. ARN offers little evidence for its place of composition. I Scholars have suggested dates from the first to ninth centuries, ${ }^{2}$ but the Rabbinic tradition has been so thoroughly edited that it is hard to identify original compositions in order to assign them a date. We shall suggest the second and third centuries as the period when the greater part of ARN took shape. ARN offers the best evidence for its social milieu, namely the Rabbinic school; its message and main thrust are directed toward the scholastic life.

\section{Social setting}

ARN presumes a school as its setting. By setting we mean the social structures and cultural conditions which surround and influence the genesis of a literary work and especially the thought world presumed by it. Evidence for the connection between ARN and the Rabbinic school has been offered previously in ch. 6 as well as at appropriate points in other chapters. The strong emphasis on study and associated topics marks out ARN as a school document rather than an address to society at large (though it has served that function, too). The chain of tradition, the stories of the founders of Rabbinic Judaism, the rules for teaching, learning and studying, the rules governing relationships among masters and disciples, exhortations to friendship and fellowship and the high honor accorded the learned all point to a scholastic setting. This school serves as the center of Judaism because all is centered on Torah and Torah is directly from God.

The Rabbinic school is not a single institution, though one might identify Johanan ben zakkai's school at Jamnia as the original Rabbinic school. Mention is made of individual Rabbis having schools and disciples in the late first century and beyond; many statements in the Babylonian Talmud describe vigorous and 
varied scholastic activites in Babylon. ${ }^{3}$ Talmudic and midrashic passages frequently affirm that exegesis and study are highly valued and that scholarship is the ideal response to Torah. The set of attitudes and the pattern of behavior which underlie these passages resulted in a rich and diverse tradition which retained an essential unity. Though these many teachers and students spread over the Near East in Tannaitic and Amoraic times, they constitute one school of thought and one intellectual tradition among the many found in the Roman and Sassanian Empires.

one might still argue that ARN addresses all Jews whatever their life situation. Especially ARNB which has more emphasis on works and less emphasis on study than ARNA ${ }^{4}$ speaks of many themes and virtues common to the whole of Judaism. Study itself is a virtue for all of Judaism, and knowledge of Torah has been highly esteemed for centuries in Jewish history. Yet even in medieval and early modern times for which we have ample data, the ideal of devotion to Talmudic study was reality for only a minority. Though the ideal Jew devotes his whole effort to study, according to some of the sayings in $A R N$ and Rabbinic literature, obviously other tasks must be done and other temperaments satisfied. The students of Torah live within a whole community and, according to the Rabbinic view, they have chosen the best path for keeping the precepts of Torah and they approximate most closely the ideal of fidelity to God through Torah. The overwhelming stress on Torah, study and a community of scholars and teachers in ARN shows that it derived from and was addressed to the school and its devotees. These specialized scholars necessarily become a separate class and must be supported by community funds, though ample evidence indicates that whether a scholar should support himself or devote full time to study was a subject of lively debate. The stories about Akiba's early poverty and Eliezer's early affluence (ARNA, ch. 6 and ARNB, chs. 12-13) show that the Rabbis desired students from all classes. (See also ARNA, ch. 3 and ARNB, ch. 4.) Though the ideas and ideals expressed in ARN are important to the whole Jewish community and realizable by all to a limited extent, these ideas and ideals are most immediately addressed to those directly associated with the Rabbinic school.

The study house as an institution for both study and prayer is mentioned several times in each version of ARN. ${ }^{5}$ This institution is presumed rather than described because ARN is more interested in the act of study than in the context in which it occurs. ARN does presume a social context for study in its instructions 
to find a teacher and a companion for study, but it does not elaborate on the institutions which might have facilitated that communal effort.

The sages are not presented as civil authorities or as influential citizens in community affairs, but as intellectual leaders. Analogies with rhetors and sophists in the Greco-Roman world and data from the Babylonian Talmud suggest that some Rabbis probably fulfilled community leadership functions. Yet even the Princes, who are the climax of the chain of tradition in PA, are given a minor place in ARN, except in ARNA, ch. 18 where Judah the Prince is paralleled to Johanan ben Zakkai. No stress is put on their authority or social position. Study and a community of scholars, not institutionalized authorities, form the heart of Judaism according to ARN.

Similarly, ARN does not associate the Rabbis with world affairs. The story of Johanan ben Zakkai's escape from Jerusalem to found the school at Jamia treats the war with Rome neutrally. Though Akiba appears often in ARN, not a word is said about the tradition that Akiba supported Bar Kosiba in the second war against Rome. ${ }^{6}$ In fact, the foreign empire is generally treated with indifference and politics as something to avoid. At the other extreme, ARN also mentions the family sparingly and always subordinates it to the study of Torah, as is clear in the stories of Akiba's devotion to Torah to the detriment of his wife and family (ARNA, ch. 6; ARNB, ch. 12). ARN is single minded in its focus on the life of study.

\section{Prace}

Consideration of the intellectual and social setting of ARN raises the question of the geographical origins of the two versions. The milieu reflected in the texts is palestinian. Virtually all the sages are Tannaim; Jerusalem and Galilee are prominent and the temporal setting is the first two centuries, C.E. The larger setting is the Roman Empire, not the Parthian or later Sassanian spheres of influence. ARNB mentions Babylon in four places but Babylon is seen from the outside. ${ }^{7}$ Neither version is very closely tied to the Babylonian Talmud in such a way that a Babylonian origin would be called for (see the previous chapter). Consequently, the traditions in both versions and probably the early forms of both versions belong to Palestine. This does not deny that later additions and editions were produced elsewhere. 
The existence of two versions invites speculation concerning the two places or groups which produced them. Neither version manifests a connection with a specific part of Palestine, that is, Judea, Galilee, Caesarea, etc. Nor can the attitudes or interests of a Rabbinic sub-group or specific sage be discerned controlling the thrust of either version.

\section{Date}

ARN tells us nothing about its date directly nor does any external evidence fix the time of origin. ARNB, ch. 19 contains three stories, two of which also occur in the sheiltot of Rab Ahai Gaon who flourished in the midale of the eighth century. ${ }^{8}$ The Sheiltot has the stories as recounted in ARNB and not as recounted in $\mathrm{b}$. Shabbat $127 \mathrm{~b}$ where variants of the three stories occur in the same order as in ARNB. From this we can conclude that the Sheiltot probably quotes ARNB. This provides us with an upper limit of about $700 \mathrm{C.E}$. for the existence of ARNB but it does not help us decide on its time of origin.

Since PA relates closely to $A R N$ and since it may be dated partly by the formation of the Mishna, we shall first conclude what is possible about PA before proposing dates for ARN. The Mishna took its present shape at the end of the first and beginning of the second centuries, C.E. J.N. Epstein has pointed out that the text of the Mishna continued to evolve after this period, but it attained substantial form at the end of the second century under Rabbi Judah the Prince. ${ }^{9}$ A. Guttmann has argued however that Tractate Abot was later added to the Mishna. As evidence he cites its lack of a Tosefta, the failure of the Talmud to quote it and Medieval evidence for Abot's different positions among the tractates of the Mishna. ${ }^{10}$ Since the earliest citations of Abot come from the fourth generation Amoraim, Guttmann suggests 300 as the date of composition of Abot. But Guttmann's evidence is all external, late, or from silence. PA is a unique tractate in the Mishna and as such could be expected to lack a Tosefta. This cannot provide us with a date for PA. Lack of citations in the Talmud may be by chance. The end of the second, beginning of the third century remains the most reasonable time for the redaction of PA and its inclusion in the Mishna. Naturally, some additions were made, such as Judah the Prince himself and his son at the beginning of ch. 2. The redaction of PA by Judah the Prince is further supported by the end of ch. I where Gamaliel and simeon ben Gamaliel are added after Hillel, without the technical 
statement that they received the Torah. Also, Johanan ben Zakkai, who is said to have received the Torah, is out of sequence in the middle of ch. 2 and almost certainly has been displaced to that position by Judah the Prince who wanted to create a direct line of authority from Moses to himself through the pairs and then the Princely line. ${ }^{11}$ That Judah the Prince proceeded in this way can be seen by a comparison with both versions of ARN which lack the Princes in the chain of tradition.

The date of some of the materials in PA can be ascertained. Johanan was probably added to the chain of tradition in the second century, the last person of whom it could be said, "He received" the Torah. 12 ARNA, ch. 14 places Johanan immediately after Hillel and Shammi and begins with the formula that he received Torah. ARNB, ch. 28 places Johanan after Hillel, but it is not until an independent collection of Johanan sayings in ch. 31 that Johanan is said to have received Torah. The variations in location argue that Johanan was added to an already existing chain which had ended with Hillel and Shammi. The use of the technical expression "received" for him in contrast to Gamaliel and Simeon suggests that he was added to the chain of tradition before they were added at the end of the second century.

Some other sayings in the chain of tradition and Johanan materials suggest a second century date, or earlier. Abba saul, who lived in the mid-second century, makes a comment on the relative merits of Johanan's disciples in PA 2:8. Since Saul knew this mishna, it must have existed at his time or before. The saying of simeon the Just that the world stands on Torah, Temple service and acts of loving kindness, seems to have had a meaning prior to the destruction of the temple which was midrashically adjusted after 70.13 The saying of the Men of the Great Assembly, to be deliberate in judgment, raise many disciples and make a hedge, is seen by $\mathrm{L}$. Finkelstein as an early instruction to judges which was later adapted to the needs of the Rabbis and their students. ${ }^{14}$ $\mathrm{J}$. Goldin understands the original saying to be a further elaboration of Qoh. 12:12 which discourages writing books and encourages oral tradition. ${ }^{15}$ Though both interpretations are speculative, they do suggest that the saying has a long and complex history of interpretation, some of it antedating the formation of the Mishna. Finally, E. Bickerman has demonstrated the original meaning of the saying of Antigonus of Soko in an earlier Hellenistic context where slaves could be provided with sustenance by their masters or left to fend for themselves. When the word prs was no longer 
understood as a slave's living allowance, it came to mean reward or compensation, its present meaning in PA. 16

Similarly, some sayings of the early sages and the four who entered the garden contain hints that they were collected in the first and second centuries. Akabya's saying is an odd series of questions which later generations saw as suspicious or dangerous. Simeon ben Eleazar, a late second century sage, already comments on it. The four who entered the garden are early second century figures and since Elisha ben Abuyah, the apostate, was shunned by later generations, his presence here, without invective and as author of a saying argues that the grouping of the four together was retained because it was early and fixed. Though PA clearly underwent development before and after it was joined to the Mishna, its structure and sayings provide enough evidence to say that it took shape during the second century.

The two versions of ARN have a close relationship to PA and the similarities and differences between them and $P A$ argue that they too were developing parallel to and in interaction with PA. As was pointed out in the previous chapter, ARN is not a commentary on the Mishna Tractate Abot, but on a different version, presumably earlier or contemporary with it. It is likely that a commentary generated in its entirety after the formation of the Mishna would have followed the Mishna Tractate Abot. Since the two versions of ARN are independent of and parallel to Tractate Abot, it is probable that all three variations on the tradition developed contemporaneously in the second century. 17 The tradition was fluid and probably oral, although written versions or parts are not excluded. The chain of tradition and materials concerning Johanan ben Zakkai and his disciples were probably joined to one another in the early or mid second century and the major components of the commentary, found in both versions, were probably in place. Whether the section on the early sages was part of the whole at this early stage is unknown; likewise, it is impossible to say anything about the enumeration sayings.

The names in ARN support its development during the second century. The names most frequently mentioned belong to sages active at Jamnia during the first generation of Tannaim: Eliezer, Joshua, Johanan ben Zakkai and their colleagues. Akiba, slightly later, is a prominent figure and then Judah the prince at the end of the second century. Neusner has pointed out that the sages at Usha following the Bar Kosiba War produced many biographical and historical materials. ${ }^{18}$ This interest in founding sages of the 
Rabbinic school is consistent with the scholastic atmosphere of ARN pointed out in the previous chapter and in ch. 6 . Members of a school tended to collect stories and examples connected to their founders and great teachers, both to establish the school's authenticity and identity and to educate its students. This process continued in the third century with addition of materials connected with Judah the Prince, the key transitional figure to the Talmudic period.

Though we cannot know for certain when these texts were honed into present shape and fleshed out with digressions and additions, the third century is a likely time for substantial editing of the second century material. Under Judah the Prince Rabbinic Judaism had received a great degree of organization and expansion. Talmudic activity was beginning, centered around the Mishna. Midrashic collections were probably taking shape during the same time. The Rabbinic schools in Palestine and Babylon were strong and would have been interested in an ideological document like ARN. Neusner has shown that many of the biographical stories about Elizer ben Hyrcanus probably took shape in the third century. ${ }^{19} \mathrm{M}$. Avi-Yonah calls the third century the century of haggadists. ${ }^{20} \mathrm{H}$. Fischel has pointed out that in Greco-Roman circles the third century was a time of collecting chriae about the philosophers and sages of that tradition. ${ }^{21}$ M. Avi-Yonah also suggests that the anit-government statements in ARNA, ch. $20 \mathrm{fit}$ most easily into the third century when the annona became a regular tax in Palestine. 22 similarly, the description of famine in ARNA, ch. 27 could easily be set in the third century. ${ }^{23}$ Both these passages are found in ARNA only and seem to be expansions of the original commentary.

In arguing for the simultaneous development of PA and the two versions of ARN we have not tried to establish an original text or core. Since the tradition developed in an oral/literary culture, its form was not fixed and there was no ur-text. When a saying occurs in all three texts, it is highly probable that that saying goes back to the beginning of the tradition. When a saying, story or exegesis is found in both versions of ARN and when it is central to a section, it is probable that the passage is relatively early in the tradition. But a list of all the materials common to both versions of ARN will not give us the original form of the tradition, oral or written, because some original or early element could have dropped out of one of the versions or some element common to both could have been added in one version and then added subsequently to the other due to the interaction of the two versions. 
We have suggested in previous chapters that certain digressions and comments may be additions, but these conclusions are based on context and the literary characteristics of the sections in question, not on their simple absence in one version.

The analysis of ARN in the previous chapters and the observations and arguments presented above suggest that PA and both versions of $A R N$ began to take shape in the first half of the second century, C.E. and achieved substantially the form they have now at the end of the second century. Nevertheless, a significant number of stories, sayings and exegeses were integrated into the two versions during the third century. There is no clear pattern to the additions and we are often able only to surmise that there might have been additions in certain places. We can be certain that $P A$ and ARN underwent a somewhat lengthy and complex development, but the exact course of that development and the precise decades in which it took place cannot be determined. 
NOTES

CHAPTER ONE

1

Schechter, ARN. Schechter's edition contains the two versions in parallel columns with notes on the manuscripts and further notes on parallels and points of interpretation.

2 For many details of interpretation, see Saldarini, ARNB and Finkelstein, Mabo.

${ }^{3}$ Many parallels are conveniently listed in schechter, ARN and Saldarini, ARNB.

${ }^{4}$ Goldin, "Two Versions."

5odd, The Bible and the Greeks, pp. 30-32; J.A. Sanders, "Torah," p. 909.

6 For a thorough discussion of Torah in Isaiah, see Jensen, The Use of tôr $\hat{a}$ by Isaiah.

7 Dodd, The Bible and the Greeks, p. 34.

8 J.A. Sanders, "Torah," p. 910.

${ }^{9}$ G.F. Moore, Judaism, I, p. 263.

10 Josephus, Antiquities, 13, 10, 6 (\#297).

11 Schăfer, "Das 'Dogma' von mundlichen Torah im rabbinischen Judentum," in Studien, pp. 153-197 shows that the explicit term "oral Torah" arose in the third century among the Amoraim. PA I:I does not specify what it includes in the term Torah.

CHAPTER TWO

${ }^{1}$ For a discussion of the enumeration form, see W.S. Towner, The Rabbinio "Enumeration."

${ }^{2}$ Actually, PA $1: 17$ and 18 cite "Simeon his son" and "Rabban simeon ben Gamaliel." This problem and others associated with the continuation of the chain will be discussed in ch. 5 .

${ }^{3}$ William McKane, Proverbs, $1-22$ and passim, distinguishes wisdom instructions and wisdom sentences. Biblical proverbs, of course, have parallel members and are not tripartite.

${ }^{4}$ For the original meaning of simeon's saying, see Goldin, "The Three Pillars."

4a küchler, Frühjülische Weisheitstraditionen, p. 185 notes that PA $1: 12-14$ has the three basic forms of wisdom sayings, imperative, indicative and interrogative.

5Towner, The Rabbinic "Enumeration", pp. 79-84; 249.

${ }^{6}$ See ch. 5 below. Also, Saldarini, "The End of the Rabbinic chain of Tradition." 
${ }^{7}$ H. Fischel, "Story," pp. 71-73. In the Biblical tradition, note the use of the first person singular in Qohelet.

${ }^{8}$ H. Fischel, Rabbinic Literature, ch. 2 .

${ }^{9}$ See Diogenes Laertius, Lives, on the disciples of plato, Aristotle, Zeno and Pythagoras. E.g., IV, 6; V, 2, 58; VII, 160, $168 ; \mathrm{IX}, 50$.

10

Goldin, "A Philosophical Session."

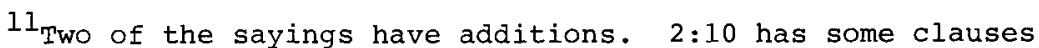
added to the initial three imperatives. $2: 14$ was probably a three part saying originally, according to Goldin, "A Philosophical Session," pp. 4-5; Heb. version, pp. 71-74. cussion.

${ }^{12}$ In ARNA Akabya asks four questions. See ch. 7 for a dis-

13 Lieberman, "How Much Greek," pp. 135-137.

${ }^{14}$ PA 3:15-16 are not attributed to Akiba in ARNB and are recorded in a different place in the text (ch. 44).

${ }^{15}$ Elisha ben Abuyah may have been put last because he was an apostate. Akiba, the best known of the four may have been put first and then moved ahead to join the early sages in ch. 3 . See L. Finkelstein, Mabo, pp. 75-77 and "Introductory study," pp. 22-24.

${ }^{16}$ Epstein, Mébolôt, p. 232.

${ }^{17}$ Finkelstein, Mabo, passim.

${ }^{18}$ Georgi, "The Records of Jesus," pp. 538-539.

${ }^{19}$ Neusner, Method and Meaning.

${ }^{20}$ Goldin, "Abot," ; 983 suggests that the tripartite saying is not just a bon mot or moral maxim, but the formulation of a fundamental principle or policy charateristic of the tradent. This suggestion has yet to be tested. Küchler, Früjülische weisheitstraditionen, PP. 176-198, surveys PA and ARN within the larger wisdom tradition.

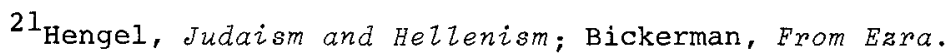

${ }^{22}$ This subject will be treated more extensively in $\mathrm{ch}$. 6 . For a convenient collection of some Greek materials, see Tod, sidelights, ch. 3 .

23 Mantel, "The Nature of the Great Synagogue"; Georgi, "The Records of Jesus"; Rivkin, A Hidden Revolution; M. Smith, "Palestinian Judaism."

24 Bikerman (sic), "La Chaîne." Bickerman also cites Sotion (known only through fragments) and jurists.

25 Bickerman, "The Maxim of Antigonus of Soko."

${ }^{26}$ Fischel, Rabbinic Literature, Part 4.

${ }^{27}$ The mass of material collected by Fischel contains many motifs, but not structural parallels or carefully nuanced 
discussions of related genres. For an extensive critique, see the unpublished paper of Shaye Cohen prepared for the 1977 meeting of the Society of Biblical Literature.

${ }^{28}$ The number seven may derive from Gilgamesh (tablet 11), according to Lesky, History of Greek Literature, p. 156.

${ }^{29}$ Stobaeus pp. 3, 1, 172. The texts are conveniently presented by B. Snell, Leben und Meinung, pp. 98-104. I am grateful to $M$. Smith for suggesting this parallel at the Richter Conversation, Brown University, 1978 .

${ }^{30}$ Fischel, "Studies," pp. 74-76 and n. 52.

${ }^{31}$ J.M. Robinson, "Logoi Sophoi"; see also Wilkin, "Wisdom and Philosophy"; Schoedel, "Jewish Wisdom."

32 Wilken, "Wisdom and Philosophy."

33 The external arguments for dating PA at 300 C.E. or later have been assembled by A. Guttmann, "Tractate Abot."

34 Epstein, Mabo.

${ }^{35}$ Culpepper, The Johannine School.

${ }^{36}$ Fischel, "Story," pp. 79-86.

37 Neusner, Eliezer, II. Avi-Yonah, The Jews in Palestine, p. 128 says that the third century is the century of haggadists. CHAPTER THREE

${ }^{1}$ Saldarini, "The End of the Rabbinic Chain" and chapters 5 and 6 below.

${ }^{2}$ According to L. Finkelstein, Mabo, pp. 67-70, Nehunya ben Ha-Kana was originally a fifth member of this group, but was eliminated because his saying was strongly pro-government.

3 b. Hagiga $14 b$.

${ }^{4}$ According to L. Finkelstein, Mabo, pp. 75-77 and "Introductory Study," pp. 22-24, Elisha ben Abuyah originally headed the list, followed by Ben Zoma, Ben Azzai and Akiba. Because Elisha apostasized Ben Zoma was put ahead of him so that an apostate would not introduce the group.

5 Interestingly, ch. 27 has the last sayings of both PA, ch. 2 and PA, ch. 3 .

${ }^{6}$ In "Introductory Study," note 5, Finkelstein mentions seven further groups of sayings used as sources.

7 See J.N. Epstein's account of the growth of the Mishna in Màbo lèe-Nîusah.

${ }^{8}$ See J. Heinenmann's critique of Finkelstein's liturgical source studies and his convincing hypothesis concerning the multiform "original" of the prayers in Prayer in the Talmud.

CHAPTER FOUR

l Goldin, "Not By an Angel." 


\section{dolah." \\ ${ }^{2}$ See L. Finkelstein, "The Maxim of the Anshe Keneset Ha-Ge-}

${ }^{3}$ Goldin, "The End of Ecclesiastes"; also "The Third Chapter," pp. $369-370$.

4 In chronological sequence, Job belongs after Adam since he is thought of as a contemporary of Abraham. Torah should be joined with the Prophets and Writings. See the order in ARNB below.

5 m. Shabbat $9: 3 ; \mathrm{m}$. Mikwaoth $8: 3$. See other interpretations in b. Shabbat $86 \mathrm{a}-\mathrm{b}$ and $\mathrm{b}$. Yebamot $62 \mathrm{a}$.

6. Schäfer, Studien, pp. 153-197, shows that explicit mention of oral Torah alongside written Torah at Sinai arises in the third century, C.E.

7 Or perhaps translate $J \jmath$ as "and not even like all the mighty men in the world," according to Goldin, ARNA p. 180, n. 53 .

${ }^{8}$ Goldin, "Third Chapter."

${ }^{9}$ Goldin, ARNA, p. 182, n. 14 says that this discussion belongs under the phrase "acts of loving kindness" where it is found in ARNB, ch. 8. But from the viewpoint of ARNA the key item for discussion is study of Torah and this case is used appropriately here to develop that theme.

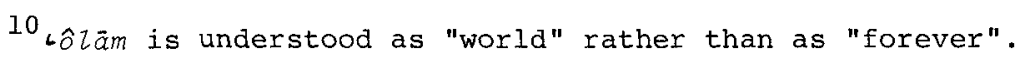

${ }^{11}$ see Saldarini, "Johanan ben Zakkai's Escape" and Schäfer, "Die Flucht Johanan."

12 Bickerman, "The Maxim of Antigonus of Soko." Urbach, The Sages, p. 403 and n. 22 disagrees with Bickerman without sufficient evidence. Urbach quickly becomes embroiled in later disputes about the relative merits of fear and love as motives.

${ }^{13}$ Fischel, "The Uses of Sorites." p. 128.

${ }^{14}$ Goldin, "The First Chapter," pp. 278-280.

15 Towner, The Rabbinic "Enumeration", pp. 75-84.

${ }^{16}$ see ch. 5 for further discussion. Finkelstein, Mabo, p. 6, n. 10, proposes the opposite theory, that Eli and Samuel were original to the chain and were dropped after 70 C.E. when the Rabbis replaced the priests as the dominant authority in Judaism.

${ }^{17}$ Saldarini, ARNB, p. $34, \mathrm{n} .42$.

${ }^{18}$ Finkelstein, Mabo, 32-35, says that fear as a better motive is an old Shammaite teaching. Vermes, Post Biblical Jewish studies, p. 114. finds justice rather than love stressed in Targums to Gen. 4:8. This was probably a continuing Rabbinic dispute. See note 12 above.
${ }^{19}$ Saldarini, ARNB, p. 131 has a chart.
20 ARNB also has the order Shammai--Hillel in ch. 46.

See Finkelstein, "Introductory Study," pp. 17-18.

${ }^{21}$ Goldin, "Two Versions." 


\section{CHAPTER FIVE}

${ }^{1}$ See Saldarini, "The End of the Rabbinic Chain."

${ }^{2}$ Fischel, "The Uses of Sorites," pp. 124-126.

${ }^{3}$ Finkelstein, Mabo, p. 233, n. 16 and "Introductory Study," pp. 48-49.

4 Fischel, "The Uses of Sorites," pp. $125-126$ and n. 18 . Fischel notes that some Greco-Roman chains use a verb without a direct object to indicate what is being passed on.

${ }^{5} \mathrm{H}$. Strack, Introduction, p. 107, and J. Lauterbach, Rabbinic Essays, p. 196, n. 38 .

6eusner, pharisees, 1:184-185. Finkelstein classifies Menahem as a "conservative," even though he is said to agree with Hillel (Akiba, p. 298).

${ }^{7}$ Josephus, Antiquities, pp. 15, 10, 5; Derenbourg, Essai, pp. $464-465$.

${ }^{8}$ Josephus, War, pp. 2, 17, 8. Lieberman, Greek, 179-181 on the basis of Shir Ha-Shirim Zuta, end. See also J. Rosenthal, "The Identity of Menahem" (In Hebrew).

"Hoenig, "Menahem" (in Hebrew).

$10_{\mathrm{b}}$. Hagiga $16 \mathrm{~b}$ and $\mathrm{p}$. Hagiga $2: 2$ (77d).

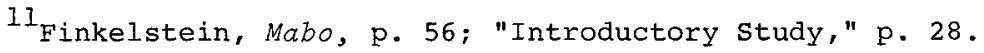

12 Hoffman, Die erste Mischna, p. 26.

13 ARNA, end of ch. 22; ARNB, end of ch. 32 .

${ }^{14}$ Bikerman, "La Châ̂.ne" and Fischel, "The Use of Sorites."

15 Bikerman, "La Châ̂ine," p.49. p. 127 .

${ }^{16}$ Cohen, "Peculium," p. 275 ff.; Fischel, "The Use of Sorites,"

${ }^{17}$ Celsus, Medical Art, Proem 8 under Tiberius.

${ }^{18}$ Eusebius, Evangeliae Praeparationis, 9.30 (447a)

19 Fischel, "The Uses of Sorites," pp. 119 and 124-129.

20 Johnson, The Purposes of the Biblical Genealogies and Wilson, Genealogy and History.

${ }^{21}$ Finkelstein, Mabo, pp. 5-18 and "Introductory Study."

22 Wilson, Genealogy, p. 154.

${ }^{23}$ Finkelstein, Mabo, pp. 9-10; Johnson, Genealogies pp. 190-191.

${ }^{24}$ Wilson, Genealogy, pp. 27-36 and passim. 


\section{CHAPTER SIX}

${ }^{1}$ Goldin, "A Philosophical Session": Fischel, "Story" and "Studies," passim. A chria is an antedote, usually about a sage or a philosopher, which culminates in a meaningful action or proverb.

2 Fischel, "Story," p. 82; M. Smith, "Palestinian Judaism"; Rivkin, $A$ Hidden Revolution, pp. 242-243; Hengel, Judaism, 1: 230247 analyzes the Qumran sect as a Hellenistic sect.

3 Lieberman, Greek and Hellenism.

4 Tod, Sidelights, Lecture 3; Ferguson, "The Attic orgeones."

5 Mantel, "The Nature of the Great synagogue."

6 Sevenster, Do You Know Greek; Fitzmyer, "The Languages"; Fischel, "Greek and Latin Languages."

${ }^{7}$ Lieberman, Greek, pp. 15-67.

${ }^{8}$ See Chaim Rabin on multilingual societies, "Hebrew and Aramaic in the First Century" in The Jewish people in the First Century, 2:1007 ff.

${ }^{9}$ Lieberman, "How Much Greek," pp. 130-131.

${ }^{10}$ Lieberman, "How Much Greek," p. 135.

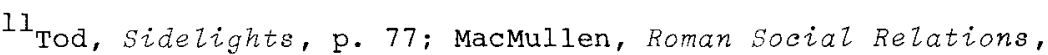
pp. $18-20$ and $73-80$.

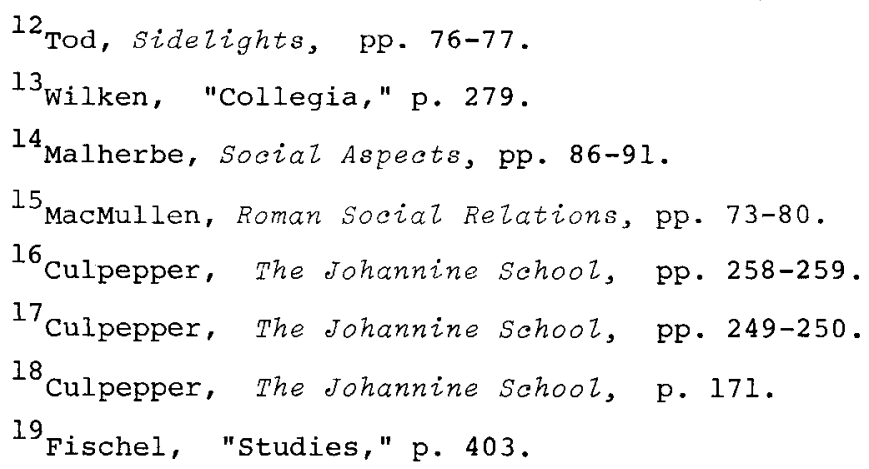
siastes," pp. 136-138.

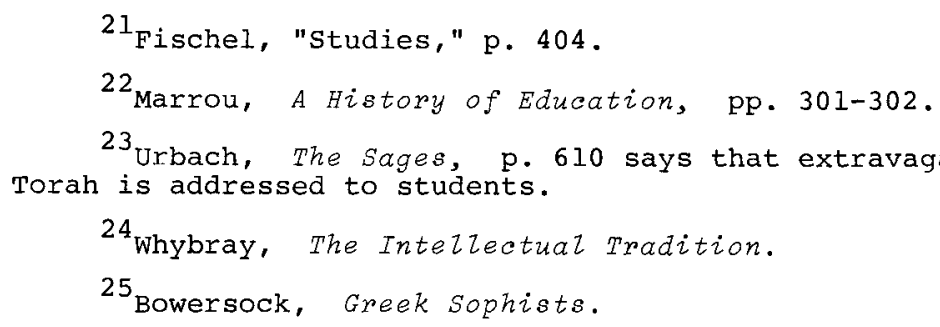
Torah is addressed to students.

${ }^{24}$ Whybray, The Intellectual Tradition.

25 Bowersock, Greek Sophists. 
${ }^{26}$ Urbach, The Sages, pp. 599-620 traces the tension between the imperative to study and the demands of holding office in the lives of the sages.

${ }^{27}$ Fischel, "Story," pp. 82-84 and passim in his works.

28 We should note that the Rabbis in Babylon, where the civil authority resided in the exilarch, participated in government and assumed multiple roles. See for example J. Neusner, Talmudic Judaism, chs. 4-8.

${ }^{29}$ Urbach, The Sages, pp. 603-620. PA 1:13, by Hillel, is the most famous stricture against using Torah: "He that puts the crown to his own use shall perish." Note that Paul is proud that he works at a craft and supports himself (1 Cor. 9:8-12).

${ }^{30}$ ARNA, chs. 1 and 28 ; ARNB, ch. 8.

3IMacMullen, Roman Social Relations, p. 20.

32 Macmullen, Roman Social Relations, passim.

33 Bowersock, Greek Sophists, ch. 4.

${ }^{34}$ Sifredt \#343, end (ed. Finkelstein, 400)

${ }^{35}$ Fischel, "studies," passim.

${ }^{36}$ Fischel, "Story," pp. 85-85; "Studies," pp. 407-411.

37 ARNA, ch. 14. gāầ $Z$ and $q \bar{a} t \bar{a} n$ are ambiguous and carry both meanings. In a culture where wisdom is often associated with age and experience, the two meanings overlap.

${ }^{38}$ Fischel notes that the encyclopedic curriculum is common in Greco-Roman literature ("Studies," p. 82). ARNB, chs. 12 and 28 has a stereotyped description of the curriculum, varying a little from what is found here in ARNA. ARNA, ch. 28 has part of the curriculum also. See b. Sukkah 28a and b. Baba Bathra 134a for further items. Mention of gemara shows that the form before us is third century or later. PA $3: 18$ indicates that the calendar and mathematics are also presumed.

${ }^{39}$ Neusner, "The Formation of Rabbinic Judaism," p. 37. Fischel, "Story," pp. 70-71 suggests that the epithets set out a typology of learning. See also the metaphors used of Socrates in Plato's Meno, p. 80 .

40 Diogenes Laertius, Lives, 7, 37, quoted in Goldin, "A Philosophical Session," p. 11 .

\section{$4{ }^{4}$ Goldin, "A philosophical Session," pp. 12-15. \\ ${ }^{42}$ Goldin, "A Philosophical Session," pp. 16-18; Fische1,} "Story," p. 75 and $n .83$. Goldin sees the exchange as the summary of an actual discussion; Fischel (p. 71, n. 61) more persuasively evaluates it as a rhetorical figure rather than an historical account. 
43 Melamed, "Lilšônah," pp. 108-109.

44 Finkelstein, Mabo, p. 44 surmises that "good impulse" was original. Goldin, "A Philosophical Session," p. 13 says good neighbor was original.

${ }^{45}$ Goldin, "A Philosophical Session," pp. 8-9.

${ }^{46}$ These stories are found in ARNB in a different order and in $b$. Shabbat 31 a with a fourth added. The stories in b. Shabbat are abbreviated and even obscure in places. ARNA shows affinities with both ARNB and b. Shabbat.

${ }^{47}$ Fischel, "Story," pp. 70-71 and 76-77.

${ }^{48}$ Goldin, "A Philosophical Session," pp. 4-5; Hebrew version, pp. $71-74$.

${ }^{49}$ Goldin, "A Philosophical Session," pp. 5-6; Hebrew version, pp. 74-75. Goldin also suggests that the other mishnaic mention of an Epicurean in $\mathrm{m}$. Sanhedrin 10:1 is meant literally.

${ }^{50}$ Saldarini, "Last Words."

${ }^{51}$ Goldin, "Two Versions," pp. 99-100.

52 Lieberman, Hellenism, p. 103. In b. Berakot $28 \mathrm{~b}$ the saying is attributed to Eliezer.

53 Alon suggests that $g\lrcorner w n$ refers to wealth which in turn leads to social status. Mekqarim, 2:49; ET 344-53.

54 Note that the parallelism is characteristic of Biblical proverbs.

\section{CHAPTER SEVEN}

${ }^{1}$ Finkelstein, Mabo, chs. 7-9. Note that the five sages match the five disciples of Johanan ben zakkai. See ch. 3 above for a presentation of Finkelstein's source theory.

2 b. Hagiga $14 b$.

${ }^{3}$ Saldarini, "Last Words."

${ }^{4}$ hnnyn and nhwny 
5inkelstein, Mabo, pp. 122-124.

${ }^{6}$ See ch. 5 above for the place of these two princes in the chain of tradition. Here they are part of the theme of the chapter, though both Johanan and Eleazar ben Azariah who are present led the school for short periods.

${ }^{7}$ Fischel, Fabbinic Literature, Part 1, argues that the story of the four is originally based on a Greco-Roman anti-Epicurean tradition. But the traditional interpretation associating it with mysticism remains the strongest interpretation. See most recentiy, Gruenwald, Apocalyptic and Merkavah Myotiaiam.

8 Finkelstein, Mabo, p. 77.

Fischel, Fabbinie Literature, p. 150, n. 121.

${ }^{10}$ Fischel, Rabbinic Literature, Parts 3 and 4 . See the exposition of ARNB below for more detail.

${ }^{11}$ see Saldarini, "Last Words," for a review of the texts.

12 mowm thws is translated as "a place of compression" by s. Lieberman in "How Much Greek" p. 137 and interpreted to refer to the womb and grave.

13 Lieberman, "How Much Greek," pP. 135-137.

${ }^{14}$ Fischel, Rabbinic Literature, pp. 70-72; "Studies," p. 73.

15 Scholem, Jewish Gnostioism, P. $77, n, 6$ quotes a text which uses similar language. But this imagery is very common; in seder Eliahu Rabba, ch. 8 Israel is God's orchard.

${ }^{16}$ Fischel, "The Uses of Sorites," p. 14l; Rabbinic Literature, pp. $74-78$.

${ }^{17}$ Fischel, Rabbinic Literature, pP. 90-91.

${ }^{18}$ Fischel, Rabbinie Literature, p. 152, n. 130 .

${ }^{19}$ Fischel, Rabbinie Literature, F. 94.

20 The other two Amoraim are Abba in ch, 25 and Rabbi Jeremiah in ch. 36 .

\section{CHAPTER EIGHT}

${ }^{1}$ See Towner, The Rabbinic "Enumeration of Seripturat Examples," for a careful form critical study of this form with special reference to the Mekilta of Rabbi Ishmael.

${ }^{2}$ Roth, Numerical Sayings, pp. 95-96.

${ }^{3}$ Roth, inmemiaal sayings, pp. 99-100. 
Chapter 8 , cont.

${ }^{4} \mathrm{~J}$. Goody, The Domestication. See especially ch. 5 on lists. Goody began his study in "The Consequences of Literacy." The transition from oral to literate culture is traced by E. Havelock, most recently in The Greek Concept of Justice and "The Alphabetization of Homer" (with citations of previous literature.)

${ }^{5}$ Towner, The Rabbinic "Enumeration", pp. 75-76.

6 Towner, The Rabbinic "Enumeration", pp. 86-95.

7 Towner, The Rabbinic "Enumeration", pp. 213; 244-250; see also pp. $75-76$ on variations in the contents of the lists.

${ }^{8}$ see Goldin, ARNA, ch. 40, nn. 33-35 for the editor, Julian oberman's highly speculative attempt to reconstruct three groups of three.

${ }^{9}$ Actually five requirements are 1 isted. See m. Demai $2: 2-3$.

${ }^{10}$ See the end of the Babylonian Talmudic Tractates Berakot, Yebamot, Nazir, Tamid and Keritot for this saying.

\section{CHAPTER NINE}

${ }^{1}$ Goldin, "Two Versions."

2 See the comparative chart in Saldarini, ARNB, pp. 303-305.

${ }^{3}$ Saldarini, "Johanan ben Zakkai's Escape"; Schäfer, "Die Flucht Johanan."

4 Daube, "Rabbinic Methods," p. 244, n. 17 says that the four stories in b. Shabbat illustrate four of Hillel's hermeneutical principles. In another place (New Testament and Rabbinic Judaism, pp. 336-337) he argues that b. Shabbat is earlier than ARN because Hillel is portrayed as accepting the Gentile as a Jew before instructing him.

${ }^{5}$ Saldarini, "Last Words," p. 37.

6aldarini, "Last Words," pp. 37-39.

${ }^{7}$ Saldarini, "Last Words," pp. 36-37. See Neusner, Development, pp. 221-224 who argues that $b$. Berakot $28 \mathrm{~b}$ is earlier.

${ }^{8}$ Goody, "The Consequences of Literacy"; Havelock the Greek Concept of Justice and Origins of Western Literacy.

9 Neusner, "Oral Tradition"; Schäfer, Studien, pp. 153-197, reviews the literature and especially Neusner's earlier work.

$I_{m}$. Peah $2: 6 ; \mathrm{m}$. Eduyyot $8: 7 ; \mathrm{m}$. Yadim $4: 3$.

$11_{\text {Lieberman, Helzenism, 83-99. }}$.

12 Neusner, "Oral Tradition" and also his History of Mishnaic Law, passim.

${ }^{13}$ See Towner, Ths Rabbinic "Enumeration." 
${ }^{14}$ Lord, The Singer of Tales, ch. 5.

15 Epstein, Mābồ lü-Nûsah.

${ }^{16}$ The exact text of the Mishna varies in the two Talmuds and in discussions within the Talmuds. The text of PA differs even more in Tractate Abot and the two versions of ARN.

\section{CHAPTER TEN}

$\mathrm{l}_{\text {Saldarini, } A R N B}$, pp. 16-17.

${ }^{2}$ Saldarini, ARNB, pp. 12-16; Goldin, ARNA, xxi.

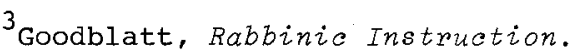

${ }^{4}$ see the previous chapter and Goldin, "Two Versions."

${ }^{5}$ see the indices in Goldin, ARNA and saldarini, ARNB.

${ }^{6}$ Schäfer, Studien, pp. 65-123, reviews all the texts.

${ }^{7}$ Saldarini, $A R N B$, pp. 16-17. The passages are in chapters $27,29,43,48$.

${ }^{8}$ sheirtot, Shemot, section 42, p. 13 .

9 Epstein, Mäbồ $\imath \breve{E}-N \hat{s} s \alpha h$.

${ }^{10}$ Guttmann, "Tractate Abot."

${ }^{11}$ See ch. 2 above and Saldarini, "The End of the Rabbinic Chain."

12 Neusner, Pharisees, I, 19 suggests that Johanan was added by his own disciples.

13 Goldin, "Three Pillars."

${ }^{14}$ Finkelstein, "The Maxim of the Anshe Keneset Ha-Gedolah."

15 Goldin, "The End of Ecclesiastes."

${ }^{16}$ Bickerman, "The Maxim of Antigonus of Soko."

${ }^{17}$ Saldarini, $A R N B$, pp. 13-15.

${ }^{18}$ Neusner, Pharisees, 3,282-286.

${ }^{19}$ Neusner, Eliezer, Vol. 2 .

20 Avi-Yonah, The Jews, p. 128.

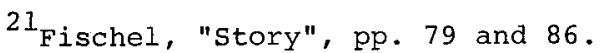

22 Avi-Yonah, The Jews, p. 96.

23 Avi-Yonah, The Jews, p. 106. See the critique of Avi-Yonah's characterization of the third century as a time of economic crisis by M.D. Goodman; in JJS. 


\section{BIBLIOGRAPHY}

Albeck, H. and H. Yalon, Šišăh Sidrê Ha-Mišnâa. Jerusalem/Tel Aviv: Bialik/Dvir, 1958. 6 Vols.

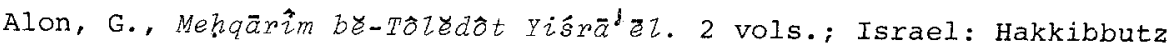
Hameuchad, 1957-1958. Trans. by I. Abrahams in an abridged form: Jews, Judaism and the Classical World: Studies in Jewish History in the Times of the Second Temple. Jerusalem: Magnes, 1977 .

Avi-Yonah, M., The Jews of Palestine: A Political History from the Bar Kokhba War to the Arab Conquest. New York: Schocken, 1976.

Bickerman, Elias, From Ezra to the Last of the Maccabees: Foundations of Post-Biblical Judaism. New York: Schocken, 1962. , The Maxim of Antigonus of Soko. HTR 44 (1959) 153-165.

Bikerman,Élie (Elias Bickerman), "La Chaîne de la Tradition Pharisienne." $R B 59$ (1952) 44-54.

Bowersock, G.W., Greek Sophists in the Roman Empire. Oxford: Clarendon, 1969

Celcus, Aulus Cornelius, De Medicina. (Ed.) W.G. Spenser. Loeb Classical Library; Cambridge/London: Harvard/Heinemann, 1938 .

Cohen Boaz, "Peculium in Roman Law" in Jewish and Roman Law. New York: Jewish Theological Seminary, 1966. Vol 1, pp. 275 ff.

Culpepper, R. Alan, The Johannine School: An Evaluation of the Johannine-School Hypothesis Based on an Investigation of the Nature of Ancient Schools. SBIDS 26; Chico, CA: Scholars Press, 1975.

Danby, Herbert, The Mishnah. London: Oxford University Press, 1939.

Daube, David, The New Testament and Rabbinic Judaism. London: Athlone, 1956.

, "Rabbinic Methods of Interpretation and Hellenistic Rhetoric." HUCA 32 (1949) 239-264.

Derenbourg, J. Essai sur l'histoire et la géographie de la Palestine. Paris: L'Imprimerie Impériale, 1867.

Diogenes Laertius. Lives of Eminent Phiosophers. (Ed.) R.D. Hick. Loeb Classical Library; London/New York: Heinemann/Putnam, 1925.

Dodd, C.H., The Bible and the Greeks. London: Hodder and Stoughton, 1964. Original ed., 1934.

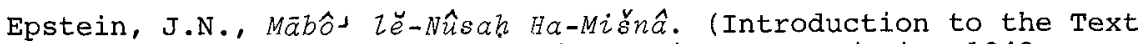
of the Mishna.) Jerusalem/Tel Aviv: Magnes/Dvir, 1948. (2 ed., 1964).

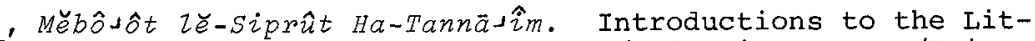
erature of the Tannaim.) Jerusalem/Tel Aviv: Magnes/Dvir, 1957 . 
Eusebius, Evangeliae Praeparationis. See Eusèbe de Césaree. La Préparation Evangelique. (Eds.) Jean Sirinelli and E. des Places. SC 206; Paris: Cerf, 1974

Ferguson, W.S., "The Attic Orgeones." HTR 37 (1944) 61-140.

Finkelstein, Louis. Akiba. Philadelphia: Jewish Publication Society, 1936 .

, "Introductory study to Pirke Abot." JBL 57 (1938) 13-50.

Mabo Ze-Massektot Abot we-Abot d'Rabbi Nathan. (Introduction to the Treatises Abot and Abot of Rabbi Nathan). New York: Jewish Theological Seminary, 1950.

"The Maxim of the Anshe Keneset Ha-Gedolah." JBL 59 (1940) 455-569.

Fischel, Henry A., "Greek and Latin Languages, Rabbinic Knowledge of." Encyclopedia Judaica. Jerusalem: Keter, 1971. Vol. 7 : $884-887$.

, Rabbinic Literature and Greco-Roman Phizosophy: A Study of Epicurea and Rhetorica in Early Midrashic Writings. SPB 21; Leiden: Brill, 1973.

"Story and History: Observations on Greco-Roman and Pharisaism" in American Oriental Society Middle west Branch SemiCentennial Volume. (Ed.) D. Sinor. Bloomington: Indiana U., 1969. Pp. 59-88.

Studies in Cynicism and the Ancient Near East: The Transformation of a Chria" in Religions in Antiquity: Essays in Memory of Erwin Ramsdell Goodenough. (Ed.) J. Neusner. Numensuppl. 14; Leiden: Brill, 1968. Pp. 372-411.

, "The Uses of Sorites (Climax, Gradatio) in the Tannaitic Period." HUCA 44 (1973) 119-151.

Fitzmyer, Joseph A. "The Languages of Palestine in the First Century." $C B Q 32$ (1970) 501-531.

Georgi, Dieter, "The Records of Jesus in the Light of Ancient Accounts of Revered Men" in the Proceedings of the Society of Biblical Literature 1972. (Ed.) L. McGaughy. Chico, CA.: Scholars Press, 1972. Vol. 2, pp. 527-542.

Goldin, Judah, "Avot" in Encyclopedia Judaica. Jerusalem: Keter, 1971. Vol 9, cols. 983-984.

, "The End of Ecclesiastes: Literal Exegesis and Its Transformation" in Biblical Motifs, (Ed.) Alexander Altmann. Cambridge, MA.: Harvard, 1966. Pp. 135-158.

- The Fathers According To Rabbi Nathan YJS 10; New Haven: Yale, 1955.

- "The First Chapter of Abot de Rabbi Nathan" in the Mordecai Kaptan Jubizee Volume. New York: Jewish Theological Seminary, 1953. Pp. 263-280.

The Living Talmud: The Wisdom of the Fathers. New York: Mentor, 1957. 
Goldin, Judah, "Not By an Angel and Not BY a Messenger" in Re $i$ gions in Antiquity: Essays in Memory of Erwin Ramsdelz Goodenough. (Ed.) J. Neusner. Leiden: Bril1, 1968. Pp. 412-424. , "A Philosophical Session in a Tannaite Academy," Traditio 21 (1965) 1-21. See the slightly different version in Hebrew: "Mašehâu "al bet midrašô šez Rabban Yohanan ben Zakkai" in the Wolfson Jubilee Volume. Jerusalem: Jewish Theological Seminary, 1965. Pp. 69-92.

- "Several Sidelights of a Torah Education in Tannaite and Early Amoraic Times" in Ex Orbe Religionum: Studia Geo Widengren. SupplNumen 21; Leiden: Brill, 1972. Vol. 1:176-191.

- "The Third Chapter of JAbot De-Rabbi Nathan." HTR 58 (1965) $365-386$.

, "The Three Pillars of Simeon the Righteous." PAAJR 17 (1958) 43-58.

"The Two Versions of Abot de Rabbi Nathan, "HUCA 19 (1946) $97-120$.

Goodblatt, David, Rabbinic Instruction in Sasanian Babyzon. SJLA 9; Leiden: Brill, 1975.

Goodman, M.D., Review of M. Avi-Yonah, The Jews of Falestine. JJS $28(1977) \quad 85-88$.

Goody, Jack and Ian Watt, "The Consequences of Literacy" in Literacy in Traditional Societies. (Ed.) Jack Goody. Cambridge: University, 1968. Pp. 27-68. - The Domestication of the Savage Mind. Cambridge: University, 1977

Gruenwald, Ithmar, Apocalyptic and Merkavah Mysticism. AGAJU 14; Leiden/Koln: Brill, 1980.

Guttmann, Alexander, "Tractate Abot--Its Place in Rabbinic Literature." JQR 41 (1950) 181-193.

Havelock, Eric A., "The Alphabetization of Homer" in Communication Arts in the Ancient World. (Eds.) Eric A. Havelock and Jackson P. Herschbell. New York: Hastings, 1978. Pp. 3-21. , The Greek Concept of Justice: From Its Shadow in Homer to Its Substance in Plato. Cambridge: Harvard, 1978. , Origins of Westem Literacy. Toronto: Ontario Institute for studies in Education, 1976.

Heinemann, Joseph, Prayer in the Talmud: Forms and Patterns. Berlin/New York: deGruyter, 1977.

Henge1, Martin, Judaism and HeZzenism: Studies in their Encounter in Palestine During the Early Hellenistic Period. 2 Vols.; Philadelphia: Fortress, 1974.

Hoenig, Sidney, "Mĕnahēm Jab-bēt-dîn hā-rījsôn šel Hizlēz." (Menahem, Hillel's First Associate.) Bitzaron 52 (1965) 87-96. 
Hoffmann, David, "Die erste Mischna und die Controversen der Tannaim" in Jahres-Bericht des Rabbiner-Seminars au Berlin. 1881-1882, 1-92.

Jensen, Joseph, The Use of tôrâ by Isaiah. CBQMs 3; Washington Catholic Biblical Assn., 1973 .

Johnson, Marshall D., The Purpose of the Biblieal Genealogies. SNTS Monograph 8; Cambridge: UP, 1969.

Josephus, Antiquities. (Ed.) Ralph Marcus. Loeb Classical Library; Cambridge, MA/ London: Harvard/Heinemann, 1943.

The Jewish War. (Ed.) H. St. J. Thackeray. Loeb ClassiCal Library; 2 vols.; London/New York: Heinemann/Putnam, $1927-1928$.

Küchler, Max, Frühüdische weisheitstraditionen: zum Fortgang weisheitzichen Denkens im Bereich des früjüdischen Jahweglaubens. Orbis biblicus et orientalis, 26; Fribourg: University and Gottingen: Vandehoeck, 1979.

Lauterbach, Jacob. Rabbinic Essays. Cincinnati: Hebrew Union College, 1951 .

Lesky, Albin, A History of Greek Literature. New York: Crowell, 1966.

Lieberman, Saul, Greek in Jewish Palestine: Studies in the Life and Manners of Jewish Palestine in the II-IV Centuries C.E. 2 ed.; New York: Feldheim, 1965.

- Hezzenism in Jewish Palestine: Studies in the Literary Transmission of Beliefs and Manners of palestine in the I Century B.C.E.--IV Century C.E. 2 ed.; New York: Jewish Theological Seminary, 1962.

, "How Much Greek in Jewish Palestine" in Biblical and other Studies. (Ed.) Alexander Altmann. Cambridge: Harvard, 1963. Pp. 123-141.

Lord, Albert B. The Singer of Tales. Cambridge: Harvard, 1960.

MacMullen, Ramsay, Roman Social Relations, 50 B.C. to A.D. 284. New Haven/London: Yale, 1974.

Malherbe, Abraham, Social Aspects of Early Christianity. Baton Rouge/London: Louisiana State University, 1977 .

Mantel, Hugo. "The Nature of the Great Synagogue." HTR 60 (1967) $69-91$.

Marrou, Henri. A History of Education in Antiquity. New York: Mentor, 1964.

McKane, William. Proverbs. OTL; Philadelphia: Westminster, 1970.

Melamed, E.z. "LiŽsônāh šel masseket Jäbôt". (Concerning the Language of Tractate Abot) Lešonēn 20 (1956) 106-111. 
Moore, George Foot, Judaism in the First Centuries of the Christian Era: The Age of the Tannaim. Cambridge, MA: Harvard, 1927-1930. Three volumes.

Neusner, Jacob, Development of a Legend: Studies on the Traditions Concerning Yohanan Ben 2akkai. SPB 16; Leiden: Brill, 1970 .

Eliezer ben Hyrcanus: The Tradition and the Man. 2 vols.; Leiden: Brill, 1973.

. "The Foundation of Rabbinic Judaism: Yavneh (Jamnia) from A.D. 70 to $100^{\prime \prime}$ in Aufsteig und Niedergang der Rómischen Welt. II Principat. Religion 19:2 (Eds.) H. Temporini and W. Hasse. Berlin/New York: de Gruyter. Pp. 3-42. - A History of the Mishnaie Law. SJLA 6 etc.; Leiden: Brill,

Method and Meaning in Ancient Judaism. BJS 10; Chico,CA.: Scholars Press, 1979.

"Oral Tradition and Oral Torah: Defining the Problematic" in Studies in Jewish Folklore. (Ed.) Frank Talmage. Cambridge, MA.: Association for Jewish Studies, 1980. Pp. 251-271.

The Rabbinic Traditions About the Pharisees Before 70. 3 Vols.; Leiden: Brill, 1971 .

Talmudic Judaism in Sasanian Babyzonia: Essays and Studies. SJLA 14; Leiden: Brill, 1976.

Rabin, Chaim, "Hebrew and Aramaic in the First Century" in The Jewish People in the First Century. (Eds.) s. Safrai et al. Compendia Rerum Iudaicarum ad Novum Testamentum; Philadelphia: Fortress, 1976. Vol. 2, pp. 1007-1039.

Rivkin, Ellis, A Hidden Revolution: The Pharisees' Search for the Kingdom Within. Nashville: Abingdon, 1978.

Robinson, James M. "'Logoi Sophon': On the Gattung of $Q$ " in Trajectories Through Early Christianity. (Eds.) J. M. Robinson and H. Koester. Philadelphia: Fortress, 1971. Pp. 71-113.

Rosenthal, Judah. "Lizhûtô šel Mĕnahēm." (The Identity of Menahem) Sinai 56 (1964-1965) 190-192.

Roth, W.M.W., Numerical Sayings in the old Testament: A FormCritical study. Leiden: Brill, 1965.

Saldarini, Anthony J., "The End of the Rabbinic Chain of Tradition." JBL 93 (1974) 97-106.

The Fathers According to Rabbi Nathan (Abot de Rabbi Nathan): Version B. SJLA 11; Leiden: Brill, 1975.

, "Johanan ben Zakkai's Escape from Jerusalem: Origin and Development of a Rabbinic Story." JSJ 6 (1975) 189-204.

"Last Words and Deathbed Scenes in Rabbinic Literature." $J Q R 68$ (1977) 28-45. 
Sanders, James A. "Torah" in the Inteppreters Dictionamy of the Bibze, Supplementary Volume. Nashville: Abingdon, 1976. Pp. 909-911.

Schäfer, Peter, "Die Flucht Joḥanan b. Zakkais aus Jerusalem und die Gründung des 'Lehrhauses' in Jabne" in Aufsteig und Niedergang der Romischen Welt. II Principat. 19:2 Religion: Judentum. (Eds.) H. Temporini et al. Berlin/New York: deGruyter, 1979. Pp. 43-101.

- Studien zur Geschichte und Theologie des Rabbinischen Judentums. AGAJU 15; Leiden: Brill, 1978 .

Schechter, S., Aboth de Rabbi Nathan. Vienna, 1887. Reprinted with 50 printing errors corrected, New York: Feldheim, 1967.

Schoedel, William R., "Jewish Wisdom and the Formation of the Christian Ascetic" in Aspects of Wisdom in Judaism and Early Christianity. (Ed.) R.L. Wilken. Notre Dame: University, 1975. Pp. 169-199.

Scholem, Gershom, Jewish Gnosticism, Merkabah Mysticism and TaZmudic Tradition. 2 ed.; New York: Jewish Theological Seminary, 1965 .

Sevenster, J.N., Do You Know Greek? How much Greek Could the First Jewish Christians Have Known? NovTestsup 19; Leiden: Brill 1968 .

Sheiztot. (Eds.) S. Karman and M. Mirsky. Jerusalem, 1964 .

Smith, Morton, "Palestinian Judaism in the First century" in Israel: Its Role in Civizization. (Ed.) M. Davis. New York: Harper, 1956. Pp. 67-81.

Snell, Bruno, Leben und Meinung der Sieben Weisen. Munchen: Heimeran, 1952 .

Strack, Hermann, Introduction to the Talmud and Midrash. Philadelphia: Jewish Publication Society, 1931.

Tod, Marcus N., Sidelights on Greek History. Oxford: Blackwell, 1932.

Towner, W. Sibley, The Rabbinic "Enumeration of Seriptural Examples": A study of a Rabbinic Pattern of Discourse with special Reference to Mekhilta D'R. Ishmael. SPB 22; Leiden: Brill, 1973 .

Urbach, E.E., The Sages: Their Concepts and Beliefs. 2 vols.; Jerusalem: Magnes, 1975.

Vermes, Geza, Post Biblical Jewish Studies. SJLA 8; Leiden: Brill, 1975.

Whybray, R.N. The Intellectual Tradition in the old Testament. BZAW 135; Berlin/New York: deGruyter, 1974.

Wilkin, Robert L. "Collegia, Philosophical Schools, and Theology" in The Catacombs and the Colliseum. (Eds.) S. Benko and J.J. O'Rourke. Valley Forge: Judson, 1971. Pp. 268-291. 
Wilkin, Robert L. "Wisdom and Philosophy in Early Christianity" in Aspects of Wisdom in Judaism and Early Christianity. (Ed.) Robert L. Wilkin. Notre Dame: University, 1975. Pp. 143-168.

Wilson, Robert R. Genealogy and History in the Biblical World. New Haven: Yale, 1977. 